\title{
Food related antioxidants in oxidative stress
}

Citation for published version (APA):

van den Berg, R. (2001). Food related antioxidants in oxidative stress. [Doctoral Thesis, Maastricht University]. Datawyse / Universitaire Pers Maastricht. https://doi.org/10.26481/dis.20010629rb

Document status and date:

Published: 01/01/2001

DOI:

10.26481/dis.20010629rb

Document Version:

Publisher's PDF, also known as Version of record

\section{Please check the document version of this publication:}

- A submitted manuscript is the version of the article upon submission and before peer-review. There can be important differences between the submitted version and the official published version of record.

People interested in the research are advised to contact the author for the final version of the publication, or visit the DOI to the publisher's website.

- The final author version and the galley proof are versions of the publication after peer review.

- The final published version features the final layout of the paper including the volume, issue and page numbers.

Link to publication

\footnotetext{
General rights rights.

- You may freely distribute the URL identifying the publication in the public portal. please follow below link for the End User Agreement:

www.umlib.nl/taverne-license

Take down policy

If you believe that this document breaches copyright please contact us at:

repository@maastrichtuniversity.nl

providing details and we will investigate your claim.
}

Copyright and moral rights for the publications made accessible in the public portal are retained by the authors and/or other copyright owners and it is a condition of accessing publications that users recognise and abide by the legal requirements associated with these

- Users may download and print one copy of any publication from the public portal for the purpose of private study or research.

- You may not further distribute the material or use it for any profit-making activity or commercial gain

If the publication is distributed under the terms of Article $25 \mathrm{fa}$ of the Dutch Copyright Act, indicated by the "Taverne" license above, 


\section{FOOD RELATED ANTIOXIDANTS IN OXIDATIVE STRESS}




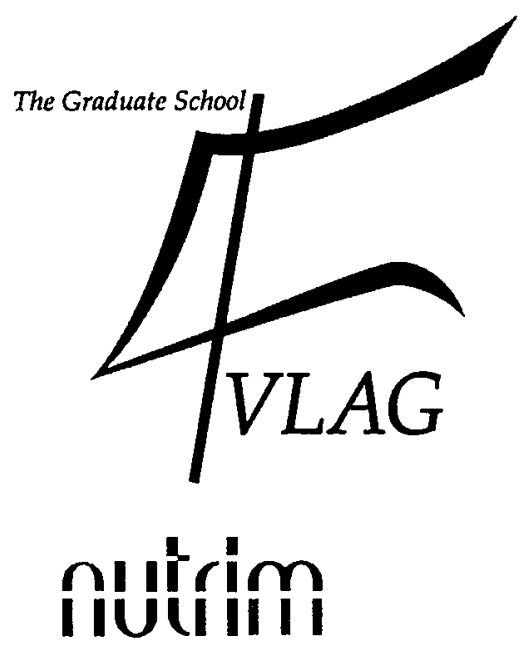

The studies presented in this thesis were performed at the Nutrition and Toxicology Research Institute Maastricht (NUTRIM), which participates in the Graduate School VLAG-2 (Food Technology, Agrobiotechnology, Nutrition and Health Sciences) accredited by the Royal Netherlands Academy of Arts and Sciences.

Financial support: TNO Nutrition and Food Research

Cover design: $\quad$ Martin van der Vaart (foto), Robin van den Berg

Lay-out: $\quad$ Vanessa. Blokdijk, Robin van den Berg

Printing: datawyse bv, Maastricht

(C) Robin van den Berg, 2001

ISBN 90-9014816-7

Printing of this thesis was financially supported by:

TNO Nutrition and Food Research,

Roche Vitamins Europe Ltd.,

Zambon Nederland BV,

Department of Pharmacology and Toxicology, Maastricht University. 


\section{FOOD RELATED ANTIOXIDANTS IN OXIDATIVE STRESS}

\section{PROEFSCHRIFT}

ter verkrijging van de graad van doctor aan de Universiteit Maastricht, op gezag van de Rector Magnificus, Prof. dr. A.C. Nieuwenhuijzen Kruseman, volgens het besluit van het College van Decanen, in het openbaar te verdedigen op vrijdag 29 juni 2001 om 14.00 uur

door

\section{Robin van den Berg}

geboren te Amsterdam op 1 juli 1972 


\section{Promotor}

Prof. dr. A. Bast

\section{Co-promotores}

Dr. G.R.M.M. Haenen

Dr. H. van den Berg (TNO Voeding, Zeist)

\section{Beoordelingscommissie}

Prof. dr. ir. P.A. van den Brandt (voorzitter)

Prof. dr. M.P. van Dieijen-Visser

Prof. dr. C.A. Rice-Evans (Wolfson Centre Age-Related Diseases, United Kingdom)

Prof. dr. ir. W.H.M. Saris

Prof. dr. ir. G. Schaafsma (TNO Voeding, Zeist) 
Aan mijn ouders en Deborah 


\section{Contents}

Chapter 1: General Introduction ...............................................

Chapter 2: Applicability of an improved TEAC assay for evaluation of antioxidant capacity measurements of mixtures.

Chapter 3: The predictive value of the antioxidant capacity of structurally related flavonoids using the Trolox Equivalent Antioxidant Capacity (TEAC) assay.

Chapter 4: Transcription factor NF- $\mathrm{KB}$ as a potential biomarker for oxidative Stress

Chapter 5: Reduction of oxidative stress in chronic hepatitis $\mathrm{C}$ by glycyrrhizin......75

Chapter 6: NF-KB activation in sarcoidosis

Chapter 7: Nuclear Factor- $\mathrm{kB}$ activation is higher in peripheral blood mononuclear cells of male smokers.

Chapter 8: A vegetable/fruit concentrate with high antioxidant capacity has no effect of on biomarkers of antioxidant status in male smokers.

Chapter 9: General Discussion and Conclusions.

Summary

Samenvatting.

Dankwoord.

Curriculum vitae.

List of publications. 
Chapter 1

General Introduction 


\section{Free Radicals and Antioxidants: Need or Threat?}

Humans are exposed to many carcinogens, but the most significant may be the reactive species derived from metabolism of oxygen and nitrogen. Formation of reactive oxygen species (ROS) and reactive nitrogen species (RNS) in the human body can cause oxidative damage to biological macromolecules such as DNA, lipids and proteins (Vaughan 1997) that may contribute to the development of cancer, cardiovascular and neurological diseases, cataract and other oxidative stress mediated dysfunctions (Gutteridge 1993; Diplock 1994; Sies 1997). Therefore, the assumption is often made that ROS/RNS are always 'bad', but the human body also needs ROS/RNS as, for example, their function in primary immune defence or for relaxation of smooth muscles in blood vessel-walls.

Typical physiological relevant ROS/RNS (see Table 1) are the superoxide radicals, peroxyl radicals, hydroxyl radicals, singlet oxygen, peroxynitrite and hydrogen peroxide. ROS/RNS are either radicals (molecules that contain at least one unpaired electron) or reactive non-radical compounds, capable of oxidizing biomolecules. Therefore, these intermediates are also called oxidants or pro-oxidants.

Table 1. Typical physiologic relevant reactive oxygen and nitrogen species

\begin{tabular}{|c|c|}
\hline \multicolumn{2}{|c|}{ Reactive oxygen species (ROS) } \\
\hline Radicals & Non radicals \\
\hline Superoxide, $\mathrm{O}_{2}{ }^{\circ-}$ & Hydrogen peroxide, $\mathrm{H}_{2} \mathrm{O}_{2}$ \\
\hline Hydroxyl, $\mathrm{OH}^{\circ}$ & Hypochlorous acid, $\mathrm{HOCl}$ \\
\hline Peroxyl, $\mathrm{RO}_{2}{ }^{\circ}$ & Hypobromous acid, $\mathrm{HOBr}$ \\
\hline Alloxyl, RO & Ozone, $\mathrm{O}_{3}$ \\
\hline Hydroperoxyl, $\mathrm{HO}_{2}{ }^{-}$ & Singlet Oxygen, ' $\mathrm{O}_{2}$ \\
\hline \multicolumn{2}{|c|}{ Reactive nitrogen species (RNS) } \\
\hline Radicals & Non radicals \\
\hline Nitric oxide, $\mathrm{NO}^{\circ}$ & Nitrous acid, $\mathrm{HNO}_{2}$ \\
\hline Nitrogen dioxide, $\mathrm{NO}_{2}{ }^{\circ}$ & Nitrosyl cation, $\mathrm{NO}^{+}$ \\
\hline & Nitroxyl anion, $\mathrm{NO}^{-}$ \\
\hline & Peroxynitrite, $\mathrm{ONOO}^{\circ}$ \\
\hline & Peroxynitrous acid, $\mathrm{ONOOH}$ \\
\hline & Alkyl peroxynitrites, ROONO \\
\hline
\end{tabular}

To counteract the prooxidant actions in the human body, an intricate network of antioxidants (Figure 1) is operative in biological systems including enzymatic and non-enzymatic antioxidants. Enzymatic antioxidants (Table 2) such as superoxide 
dismutases (SOD), catalase, and glutathione peroxidases provide the first line of defence. SOD catalyses the dismutation of superoxide to oxygen and peroxide, which is protonated to form hydrogen peroxide. Although hydrogen peroxide is a powerful oxidant, it is relatively unreactive towards most biologic substrates unless it is present in unphysiologically high concentrations. Catalase converts hydrogen peroxide in water and oxygen and glutathione peroxidases reduce hydrogen peroxide and organic hydroperoxides. Indirect antioxidant functions are mediated by enzymes that restore endogenous antioxidant levels; e.g. glutathione (GSH) levels are replenished on reduction of oxidized glutathione (GSSG) by glutathione reductase. Reactive products or xenobiotics, e.g. epoxide, can be detoxified by phase II detoxification enzymes such as glutathione-S-transferases to favour their excretion. Metal chelating plasma proteins (e.g. transferrin, ceruloplasmin and albumin) prevent the formation of ROS/RNS by controlling the levels of free iron or copper ions. These metal chelating proteins bind the redox active metals and limit the production of free radicals.

Table 2. Enzymatic antioxidants

\begin{tabular}{ll}
\hline $\begin{array}{l}\text { Enzymatic antioxidants } \\
\text { Enzyme }\end{array}$ & Reaction Catalysed \\
\hline Superoxide dismutase & $\mathrm{O}_{2}^{-*}+\mathrm{O}_{2}^{--}+2 \mathrm{H}^{+} \rightarrow \mathrm{H}_{2} \mathrm{O}_{2}+\mathrm{O}_{2}$ \\
Catalase & $\mathrm{H}_{2} \mathrm{O}_{2}+\mathrm{H}_{2} \mathrm{O}_{2} \rightarrow 2 \mathrm{H}_{2} \mathrm{O}+\mathrm{O}_{2}$ \\
Glutathione peroxidase & $2 \mathrm{GSH}+\mathrm{ROOH} \rightarrow \mathrm{GSSG}+\mathrm{ROH}+\mathrm{H}_{2} \mathrm{O}$ \\
\hline
\end{tabular}

The human diet also provides a range of different compounds that possess antioxidant activities or have been suggested to scavenge ROS/RNS based on their structural properties (Table 3 ). The most prominent representatives of dietary antioxidants are ascorbate (vitamin $\mathrm{C}$ ), tocopherols (vitamin E), carotenoids and flavonoids. Antioxidants have different solubilities, which partition across the phases of tissues, cells and macromolecular structures: water-soluble ascorbate, glutathione and urate; lipid-soluble tocopherols and carotenoids, and intermediatory-soluble flavonoids. The protection against ROS/RNS provided by fruit and vegetables could arise through an integrated reductive environment delivered by antioxidants of differing solubility in each of the tissues, cellular and macromolecular phases (Eastwood 1999). 


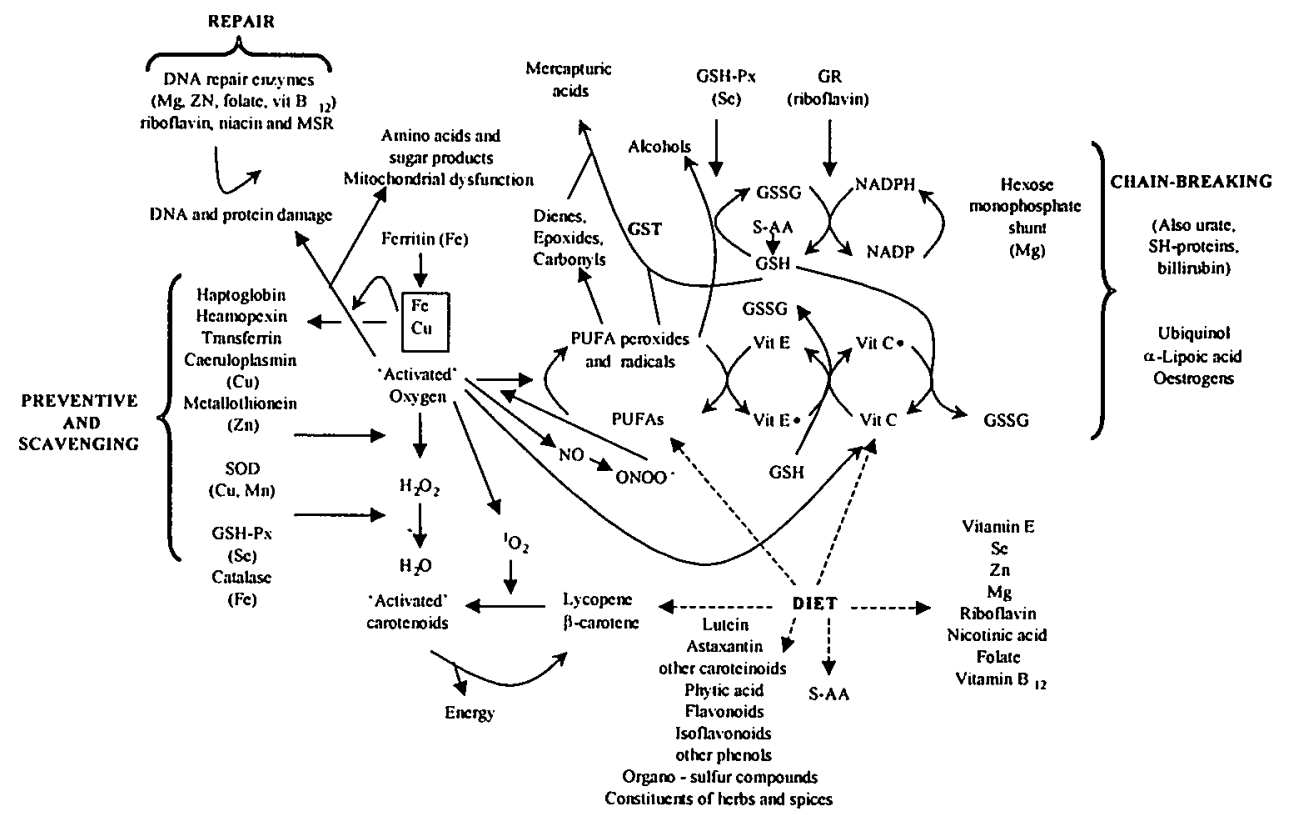

Figure 1.. Antioxidant defense system. GR, Glutathione reductase; GSH, Reduced glutathione; GSH-Px, Glutathione peroxidase; GSSG, Oxidized glutathione; GST, Glutathione-S-transferase; MSR, Methione sulphoxide reductase; PUFA, Polyunsaturated fatty acids; S-AA, Sulfur amino acids; SH-proteins, Sulphydryl proteins; SOD,

Superoxide dismutase; $\mathrm{Fe}$, Transition metal-catalyzed oxidant damage to biomolecules. (based on Benzie 2000) $\mathrm{Cu}$

Table 3. Prominent representative dietary antioxidants

\begin{tabular}{ll}
\hline $\begin{array}{l}\text { Naturally occurring non-enzymatic antioxidants } \\
\text { Hydrophilic }\end{array}$ & Lipophilic \\
\hline Ascorbic acid & Carotenoids \\
Glutathione & $\alpha$-Tocopherol \\
& Ubiquinol-10 \\
Flavonoids & Flavonoids \\
\hline
\end{tabular}

Observational epidemiological studies clearly show a correlation between the increased consumption of food rich in antioxidants and a decreased risk of several oxidative stress related diseases (Steinmetz \& Potter 1996). These observations suggest that poor nutritional status may modulate ROS-mediated cellular damage due to an impaired defence. In addition to protection against direct oxygen radical induced toxicity, antioxidants may also provide protection through their ability to inhibit the activation of oxidant-sensitive transcription factors (e.g. NF-KB) and subsequent 
production of pro-inflammatory mediators and adhesion molecules. Thus, maintaining adequate antioxidant status may be a useful approach to attenuate the cellular injury and dysfunction observed in inflammatory disorders (Figure 2). Because of apparent importance of ROS/RNS as toxins, mediators, and modulators of inflammatory gene activation, antioxidants might be used as therapeutic agents for a number of different disease states.

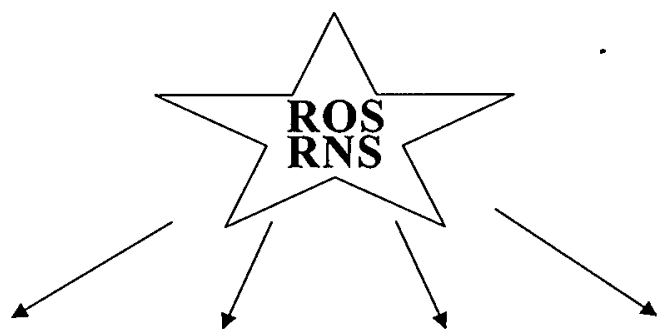

DNA breakage, mutation Oncogene activation

Peroxidation of Enzyme Carboliydrate crossTumor suppressor gene activation

unsaturated fatty acid activation/inactivation linking

Loss of membrane protein cross-linking receptor disturbance

fluidity/function protein fragmentation

Ox LDL, formation changes in
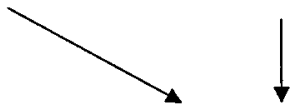
immunogenicity
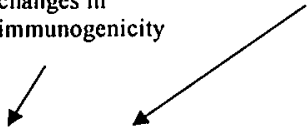

Mitochond rial damage/disruption Disordered cellular metabolism

$$
\text { Carcinogenesis }
$$

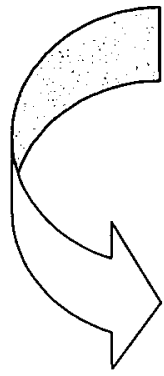

Atherogenesis

Autoimmunity

Cell damage/death

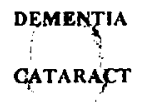

STROKE

CORONARY

HEART

DISEASE

AGEING

DIABETES

CANCER

Figure 2. Reactive oxygen/nitrogen species increase risk disease through damage to key biological structures (based on Benzie 2000) 


\section{How to assess/quantify health benefits from antioxidants in humans?}

A double-blind, placebo controlled intervention trial in a sufficiently large population group remains the ultimate proof to demonstrate health benefits, such as a reduction in disease risk. Traditionally, observational epidemiological studies on disease risk were focussed on clinical outcome with hard clinical endpoints. Such studies are indispensable, but they are time- and money consuming and may have intrinsic limitations. A promising approach to strengthen epidemiological studies is the use of biomarkers. The biomarker concept was recently discussed by ILSI FUFOSE Concerted action (Diplock et al. 1998, 1999). A biomarker can be defined as an indicator on a biochemical, genetic or cellular level, reflecting exposure to a compound, susceptibility for a disease or the health status of a subject. A biomarker of oxidative stress reflects radical burden, (susceptibility of) oxidative damage, and oxidative stress mediated disease, or health status. For example, if we assume that direct damage to DNA by reactive oxygen species contributes significantly to agerelated development of cancer, then agents that decrease such damage should decrease the risk of cancer development. The steady-state level of oxidative DNA damage in human tissues is then a surrogate marker (biomarker) for later cancer development (Halliwell 1999).

In the physiological evaluation of a biomarker, it is important that there is a wellestablished relationship between the response of the biomarker and the effect monitored. Ideally, the biomarker is the only target in the etiology. However, minor pathways may also provide suitable biomarkers. In the causal pathway of disease occurrence one might distinguish biomarkers of exposure (dietary intake), biomarkers of biological response and of (subclinical) disease and biomarkers of susceptibility (Figure 3). For example, blood levels of vitamin $\mathrm{E}$ (exposure marker) may be studied in relation to oxidation resistance of LDL (a biological response marker) or to carotid artery wall thickness (a disease marker), in subjects with familial hypercholesterolaemia, or specific genotype (both susceptibility markers). Although biomarkers have the potential for improving validity, several problems are encountered. Biomarkers of exposure should accurately reflect relevant dietary intake or body status, while the 'early disease' markers should have predictive value for the hard end-point. 


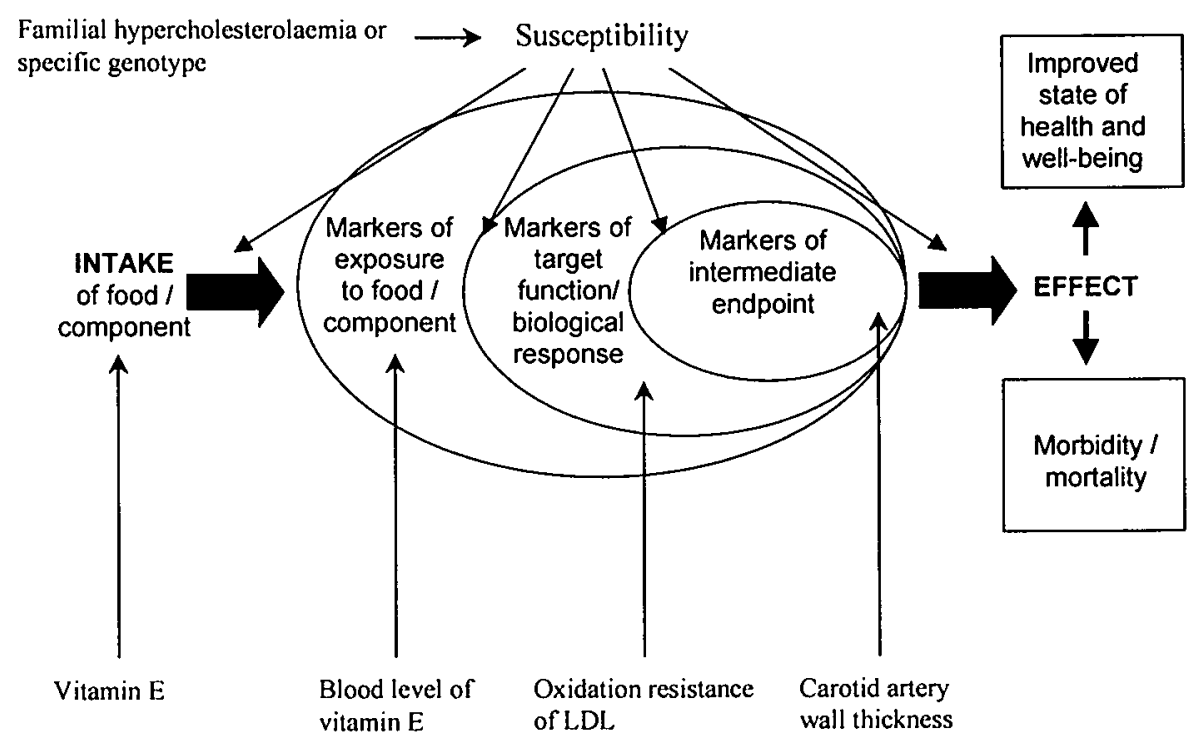

Figure 3. Classification of biomarkers relevant to the effect of antioxidants (example of vilamin E; modified from ILSI Europe, 1999).

An effective nutritional strategy will require knowledge of the type of antioxidants in the diet, their food sources, bioavailability and required levels of intake for protective effects. Protective effects of antioxidants have been found in mechanistic (in vitro), in animal studies (Benzie 1996), as well as in epidemiological studies (Block et al. 1992) and in some small scale intervention studies (Pool-Zobel et al. 1997; Young et al. 1999; Porrini \& Riso 2000). For evaluation of the effect of antioxidants the total evidence from basic science, epidemiological and intervention studies, rather then that of one type of study has to be considered.

Application of biomarkers requires ability to measure oxidative damage to relevant molecular target in the appropriate tissue. One obvious problem is the limited availability of healthy human tissues from which to obtain it. One cannot ethically biopsy the colon, prostate or breast of healthy subjects multiple times to investigate how DNA damage is affected by dietary manipulations. Therefore, studies mostly use cells from 'easy' accessible tissues (e.g. buccal cells) or blood cells assuming that changes here will be reflected in the tissue at risk of for example cancer development later in life. These cells/tissues are not necessarily the target cells from a subject.

Another problem is the isolation of these target cells. All steps used for isolation and purification have the potential to cause an artefactual raise in the apparent steady-state 
levels of oxidative stress or damage and could invalidate the measurement. Nevertheless, several laboratories have developed standardized analytical protocols that could prevent such artefacts.

In the evaluation of the suitability of a marker both analytical and physiological criteria should be used. For the analytical validation procedures that have been developed for standardization and validation of methods for the determination of drugs (Shah et al. 1992) could also be applicable for biomarkers. According to this procedure criteria for the lower limit of quantification, precision, accuracy and selectivity should be given. A major problem encountered for the analytical validation of biomarkers is that many compounds used as a biomarker have a 'normal' background concentration, and therefore no completely blank matrix is available. This hampers the correct estimation of the lower limit of quantification and the accuracy. For the analysis of drugs, the registration authorities accept an inaccuracy and imprecision up to $15 \%$ at the normal levels, and $20 \%$ at the lower limit of quantification (Shah et al. 1992). For biomarker assays, where the differences in concentration between the normal and elevated levels can be relatively low, stricter criteria for the accuracy and precision are probably needed. An important practical point performing large trials for establishing a claim is the feasibility of the methodology to be applied to a large sample size. Collection, storage and transport of samples as well as time-consuming laboratory procedures have to be taken into account. In such human studies internal validity must be ensured by proper comparability of intervention and control groups, or of cases and controls.

For pathophysiological evaluation to assess relevance of the marker to biological function human (intervention) studies, using subjects with an established oxidative stress, or in patients suffering from a disease associated with increased oxidative stress such as in diabetes, or with inflammation related diseases are required. Such studies will, in turn, eventually accept or disprove the biomarkers used. Human intervention studies using antioxidants or food products generally aim at establishing either enhanced function (type A claim) or reduced risk (type B claim). Regarding study design, for type A claims biomarkers of target function/biological response are required and for type $B$ claims biomarkers of intermediate end-points. Although the interest in the use of antioxidants for treatment of human diseases, and in the role of dietary antioxidant in the prevention of disease development has been sustained for at least two decades, contradictory effects accumulate. For example vitamin $E$ 
supplements were protective against cardiovascular disease in the CHAOS study (Stephens et al. 1996), but not in the GISSI-Prevenzione trial (GISSI-Prevenzione Investigators 1999). An antioxidant paradox was postulated by Halliwell (2000) to explain these contradictory effects. Both trials studied high-risk patients to prevent second events. One factor, which was suggested as an explanation, was that fatal myocardial infarction is often associated with rupture of advanced unstable plaques. In such plaques, free transition-metal ions are presents (Makjanic et al. 1999) and vitamin E could interact with them to exert pro-oxidant effects (Maiorino et al. 1993). This can possibly explain why highly oxidized lipids and vitamin E coexist (Niu et al. 1999). Thus, high-dose vitamin E could facilitate rupture, most likely soon after administration begins, as was seen in CHAOS and protective effects took longer to establish (200 days or more). Second, unlike the Cambridge population, the Italian population already has the benefits of a Mediterranean diet rich in phenolic antioxidants yet developed cardiovascular disease anyway. This population may be 'selected' not to respond in a beneficial way to antioxidant supplements, especially as synthetic vitamin E rather than pure RRR $\alpha$-tocopherol was used. Halliwell (2000) suggested that perhaps their atherosclerotic lesions have less free transition-metal ions and are thus less prone to be rendered unstable by pro-oxidant effects of antioxidants. Also, subjects consuming diets rich in fruits and vegetables apparently have a lower risk of getting cancer and an increased concentration of $\beta$-carotene in the blood. Intervention with (high dose) $\beta$-carotene supplements, however, did not exert an anticancer effect, rather the opposite effect was found in smokers (Rowe 1996).

From this antioxidant paradox one could also introduce a "biomarker paradox". Since a biomarker that is increased is usually considered as 'bad' or associated with increased disease risk, reducing this increased biomarker might be considered as 'good' or 'decreased risk', the opposite could also be the case. For example increased DNA damage can be ascribed to an increase in free radical attack on DNA or decreased repair. If the biomarker of DNA damage (e.g. 8-hydroxy-deoxyguanosine) is increased this could be interpreted as 'bad' as increased radical attack or 'good' as for increased repair. Another example of a biomarker paradox is the marker superoxide dismutase (SOD). SOD is an enzymatic antioxidant, which provides the first line of defence in the human body (page 10-11) is considered as 'good' when increased. However, SOD has been shown to be increased in Down syndrome and is suggested to be responsible for oxidative stress and subsequently neural dysfunction in 
these subjects (lannello et al. 1999). Like SOD, catalase, which converts hydrogen peroxide in water and oxygen, is considered as a 'good' enzymatic antioxidant. An increased catalase activity could be interpreted as 'good' or 'better' protected. However, with doxorubicin induced heart toxicity due to excessive production of radicals, catalase activity is paradoxically increased (Julicher et al. 1988).

Before starting an intervention trial one should be aware of these contradictions and carefully select the relevant markers and include a well-characterized study population. Methodologies of commonly used markers for evaluating and quantifying antioxidant protection and oxidative damage in humans are discussed below.

\section{Methodologies of markers for evaluating antioxidant protection and oxidative damage}

Antioxidant capacity can be assessed in either food products as well in biological samples and can be monitored by a variety of simple, non-specific, high-throughput screenings assays. These assays are generally scavenging assays using relatively 'stable' synthetic free radicals (e.g. the 2,2'-azinobis-(3-ethylbenzthiazoline-6sulphonate (ABTS) radical), or reactive 'natural' occurring radicals (e.g. $\mathrm{OH}^{*}$ or $\mathrm{O}_{2}{ }^{\circ}$ ). Total antioxidant capacity of biological samples can also be evaluated in human studies, which measure free-radical damage products of endogenous compounds such as lipids or DNA. Diet induced changes from base-line levels are indicative for the antioxidant capacity of the diet or (food) product. A general problem with these type of assays is that there they are, as yet, poorly validated, and therefore, their specificity as biomarker is still under debate. Measurement of total antioxidant capacity of biological fluids might be useful as a marker for the ability of antioxidants present in body fluids in preventing oxidative damage to membranes and other cellular components.

The possible interaction among different antioxidants in vivo makes the measurement of any individual antioxidant less representative compared to the overall antioxidant status. Several methods have been developed to measure the total antioxidant capacity of biological samples or food products. These methods have been classified as inhibition methods involving reactive species, which are usually free radicals.

The total radical trapping parameter (TRAP) assay of Wayner et al. (1985) was the first and the most widely applied strategy for measuring total antioxidant capacity of plasma or serum. The TRAP assay uses peroxyl radicals generated from 2,2'-azobis(2- 
amidinopropane) dihydrochloride (ABAP) and peroxydizable materials present in plasma or other biological fluids. After adding ABAP to the plasma, the oxidation of oxidizing materials is monitored by measuring the oxygen consumed during the reaction. During an induction period, this oxidation is inhibited by antioxidants present in the plasma. The induction period (lag phase) is quantified by standard addition of 6hydroxyl-2,5,7,8-tetramethylchroman-carboxylic acid (Trolox), and the lag-phase of plasma related that of Trolox. A major problem with the original TRAP assay lies in the instability of the oxygen electrode.

Using this original TRAP assay, Mulholland and Strain (1991) reported that serum TRAP values were significantly lower in patients with acute myocardial infarction when compared to sex- and age-matched controls. The plasma TRAP values were also reported to decline significantly by about $40 \%$ during chemotherapy in patients with haematologic malignancies (Dürken et al. 1995).

Since then, a lot of modified TRAP-like assays have been developed. In 1992 the first modified TRAP assay was reported by Metsä-Ketelä \& Kirkola using a chemiluminescense-based TRAP assay. In this method peroxyl radicals produced from ABAP oxidize luminol, leading to the formation of luminol radicals that emit light. This method was further modified by Whitehead et al. (1992) using hydrogen peroxide or perborate for the oxidation of luminol and the enhancer para-iodophenol giving a more intense, prolonged, and stable light emission. Other methods that also measures TRAP are the dichlorofluorescin-diacetate based assay (Valkonen \& Kuusi 1997), the total oxyradical scavenging capacity assay of Winston et al. (1998), the crocin based assays (Tubaro et al. 1998) and the phycoerythrin based assays (Glazer 1990, Cao et al. 1993).

One of the most interesting methods is the one presented by Miller et al. (1993). The method was first used to ascertain total antioxidant capacity in blood and other human fluids. This method is based on the inhibition by antioxidants of the absorbance of the radical anion of 2,2'-azinobis-(3-ethylbenzthiazoline-6-sulphonate) (ABTS), which has a characteristic long wavelength absorption spectrum showing maxima at 660,734 and $820 \mathrm{~nm}$. The ABTS radical anions, that are quite stable, are formed by the interaction of ABTS with the ferrylmyoglobin radical species (metmyglobin) with hydrogen peroxide (Figure 4). During the formation period, the accumulation of ABTS radicals is inhibited by antioxidants present in the plasma. The length of the induction period (lag phase) is also compared to that of Trolox as in the original TRAP assay of Wayner 
et al. (1985). The specific properties of ABTS were already routinely used in hospitals in kinetic methods for enzyme-activity measurements, e.g. the 'glucose-oxidase assay' (Majkic et al. 1975) to give ABTS radicals by oxidation with hydrogen peroxide in the presence of peroxidase. Also in a simple kinetic method for determination of serum cholesterol (Majkic \& Berkes 1977), of haemoglobin (Takayanagi \& Yashiro 1984) and uric acid (Majkic-Singh et al. 1984) the ABTS radical was used.

The original radical trapping assay of Miller et al. (1993), also called the Trolox equivalent antioxidant capacity (TEAC) assay, has been commercialized by Randox Laboratories (San Francisco, CA, USA). The intra- and interassay CV of the TEAC assay were reported to be $0.54-1.59 \%$ and $3.6-6.1 \%$, respectively (Rice-Evans \& Miller 1994).

Plasma antioxidant capacity was found to be increased in patients with acute myocardial infarction (Guller et al. 1998) and decreased in premature infants (Miller et al. 1993, Rice-Evans \& Miller 1994). However, the low plasma TEAC found in premature infants was mainly due to lower protein content of the plasma. The TEAC of premature infants will be significantly higher, not lower, compared to term infants or adults when the data are based on the amount of total protein contained in the plasma (Cao et al. 1996). All compounds present in the serum or plasma that are able to scavenge the radicals are detected as potential antioxidants.

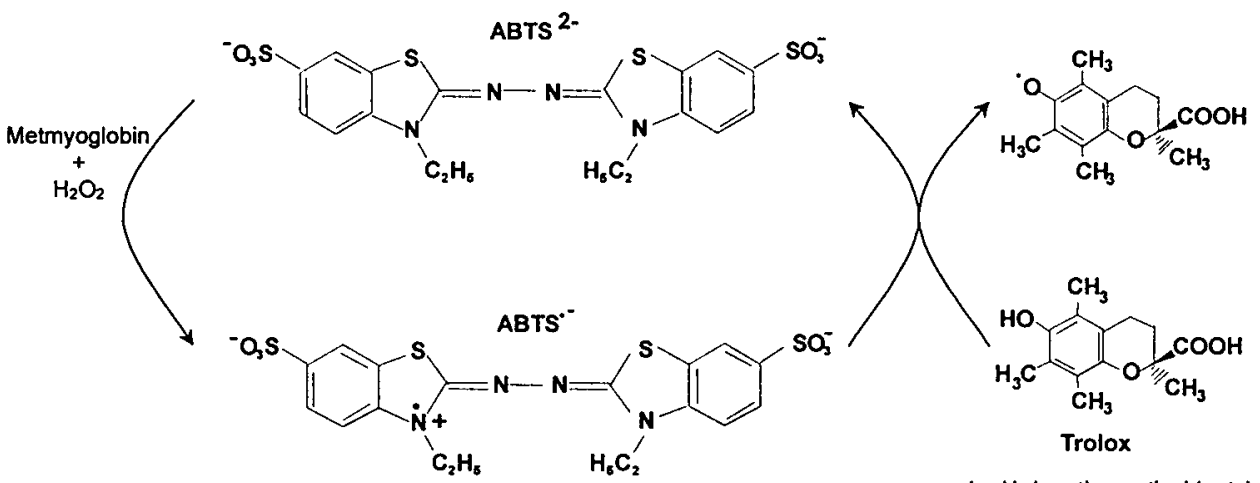

(or H-donating antioxidants)

Figure 4. The formation of the 'stable' radical ABTS and the reaction with the watersoluble vitamin E analogue Trolox. 
The greater part of the activity of serum or plasma (approximately $80 \%$ ) has to be ascribed to albumin and urate (Wayner et al. 1987). Due to the high antioxidant capacity of plasma, effects of antioxidant supplementation are relatively small. To reduce the high level of antioxidant capacity the TEAC should be measured in deproteinated plasma, which makes the assay more sensitive.

In the original TEAC assay the lag-phase caused by different antioxidants in the production of ABTS radicals is determined. ABTS radicals are generated from ABTS and hydrogen peroxide by metmyoglobin. The reduction of the amount of ABTS radicals caused by the added antioxidant at a fixed time point is quantified (Miller et al. 1993). Added antioxidants quench ABTS radical anions formed by the interaction of hydrogen peroxide with metmyoglobin. However, a direct interaction of an ingredient of the sample with the reagent cannot be totally excluded (Cao \& Prior 1998). These interactions may reduce or even increase the production of radical species. The specificity of the TEAC assay is measuring capacity of a sample to directly quench free radicals is not always guaranteed (Strube et al. 1997), because compounds may also inhibit metmyoglobin and thus prevent ABTS radical formation leading to the false conclusion that these compounds are antioxidants.

\section{Currently used methods assessing scavenging of 'stable' non-biological free radicals}

Besides the TEAC assay, which is a sensitive but non-specific and non-invasive method for assessing total antioxidant capacity of water-soluble antioxidants, also many other methods are performed.

The oxygen radical absorbance capacity (ORAC) assay is used to quantify the oxygen radical absorbance capacity of antioxidants in food and biological samples (Cao et al. 1993). In this assay, beta-phycoerythrin (beta-PE) is used as an indicator protein and 2,2'-azobis(2-amidinopropane) dihydrochloride (ABAP) as a peroxyl radical generator. In this assay the reaction goes to completion, so that both inhibition time and inhibition degree is considered in quantifying ORAC. The ORAC assay responds to numerous water-soluble antioxidants and is therefore a sensitive, non-specific method. However, the ORAC is more time-consuming compared with other total antioxidant capacity measurements.

The method using relatively stable 2,2-diphenyl-1-picrylhydrazyl (DPPH') free radicals is applied for antioxidant activity measurements of food and biological samples (Bondet et al. 1997). The disappearance of the radical can be followed 
spectrophotometricly and is expressed as radical scavenging ability. The DPPH assay is used for lipid-soluble compounds and is a sensitive, non-specific assay. Interpretation of this assay could be complicated if the absorption spectrum of test compounds overlaps with the DPPH ${ }^{*}$ spectrum $(515 \mathrm{~nm})$ as with compounds such as carotenoids (Nomura et al. 1997).

The ferric reducing ability (FRAP) assay is a simple test measuring the ferric reducing ability of food and plasma. This assay has been presented as a novel method for assessing 'antioxidant power' (Benzie \& Strain 1996) but is not a radical scavenging assay. Ferric to ferrous ion reduction at low $\mathrm{pH}$ causes formation of a coloured ferrous-tripyridyltriazine complex. FRAP values are obtained by comparing the change in absorbance. This assay is simple and inexpensive but does not measure the sulphydryl group-containing antioxidants (Cao \& Prior 1998). The antioxidant capacity of an antioxidant against a free radical does not necessarily match its ability to reduce $\mathrm{Fe}^{3+}$ to $\mathrm{Fe}^{2+}$. Interpretation of the assay is complicated since the reduction of iron is also involved in free radical generation process as e.g. the catalysed $\mathrm{OH}^{*}$ generation from $\mathrm{H}_{2} \mathrm{O}_{2}$.

In vitro methods assessing scavenging of biological relevant free radicals Hydroxyl radical $\left(\mathrm{OH}^{\circ}\right)$ scavenging can be indirectly measured. In the $\mathrm{OH}^{\bullet}$ scavenging assay, or the 'deoxyribose assay', $\mathrm{OH}^{\bullet}$ radicals are generated from hydrogen peroxide, ascorbate and $\mathrm{FeCl}_{3}$. Scavenging activity can be assessed by measuring competition between the test compound with deoxyribose for hydroxyl radicals (Halliwell et al. 1987). However artefacts may occur with this test, such as: (i) some substances can rapidly react with hydrogen peroxide or (ii) compounds interfere with the measurement products.

Superoxide radical $\left(\mathrm{O}_{2}{ }^{\circ}\right)$ radical scavenging can also be indirectly measured. In the superoxide radical scavenging assay, $\mathrm{O}_{2}{ }^{-}$is generated from xanthine/xanthine oxidase $(\mathrm{X} / \mathrm{XO})$ and scavenging can be measured by reaction of $\mathrm{O}_{2}{ }^{--}$with cytochrome $\mathrm{C}$ or nitro-blue tetrazolium (NBT) (Halliwell 1985). This assay is also sensitive to artefacts, such as inhibition of xanthine oxidase or reducing cytochrome $\mathrm{C}$ or NBT by the compounds. Other complications may arise with test compound(s) that absorb strongly at $290 \mathrm{~nm}$ or formation of products that reduces cytochrome C or NBT.

Scavenging of various free radicals, such as $\mathrm{OH}^{\bullet}$ and $\mathrm{O}_{2}{ }^{*}$, can be assessed by electron spin resonance (ESR) with a spin trap e.g. DMPO (Noda et al. 1997). Using ESR, 
radical scavenging activity of several body fluids can be measured by normalizing the ESR signals relative to the standard activity of vitamin $\mathrm{C}$ or a stable water-soluble analogue of vitamin $\mathrm{E}$. This method is less prone to artefacts, but also less sensitive and more laborious compared to the deoxyribose and the superoxide radical scavenging assay.

\section{Methods assessing oxidative damage}

\section{Oxidative damage to DNA}

In stead of scavenging assays, damage to DNA, proteins and lipids can also be used for monitoring total antioxidant capacity. Oxidative DNA damage can be characterized ex vivo by measuring modified DNA bases as a result of several ROS/RNS attack on DNA. The most exploited DNA lesion, used as an index of oxidative DNA damage, is 8-hydroxy-deoxyguanosine (8-OHdG) (Loft et al. 1993). This product is a result of free radical attack upon guanine and may be a useful marker of damage on DNA since it is excreted in urine. For measurement of $8-\mathrm{OHdG}$ (which is the most commonly measured DNA lesion), high performance liquid chromatography with electrochemical detection (HPLC-ECD) (Shigenaga et al. 1994) or gas chromatography with mass spectrometry (GC-MS) (Dizdaroglu, 1993) techniques are used. Both methods suffer from artefactual oxidation of guanine during the isolation and enzymatic digestion of DNA and during the chemical derivatization procedure for the GC-MS method. The analysis of 8-OHdG is often conducted with lymphocytes and urine. Nevertheless, it is uncertain whether measurement of oxidised DNA in lymphocytes reflects oxidative damage in other tissues.

It is often assumed that urinary $8-\mathrm{OHdG}$ is derived from cellular DNA repair processes. Estimates of the rate of input of oxidative damage have been based on urinary $8-\mathrm{OHdG}$ levels, however, it is 8 -oxoguanine, and not $8-\mathrm{OHdG}$ that is released by base excision repair. Urinary $8-\mathrm{OHdG}$ instead may be derived from DNA breakdown products from dead cells that are oxidised during elimination (ESCODD, 2000). HPLC-EC is the most commonly used method; it is sensitive and the easiest method to use. The GC-MS method is more specific, measures the base and not the nucleoside, but is more laborious and is not used for urine measurement. Other oxidised bases, such as 8-hydroxy-deoxyadenosine, can also be measured, however, 8OHdG seems more mutagenic and therefore more favourable (ILSI Europe 1999). 
Another technique for measuring antioxidant capacity by evaluating DNA damage is the highly sensitive 'comet assay' using single cell gel electrophoresis (Collins et al. 1993). This assay measures DNA damage, i.e. DNA breaks in cells e.g. lymphocytes (Anderson et al. 1994; Betti et al. 1993). DNA damage (i.e. breaks) can be visualized by staining and unwinding electrophoresis of the DNA. The assay can be quantified by scoring of fluorescence intensity of the tails. The sensitivity of this technique can be improved by the use of DNA restriction enzymes (e.g. endonuclease-III) converting the oxidized bases to strand breaks (Duthie et al. 1996). However, basal levels as well as the reported effects of the interventions are rather variable, possibly reflecting differences in the populations, regimens, functional correlates of the biomarkers as well as between laboratory and assay variations. It has been suggested that antioxidant depletion due to nutritional deficiency or an increased oxidative stress might facilitate demonstration of protective effects of antioxidants with respect to DNA damage (Loft \& Poulsen 2000; Moller et al. 2000). In general, the comet assay is considered to be a suitable, sensitive, and quantitative, test for DNA-damaging potential in biomonitoring studies.

\section{Oxidative damage to proteins}

The field of protein oxidation is very much in its infancy. Nevertheless, oxidative damage to proteins might be of importance in vivo because it may affect receptor function, enzyme activity or transport mechanisms and may contribute to secondary damage to other biomolecules, such as inactivation of DNA repair enzymes. Attack of RNS on tyrosine results into the production of 3-nitrotyrosine, which can be measured immunologically, by HPLC-ECD or GC-MS (van der Vliet et al. 1996). In terms of sensitivity and specificity, it would appear that methods based on combinations of HPLC and various types of ECD are very versatile giving a limit of detection of 20 fmol per injection of protein hydrolysate (Herce-Pagliai et al. 1998). These methods are limited by the sample quantity and the preparation that is required to achieve acceptable chromatograms. A problem with these methods is that acid hydrolysis used for the digestion of tissues and proteins causes the nitration of tyrosine as an artifact. Nitrotyrosine is also reportedly degraded by $\mathrm{HOCl}$, questioning its validity as an oxidative biomarker.

More use has been made of the carbonyl assay (Levin et al. 1994), a sensitive but nonspecific assay of oxidative protein damage assessing 'steady-state' protein damage in 
human tissues and body fluids. The carbonyl assay is based on the reaction of ROS with amino acid residues in proteins (particularly histidine, arginine, lysine and proline) giving carbonyl functions that can be measured after the reaction with 2,4dinitrophenylhydrazine and detected using enzyme linked immuno sorbent assay (ELISA) (Buss et al. 1997). Measurement of carbonyls in human plasma can be a useful marker, but more work has to be done to identify the molecular nature of the protein carbonyls in human plasma.

\section{Oxidative damage to lipids: Lipid Peroxidation}

Lipid peroxidation results in the formation of conjugated dienes, lipid hydroperoxides and degradation products such as alkanes, aldehydes and isoprostanes. For quantitative assessment of lipid peroxidation a range of methods are available.

Measurement of conjugated diene formation is generally applied as a dynamic quantitation e.g. during the oxidation of low-density lipoproteins (LDL), and is not generally applied to samples obtained in vivo. LDL oxidation is (in vitro) initiated by free radicals. During this process, the rate of oxidation is dependent on endogenous antioxidants in LDL, accounting for the lag-phase of oxidation. LDL oxidation is efficiently inhibited by lipophilic antioxidants of which $\alpha$-tocopherol appears to be the most important (Esterbauer et al. 1992).

Lipid hydroperoxides readily decompose, but can be measured directly and indirectly by a variety of techniques (e.g. Jiang et al. 1992; Thomas et al. 1989). Interpretations of the results of these assays are complicated due the unstable products with a short half-lives. Measurement of malondialdehyde (MDA) by the thiobarbituric acid reactive substances (TBARS) assay is non-specific, and is generally poor when applied to biological samples (Diplock et al. 1998). However, HPLC (with fluorometric detection) based TBA-tests record comparable low values between different laboraries, provided that butylated hydroxytoluene (BHT) is added with the TBA reagents (Halliwell \& Chirico, 1993). MDA is one of the many products formed during the radical induced decomposition of polyunsaturated fatty acids. Most often, MDA assay is determined using its reactivity at high temperature and low $\mathrm{pH}$, towards thiobarbituric acid. This reaction is very sensitive but the specificity, even with optimized pre-analytical (sampling, preservatives), and analytical stages (fluorescence, HPLC) is still a matter of debate (Lefevre et al. 1998). The TBARS assay should be considered as a test, providing global information on lipoperoxidation whereas specific 
determination of MDA can only appreciate one of the end-product formed during oxidative stress.

More recent assays based on the measurement of MDA or HNE-lysine adducts are likely to be more applicable to biological samples, since adducts of these reactive aldehydes are relatively stable (Moore \& Roberts 1998). The discovery of the isoprostanes as lipid peroxidation products from arachidonic acid, which can be measured by gas chromatography mass spectrometry (Morrow \& Roberts 1994), has opened a new avenue by which to quantify lipid peroxidation in vivo. $F_{2}$-isoprostanes can be measured in plasma and urine of healthy human subjects and are indicative of ongoing lipid peroxidation. This urinary marker of lipid oxidation as an indicator of whole body lipid peroxidation meets all criteria to be a useful marker, but the major question is whether as minor lipid peroxidation products, isoprostanes are indicative of a major pathway involved in the disease process.

'Whole body' lipid peroxidation can also be determined by measuring hydrocarbon gases (ethane, pentane) in exhaled air and urinary secretion of TBARS (Gutteridge \& Thickner, 1978). Hydrocarbon gas exhalation has too many confounding variables to be applicable in free-living human subjects (Springfield \& Levitt, 1994). Urinary TBARS is also not considered as a suitable assay to assess whole-body lipid peroxidation in response to changes in dietary composition (Brown et al. 1995), because many artificial products could be generated.

\section{(Functional) markers of oxidative stress}

Antioxidant status and markers of oxidative damage (DNA adducts, lipid- and protein oxidation products) are frequently used to assess anti- and pro-oxidant effects. However, gene expression, being an important modulator of cell functions, has been shown, in some cases, to be under redox control.

ROS are involved in the regulation of gene expression (Sen \& Packer 1996). Changes in gene expression can provide a sensitive marker of oxidative stress (or changes in antioxidant status) of tissue, but the development of markers based on such changes is at an early stage. Expression of genes selected should be specifically induced by oxidative stress, if possible, and the functional significance of the gene product and its induction should be known.

For a better understanding of ROS-associated disorders, recent studies have focussed on the regulation of gene expression by intracellular reduction-oxidation (redox) state. 
A well-defined transcription factor, nuclear factor (NF) $\mathrm{\kappa B}$, has been identified to be regulated by the intracellular redox state. Transcription factors are proteins that bind to regulatory sequences, usually in the $5^{\prime}$ upstream promoter region of target genes, to increase the rate of gene expression. This may affect protein synthesis, which could result in altered cellular function.

The transcription factor NF- $\mathrm{KB}$ is of considerable interest to the field of free radical biology because it is activated by ROS and this enhanced activity can be modulated by antioxidants (Sen \& Packer 1996). Because ROS are generated under numerous pathological conditions, measurement of NF-kB activation could provide important insight into the etiology of these disorders and also offers the potential of NF- $\mathrm{KB}$ as a functional biomarker for oxidative stress.

To clarify the role of NF- $\mathrm{KB}$ in various aspects of cell function, inflammatory processes and pathologies, clinical studies have to be performed using NF- $\mathrm{KB}$ activity as a target for intervention with drugs or food components. Because of the involvement of NF- $\mathrm{KB}$ in numerous pathophysiological processes an unequivocal NF$\kappa \mathrm{B}$ determination might be useful in order to be able to use NF- $\mathrm{KB}$ as a functional biomarker. The most widely applied method to establish NF- $k B$ activation is the electromobility shift assay (EMSA). In EMSA, differences in concentration of NF- $\mathrm{kB}$ proteins that have been translocated to the nucleus can be detected. Quantification of these proteins might provide useful information about the intracellular redox status with the aim to further explore the potential of antioxidant therapy. Fundamental research in this rapidly developing area is focussed on elucidating the exact role of $\mathrm{NF}-\mathrm{kB}$ in oxidative stress related processes and the molecular mechanism of action of antioxidants.

This NF-kB redox-controlled mechanism is quite distinct from the response to antioxidants that involves up-regulation of certain specific genes (e.g. glutathione-Stransferase) as a consequence, for example of the antioxidant responsive element (ARE) present in the promotor. Such genes respond to a diverse selection of antioxidants and might reflect changes in oxidative status. Both induction of glutathione-S-transferases (GST $\alpha$ and GST $\pi$ ), a family of phase II enzymes might be used as markers of oxidative stress. GSTs are able to conjugate electrophiles with glutathione (GSH), or by a glutathione-dependent peroxidase activity. They may also participate in the repair of damaged cellular macromolecules as a result of oxidative stress. In addition, GST $\pi$ can react directly with reactive oxygen species via a sensitive 
SH-group, or be inactivated by disulphide formation that can be reversed by glutathione. Therefore, it has a specific response to oxidative stress (Xia et al. 1996). Glutathione itself, in its reduced form (GSH), is a powerful intracellular antioxidant, and the ratio of reduced to oxidised glutathione (GSH/GSSG ratio) might serve as a representative marker of the antioxidant capacity of the cell. Several clinical conditions are associated with reduced GSH levels (diabetes, sepsis, inflammatory lung processes, cancer and immunodeficiency states; Exner et al. 2000), that as a consequence can result in a lowered cellular redox potential. Thus, the GSH/GSSG ratio in blood could also serve as a functional marker of oxidative stress.

\section{Antioxidant Capacity of Food: relation with biomarkers of the antioxidant status and oxidative damage; Rationale of the project}

As indicated, most of the methods discussed on page 18-28 are being used in both biological matrices, as in food products or diets. Compounds with antioxidant capacity occur widely in 'natural' food products. Analysis of the content and potential antioxidant capacity of the separate compounds is time-consuming and costly. Moreover, these compounds function in a complex network with a dynamic interaction. Measurement has therefore been focussed on determination of the total antioxidant capacity of food.

Total antioxidant capacity of food is of relevance for product quality as it may be a determinant of product quality, related to protection against oxidative damage of the product, such as lipid oxidation (i.e. rancidity), resulting in changes in sensory characteristics and product stability. Another interesting aspect is the potential health benefit of food products (diets) with a high total antioxidant capacity, i.e. food as a supplier of antioxidants to the (human) organism.

The rationale behind the work described in this thesis was to develop and evaluate methods to assess the total antioxidant capacity of food (products), including both the water- and lipid-soluble compounds. Next, to 'evaluate' these methods with respect to their prognostic value for 'in vivo' efficacy, i.e. to assess the relationship between the total antioxidant capacity of food products and the (plasma) antioxidant status, respectively, the effect on biomarkers of oxidative stress, in subjects after consumption of these products.

As described on page 18-28 several methods and approaches for measuring 'total' antioxidant capacity in food products have been reported. A general problem with 
these methods is that they are poorly validated, and have a 'low' specificity. However, a limited specificity can also be considered as 'positive', or even a prerequisite for such assays, so long as these methods intend to measure the overall antioxidant characteristic of the product, regardless of the contribution of each separate compound. In this project we especially focussed on the TEAC assay to assess the total antioxidant capacity of food, and the in vivo activation of the redox controlled transcription factor NF- $\mathrm{\kappa B}$ as a functional biomarker for oxidative stress.

The aim of the project was: (i) to use and evaluate the TEAC assay for assessment of the antioxidant capacity of food products; (ii) to establish the relationship between the TEAC of food (products), the potential effect on antioxidant status and markers of oxidative stress in humans; (iii) to assess the potential of NF- $\mathrm{KB}$ activation as a biomarker of oxidative stress.

\section{References}

Anderson, D., Yu, T.W., Phillips, B.J., Schmezer, P. (1994) The effect of various antioxidants and other modifying agents on oxygen-radical-generated DNA damage in human lymphocytes in the COMET assay. Mutat. Res. 307: 261-271.

Benzie, I.F.F. (1996) Lipid peroxidation: a review of causes, consequences, measurement and dietary influences. Int. J. Food Sci. Nutr. 47: 233-261.

Benzie, I.F.F., Strain, J.J. (1996) The ferric reducing ability of plasma (FRAP) as a measure of "antioxidant power": the FRAP assay. Anal. Biochem. 239: 70-76.

Benzie I.F.F. (2000) Evolution of antioxidant defence mechanisms. Eur. J. Nutr. 39: 53-61.

Betti, C., Barale, R., Pool-Zobel, B.L. (1993) Comparative studies on cytotoxic and genotoxic effects of two organic mercury compounds in lymphocytes and gastric mucosa cells of Sprague-Dawley rats. Environ. Mol. Mutagen. 22: 172-180.

Block, G., Patterson, B., Subar, A. (1992) Fruit, vegetables and cancer prevention: A review of the epidemiological evidence. Nutr. Cancer 18: 1-29.

Bondet, V., Brand-Williams, W., Berset, C. (1997) Kinetics and mechanisms of antioxidant activity using the DPPH• free radical method. Lebensm. Wiss. Technol. 30: 609-615.

Brown, E.D., Morris, V.C., Rhodes, D.G., Sinha, R., Levander, O.A. (1995) Urinary malondialdehyde-equivalents during ingestion of meat cooked at high or low temperatures. Lipids. 30: 1053-1056.

Buss, H., Chan, T.P., Sluis, K.B., Domigan, N.M., Winterbourn, C.C. (1997) Protein carbonyl measurement by a sensitive ELISA method. Free Radic. Biol. Med. 23: 361-366.

Cao. G., Alessio, H.M., Cutler, R.G. (1993) Oxygen-radical absorbance capacity assay for antioxidants. Free Radic. Biol. Med. 14: 303-311.

Cao, G., Giovanoni, M., Prior, R.L. (1996) Antioxidant capacity decreases during growth but not aging in rat serum and brain. Arch. Gerontol. Geriatr. 22: 27-37.

Cao, G., Prior, R.L. (1998) Comparison of different analytical methods for assessing total antioxidant capacity of human serum. Clin. Chem. 44: 1309-1315.

Collins, A.R., Duthie, S.J., Dobson, V.L. (1993) Direct enzymic detection of endogenous oxidative base damage in human lymphocyte DNA. Carcinogenesis. 14: 1733-1735. 
Diplock, A.T. (1994) Antioxidants and disease prevention. Mol. Aspects Med.15: 293-376

Diplock, A.T., Charleux, J.L., Crozier-Willi, G., Kok, F.J., Rice-Evans, C., Roberfroid, M., Stahl, W., Vina-Ribes, J. (1998) Functional food science and defence against reactive oxidative species. Br. J. Nutr. 80: S77-S112.

Diplock, A.T., Aggett, P.J., Ashwell, M., Bornet, F., Fern, E.B., Roberfroid, M. (1999) Scientific Concept of Functional Food in Europe: Consensus document. Br. J. Nutr. 81: S1-S27.

Dizdaroglu, M. (1993) Quantitative determination of oxidative base damage in DNA by stable isotope-dilution mass spectrometry. FEBS Lett. 315: 1-6.

Dürken, M., Agbenu, J., Finckh, B., Hübner, C., Pichlmeier, U., Zeller, W., Winkler, K., Zander, A., Kohlschütter, A. (1995) Deteriorating free radical-trapping capacity and antioxidant status in plasma during bone marrow transplantation. Bone Marrow Transplant. 15: 757-762.

Duthie, S.J., Ma, A., Ross, M.A., Collins, A.R. (1996) Antioxidant supplementation decreases oxidative DNA damage in human lymphocytes. Cancer Res. 56: 1291-1295.

Eastwood, M.A. (1999) Interaction of dietary antioxidants in vivo: how fruit and vegetables prevent disease? QJM. 92: 527-530.

ESCODD (European Standards Committee on Oxidative DNA Damage) (2000) Comparison of different methods of measuring 8-oxoguanine as a marker of oxidative DNA damage. Free Radic. Res. 32: 333-341.

Esterbauer, H., Gebicki, J., Puhl, H., Jurgens, G. (1992) The role of lipid peroxidation and antioxidants in oxidative modification of LDL. Free Radic. Biol. Med. 13: 341-390.

Exner, R., Wessner, B., Manhart, N., Roth, E. (2000) Therapeutic potential of glutathione. Wien Klin Wochenschr. 112: 610-616.

Glazer, A.N. (1990) Phycoerythrin fluorescence-based assay for reactive oxygen species. Methods Enzymol. 186: 161-168.

GISSI-Prevenzione Investigators (1999) Dietary supplementation with n-3 polyunsaturated fatty acids and vitamin $E$ after myocardial infarction: results of the GISSI-Prevenzione trial. Lancet 354: 447-455.

Guller, K., Palanduz, S., Ademoglu, E., Sahnayenli, N., Gokkusu, C., Vatansever, S. (1998) Total antioxidant status, lipid parameters, lipid peroxidation and glutathione levels in patients with acute myocardial infarction. Med. Sci. Res. 26: 105-106.

Gutteridge, J.M., Tickner, T.R. (1978) The characterisation of thiobarbituric acid reactivity in human plasma and urine. Anal. Biochem. 91: 250-257.

Gutteridge, J.M. (1993) Free radicals in disease processes: a compilation of cause and consequence. Free Radic. Res. Commun. 19: 141-158.

Halliwell, B. (1985) Use of desferrioxamine as a 'probe' for iron-dependent formation of hydroxyl radicals. Evidence for a direct reaction between desferal and the superoxide radical. Biochem. Pharmacol. 34: 229-233.

Halliwell, B., Gutteridge, J.M., Aruoma, O.I. (1987) The deoxyribose method: a simple "testtube" assay for determination of rate constants for reactions of hydroxyl radicals. Anal. Biochem. 165: 215-219.

Halliwell, B., Chirico, S. (1993) Lipid peroxidation: its mechanism, measurement, and significance. Am. J. Clin. Nutr. 57: 715S-725S.

Halliwell, B. (1999) Establishing the significance and optimal intake of dietary antioxidants: the biomarker concept. Nutr. Rev. 57: 104-113.

Halliwell, B. (2000) The antioxidant paradox. Lancet 355: 1179-1180.

Herce-Pagliai, C., Kotecha, S., Shuker, D.E. (1998) Analytical methods for 3-nitrotyrosine as a marker of exposure to reactive nitrogen species: a review. Nitric Oxide 2: 324-336. 
Iannello RC, Crack PJ, de Haan JB, Kola I. (1999) Oxidative stress and neural dysfunction in Down syndrome. J. Neural. Transm. Suppl. 57: 257-267.

ILSI Europe (1999) Report on markers of oxidative damage and antioxidant protection: Current status and relevance to disease. In ILSI report series. Brussels, ILSI Europe.

Jiang, Z.Y., Hunt, J.V., Wolff, S.P. (1992) Ferrous ion oxidation in the presence of xylenol orange for detection of lipid hydroperoxide in low density lipoprotein. Anal. Biochem. 202: 384-389.

Julicher, R.H., Sterrenberg, L., Haenen, G.R.M.M., Bast, A., Noordhoek, J. (1988) The effect of chronic adriamycin treatment on heart kidney and liver tissue of male and female rat. Arch Toxicol. 61: 275-281.

Lefevre, G., Beljean-Leymarie, M., Beyerle, F., Bonnefont-Rousselot, D., Cristol, J.P., Therond, P., Torreilles. (1998) Evaluation of lipid peroxidation by measuring thiobarbituric acid reactive substances. J. Ann. Biol. Clin. 56: 305-319 (in French).

Levine, R.L., Williams, J.A., Stadtman, E.R., Shacter, E. (1994) Carbonyl assays for determination of oxidatively modified proteins. Methods Enzymol. 233: 346-357.

Loft, S., Fischer-Nielsen, A., Jeding, I.B., Vistisen, K., Poulsen, H.E. (1993) 8Hydroxydeoxyguanosine as a urinary biomarker of oxidative DNA damage. J. Toxicol. Environ. Health 40: 391-404.

Loft, S., Poulsen, H.E. (2000) Antioxidant intervention studies related to DNA damage, DNA repair and gene expression. Free Radic. Res. S67-83.

Maiorino, M., Zamburlini, A., Roveri, A., Ursini, F. (1993) Prooxidant role of vitamin E in copper induced lipid peroxidation. FEBS Lett. 330: 174-176.

Majkic, N., Djordjevic-Spasic, S., Berkes, I. (1975) A kinetic method for the determination of the activity of "aerobic transhydrogenases". Clin. Chim. Acta. 65: 227-233.

Majkic, N., Berkes, I. (1977) Determination of free and esterified cholesterol by a kinetic method. I. The introduction of the enzymatic method with 2,2'-azino-di-3[ethylbenzthiazolin sulfonic acid (6)] (ABTS). Clin. Chim. Acta. 80: 121-131.

Majkic-Singh N, Said BA, Spasic S, Berkes I. (1984) Evaluation of the enzymatic assay of serum uric acid with 2,2'-azino-di(3-ethylbenzthiazoline-6-sulphonate) (ABTS) as chromogen. Ann. Clin. Biochem. 21: 504-509.

Makjanic, J., Ponraj, D., Tan, B.K.H., Watt, F. (1999) Nuclear microscopy investigations into the role of iron in atherosclerosis. Nucl. Inst. Meth. Res. Sect. B 159: 356-360.

Metsä-Ketelä, T., Kirkola, A.L. (1992) Total peroxyl radical-trapping capability of human LDL. Free Radic. Res. Commun. 16S: 215.

Miller, N.J., Rice-Evans, C., Davies, M.J., Gopinathan, V., Milner, A. (1993) A novel method for measuring antioxidant capacity and its application to monitoring the antioxidant status in premature neonates. Clin. Sci. 84: 407-412.

Moller, P., Knudsen, L.E., Loft, S., Wallin, H. (2000) The comet assay as a rapid test in biomonitoring occupational exposure to DNA-damaging agents and effect of confounding factors. Cancer Epidemiol. Biomarkers Prev. 9: 1005-1015.

Moore, K., Roberts, L.J. II (1998) Measurement of lipid peroxidation. Free Radic. Res. 28: 659-671.

Morrow, J.D., Roberts, L.J. II (1994) Mass spectrometry of prostanoids: F2-isoprostanes produced by non-cyclooxygenase free radical-catalyzed mechanism. Methods Enzymol. 233: 163-174.

Mulholland, C.W., Strain, J.J. (1991) Serum total free radical trapping ability in acute myocardial infarction. Clin. Biochem. 24: 437-441. 
Niu, X., Zammit, V., Upston, J.M., Dean, R.T., Stocker, R. (1999) Coexistence of oxidized lipids and alpha-tocopherol in all lipoprotein density fractions isolated from advanced human atherosclerotic plaques. Arterioscler. Thromb. Vasc. Biol. 19: 1708-1718.

Noda, Y., Anzai, K., Mori, A., Kohno, M., Shinmei, M., Packer, L. (1997) Hydroxyl and superoxide anion radical scavenging activities of natural source antioxidants using the computerized JES-FR30 ESR spectrometer system. Biochem. Mol. Biol. Int. 42: 35-44.

Nomura, T., Kikuchi, M., Kubodera, A., Kawakami, Y. (1997) Proton-donative antioxidant activity of fucoxanthin with 1,1-diphenyl-2-picrylhydrazyl (DPPH). Biochem. Mol. Biol. Int. 42: 361-370.

Pool-Zobel, B.L., Bub, A., Müller, H., Wollowski, I., Rechkemmer, G. (1997) Consumption of vegetables reduces genetic damage in humans: first results of an intervention trial with carotenoid-rich foods. Carcinogenesis 18: 1847-1850.

Porrini, M., Riso, P. (2000) Lymphocyte lycopene concentration and DNA protection from oxidative damage is increased in women after a short period of tomato consumption. $J$. Nutr. 130: 189-192.

Rice-Evans, C.A., Miller, N.J. (1994) Total antioxidant status in plasma and body fluids. Meth. Enzymol. 234: 279-293.

Rowe, P.M. (1996) Beta-carotene takes a collective beating. Lancet. 347: 249.

Sen, C.K., Packer, L. (1996) Antioxidant and redox regulation of gene transcription. FASEB J. 10: 709-720.

Shah, V.P., Behl, C.R., Flynn, G.L., Higuchi, W.I., Schaefer, H. (1992) Principles and criteria in the development and optimization of topical therapeutic products. J. Pharm. Sci. 81: $1051-1054$.

Shigenaga, M.K., Aboujaoude, E.N., Chen, Q., Ames, B.N. (1994) Assays of oxidative DNA damage biomarkers 8-oxo-2'-deoxyguanosine and 8-oxoguanine in nuclear DNA and biological fluids by high-performance liquid chromatography with electrochemical detection. Methods Enzymol. 234: 16-33.

Sies, H. (1997) Oxidative stress: oxidants and antioxidants. Exp. Physiol. 82: 291-295.

Springfield, J.R., Levitt, M.D. (1994) Pitfalls in the use of breath pentane measurements to assess lipid peroxidation. J. Lipid. Res. 35: 1497-1504.

Steinmetz, K.A., Potter, J.D. (1996) Vegetables, fruit, and cancer prevention: a review. J. Am. Diet Assoc. 96: 1027-1039.

Stephens NG, Parsons A, Schofield PM, Kelly F, Cheeseman K, Mitchinson MJ. (1996) Randomised controlled trial of vitamin $\mathrm{E}$ in patients with coronary disease: Cambridge Heart Antioxidant Study (CHAOS). Lancet. 347: 781-786.

Strube, M., Haenen, G.R.M.M., van den Berg, H., Bast, A. (1997) Pitfalls in a method for assessment of total antioxidant capacity. Free Radic. Res. 26: 515-521.

Takayanagi, M., Yashiro, T. (1984) Colorimetry of hemoglobin in plasma with 2,2'-azinodi(3-ethylbenzthiazoline-6-sulfonic acid) (ABTS). Clin. Chem. 30: 357-359.

Thomas, S.M., Jessup, W., Gebicki, J.M., Dean, R.T. (1989) A continuous-flow automated assay for iodometric estimation of hydroperoxides.

Anal. Biochem. 176: 353-359.

Tubaro, F., Ghiselli, A., Rapuzzi, P., Maiorino, M., Ursini, F. (1998) Analysis of plasma antioxidant capacity by competition kinetics. Free Radic. Biol. Med. 24: 1228-1234.

Valkonen, M., Kuusi, T. (1997) Spectrophotometric assay for total peroxyl radical-trapping antioxidant potential in human serum. J. Lipid Res. 38: 823-833.

Van der Vliet, A., Eiserich, J.P., Kaur, H., Cross, C.E., Halliwell, B. (1996) Nitrotyrosine as biomarker for reactive nitrogen species. Methods Enzymol. 269: 175-184. 
Vaughan, M. (1997) Oxidative damage to macromolecules mini-review series. J. Biol. Chem. 272: 18513.

Wayner, D.D., Burton, G.W., Ingold, K.U., Locke, S. (1985) Quantitative measurement of the total, peroxyl radical-trapping antioxidant capability of human blood plasma by controlled peroxidation. The important contribution made by plasma proteins. FEBS Lett. 187: 33-37.

Wayner, D.D., Burton, G.W., Ingold, K.U., Barclay, L.R., Locke, S.J. (1987) The relative contributions of vitamin $\mathrm{E}$, urate, ascorbate and proteins to the total peroxyl radicaltrapping antioxidant activity of human blood plasma. Biochim Biophys Acta. 924: 408419.

Whitehead, T.P., Thorpe, G.H.G., Maxwell, S.R.J. (1992) Enhanced chemiluminoscent assay for antioxidant capacity in biological fluids. Anal. Chim. Acta 266: 265-277.

Winston, G.W., Regoli, F., Dugas, A.J. Jr., Fong, J.H., Blanchard, K.A. (1998) A rapid gas chromatographic assay for determining oxyradical scavenging capacity of antioxidants and biological fluids. Free Radic. Biol. Med. 24: 480-493.

Xia, C., Hu, J., Ketterer, B., Taylor, J.B. (1996) The organization of the human GSTP1-1 gene promoter and its response to retinoic acid and cellular redox status. Biochem J. 313: 155-161.

Young J.F., Nielsen, S.E., Haraldsdottir, J., Daneshvar, B., Lauridsen, S.T., Knuthsen, P., Crozier, A., Sandstrom, B., Dragsted, L.O. (1999) Effect of fruit juice intake on urinary quercetin excretion and biomarkers of antioxidative status. Am. J. Clin. Nutr. 69: 87-94. 


\section{Chapter 2}

Applicability of an improved Trolox equivalent antioxidant capacity (TEAC) assay for evaluation of antioxidant capacity measurements of mixtures

Robin van den Berg, Guido R.M.M. Haenen, Henk van den Berg and Aalt Bast

Food Chemistry 66 (4), 511-517 (1999) 


\begin{abstract}
The TEAC (Trolox equivalent antioxidant capacity) assay is based on scavenging of 2,2'-azinobis-(3-ethylbenzothiazoline-6-sulfonate) radical anions (ABTS*). In this report we describe a modification based on pre-generation of the ABTS radical anions with a thermolabile azo compound, $2,2^{\circ}$-azobis-(2-amidinopropane) $\mathrm{HCl}$ (ABAP). This modification makes the assay less susceptible to artefacts, e.g. influence on the radical generation process. For most antioxidants tested, a biphasic reaction pattern was seen, i.e. a fast and slow scavenging rate.

We evaluated application of the assay with both lipophilic and hydrophilic compounds with antioxidant capacity. Several organic solvents, compatible with water, were tested with $\alpha$-tocopherol, quercetin and $\beta$-carotene. It was found that the TEACs differed in various solvents. Under standardized conditions additivity of TEACs obtained from individual antioxidants could be demonstrated. This might enable application of the assay for the identification of 'unknown' antioxidants.
\end{abstract}




\section{Introduction}

It is increasingly recognized that oxidative stress is involved in the pathophysiology of various chronic diseases, such as cardiovascular disease and cancer, and that dietary antioxidants may play a role in prevention of these diseases (Halliwell and Gutteridge, 1985). Besides the antioxidant (pro-)vitamins, such as vitamin E, C and $\beta$-carotene, the number of other compounds reported to have antioxidant activity is increasing. There is a continuous search for 'new' compounds and unidentified food ingredients with an antioxidant potential.

A wide range of methods is currently used to assess antioxidant capacity (Halliwell et al. 1995), for example for measurement of prevention of oxidative damage to biomolecules such as lipids or DNA and methods assessing radical scavenging. Both in vivo and in vitro assays are used and all methods have their own advantages and limitations.

Simple scavenging assays, such as the TRAP (Total Reactive Antioxidant Potential or Total Radical-trapping Antioxidant Parameter; Wayner et al. 1987) and the TEAC (Trolox Equivalent Antioxidant Capacity) assay, have gained popularity because they enable high-throughput screening on potential antioxidant capacity. Such methods are used to assess antioxidant capacity of biological matrices, such as plasma, as well as single compounds, food components or food extracts.

The TEAC assay, originally described by Miller et al. (1993), is based on scavenging of long-lived radical anions (ABTS*; Scott et al. 1993). In this assay radicals are generated through the peroxidase activity of metmyoglobin in the presence of hydrogen peroxide and can easily be detected spectrophotometrically at $734 \mathrm{~nm}$. In this assay antioxidants are added before the ABTS“ formation is initiated by hydrogen peroxide, resulting in a delay in radical formation ('lag-time'), which is measured. A TEAC value can be assigned to all compounds able to scavenge the ABTS" by comparing their scavenging capacity to that of Trolox, a water-soluble vitamin $\mathrm{E}$ analogue. Arnao et al. (1996) reported a modification of the TEAC assay by introducing HRP (horseradish peroxidase) for generation of the ABTS*. However, Strube et al. (1997) showed that these 'pre-addition' assays might result in overestimation of the antioxidant capacity due to compounds interfering with the formation of the ABTS"- and proposed a 'post-addition' protocol, in which compounds were added after radical formation. 
In this report we describe a further refinement of the assay by pre-generating the ABTS $^{*}$ in the presence of a thermolabile azo compound, 2,2'-azobis-(2amidinopropane) (ABAP) (Campos et al. 1996). Generation of radicals before the antioxidants are added prevents interference of compounds which affect radical formation. This modification makes the assay less susceptible to artefacts and prevents overestimation of antioxidant capacity.

We also address the difference in reaction kinetics between various compounds as well as the measurement of compounds with different hydrophobicity. Because the TEAC is performed in an aqueous buffer only water-soluble compounds are measured. As foods generally contain both water- and lipid-soluble compounds with antioxidant capacity, it would be attractive to be able to use one method for screening on potential scavenging capacity. We looked into the possibility to evaluate lipid-soluble compounds in the TEAC assay by solubilizing these compounds, especially $\alpha$ tocopherol and the carotenoid $\beta$-carotene, in the aqueous assay medium using suitable solvents.

\section{Materials and methods}

\section{Chemicals}

ABTS $^{2-}$ (2,2'-azinobis-(3-ethylbenzthiazoline-6-sulfonate) was obtained as sulfonic acid from Sigma (St. Louis, MO), ABAP ((2,2'-azobis-(2-amidinopropane)HCl) from Polysciences (Warrington, PA), Trolox ((+/-)-6-hydroxy-2,5,7,8-tetramethyl-chroman2-carboxylic acid, 97\%) from Aldrich (Milwaukee, WI), sodium-L-(+)-ascorbate from Merck (Darmstadt, Germany), quercetin, hesperidin and naringin from Fluka (Bio Chemica, Buchs, Switzerland), $\alpha$-tocopherol (95\%) and lycopene from Sigma, $\beta$ carotene from Merck and zeaxantin, $\beta$-cryptoxantin and narirutin from Roth (Kalsruhe, Germany). Ethanol (absolute) was purchased from J.T. Baker (Deventer, Netherlands), acetone (p.a.) from Merck and Triton X-100 (ethoxylated p-tert-octylphenol) from Koch-light Laboratories (Colebrook, Bucks, UK). THF (tetrahydrofuran) was obtained from Lab Scan (Dublin, Ireland) and SDS (sodium dodecyl sulfate) from Merck. All other chemicals were purchased from Merck and were all of p.a. quality.

Just before use THF was purified by distillation. A few pellets of potassium hydroxide were added to the THF before distillation. 


\section{Apparatus}

A Pharmacia Ultraspec 4000 spectrophotometer with a thermostatic cuvette holder maintained at $37^{\circ} \mathrm{C}$ was used for all antioxidant capacity measurements.

\section{Measurement of total antioxidant capacity}

An ABTS ${ }^{*}$ solution was prepared by mixing $2.5 \mathrm{mM} \mathrm{ABAP}$ with $20 \mathrm{mM} \mathrm{ABTS}{ }^{2-}$ stock solution in $100 \mathrm{mM}$ phosphate buffer (pH 7.4), containing $150 \mathrm{mM} \mathrm{NaCl}$ (PBS). The solution was heated for $12 \mathrm{~min}$ at $60^{\circ} \mathrm{C}$, protected from light and stored at room temperature. To check ABTS" formation the absorbance at $734 \mathrm{~nm}$ was determined (absorption had to be between 0.35 and 0.40). A fresh ABTS/ABAP stock solution was prepared every day. Because of a gradual decrease in absorbance of the ABTS/ABAP stock solution (ca. $2 \%$ per hour) appropriate blanks were recorded for each measurement (the blank is the decrease in absorption of the solvent without the compound added).

For measuring antioxidant capacity $40 \mu \mathrm{l}$ of the sample was mixed with $1960 \mu \mathrm{l}$ of the radical solution. Absorbance was monitored at $734 \mathrm{~nm}$ for $6 \mathrm{~min}$. The decrease in absorption at $734 \mathrm{~nm} 6 \mathrm{~min}$ after addition of a compound was used for calculating the TEAC. All experiments were performed at least in triplicate and in a concentration range between 1.0 and $10.0 \mu \mathrm{M}$ (final concentrations). The antioxidants were dissolved in different solutions: ethanol, THF, acetone, SDS (final concentration in assay $0.03 \mathrm{mM}$ ) and TX-100 (final concentration in assay $17 \mathrm{mM}$ ).

\section{Preparation of antioxidant mixture}

Single solutions of $\alpha$-tocopherol, $\beta$-carotene and vitamin $C$ were prepared in ethanol, THF and PBS, respectively. Further dilutions were made in ethanol, thus the TEAC of the single compounds and the mixture were determined in ethanol (no more than $0.04 \%$ of another solvent left).

\section{Calculations of antioxidant capacity}

A calibration curve was prepared with different concentrations of Trolox. By measuring $\triangle \mathrm{Abs}$ over $6 \mathrm{~min}$ for Trolox (standard range of $0-10 \mu \mathrm{M}$ ), absorbance values were corrected for the solvent.

$$
\Delta \mathrm{A}_{\text {Trolox }}=\left(\mathrm{A}_{\mathrm{t}=0 \text { Trolox }}-\mathrm{A}_{\mathrm{t}=6 \text { min Trolox }}\right)-\Delta \mathrm{A}_{\text {Solvent }}(0-6 \text { min })
$$


The regression coefficient (r.c.) is calculated from the calibration curve.

$$
\Delta \mathrm{A}_{\text {Trolox }}=\text { r.c. } *[\text { Trolox }]
$$

The r.c. should be 0.028 per $\mu \mathrm{M}$ Trolox. To establish the TEAC for unknown compounds the $\triangle \mathrm{A}$ unknown was measured in the same way and corrected for the blank value. The TEAC of an unknown compound $X$ gives the antioxidant capacity of that compound relative, on a molar basis, to Trolox.

$$
\operatorname{TEAC}_{\mathrm{X}}=\Delta \mathrm{A}_{\mathrm{X}} /\left(\text { r.c. }{ }^{*}[x]\right)
$$

The TEAC of mixtures, such as a food (vegetable) extract or a drink, represents the concentration of a Trolox solution that has the same antioxidant capacity as the mixture. Usually the mixture or extract has to be diluted to have it fit in the range of the assay. Appropriate correction for the dilutions should be made.

$$
\mathrm{TEAC}_{\text {solution }}=\left(\Delta \mathrm{A}_{\text {solution }} / \text { r.c. }\right) * \text { dilution factor }(\mathrm{M})
$$

\section{Results}

\section{Modification of the assay}

The 'original' TEAC assay was modified to prevent artefacts due to interference with radical generation. Strube et al. (1997) has shown that, for example, potassium cyanide inhibits radical formation rather than scavenging ABTS*. Such an inhibitory effect results in overestimation of the antioxidant capacity of compounds, or measuring TEACs for compounds that have actually no antioxidant potential. Therefore, ABTS* were pre-generated by heating $\mathrm{ABTS}^{2-}$ with the thermolabile azo compound $2,2^{\prime}$ azobis-(2-amidinopropane) (ABAP). This modified protocol was evaluated by adding single compounds to the assay.

Cyanide, giving an apparent TEAC in the original assay, showed no antioxidant capacity in the modified assay. Trolox reacts instantaneously with ABTS** (Fig. 1A). When quercetin was added to the ABTS**, a biphasic reaction was observed (Fig. 1B). This reaction pattern implies that for the reaction of $\mathrm{ABTS}^{*}$ with quercetin, the reduction in absorption ( $\triangle \mathrm{A}_{\mathrm{X}}$, in section calculation of antioxidant capacity (3)), and 
thus the TEAC, depends on the time point used to read the absorption. Although to a lesser extent, such a biphasic reaction pattern was also observed for vitamin $\mathrm{C}$ (Fig. 1C). This biphasic response was described as the TEAC at $10 \mathrm{~s}$ and $6 \mathrm{~min}$ respectively. The $10 \mathrm{~s}$ TEAC gives the 'fast' reaction, whereas the TEAC at 6 min was chosen because Miller used the same time period and it also includes the greater part of the 'slow' reaction.

As shown in Figure 2, the TEAC for quercetin is concentration-dependent: a higher concentration resulted in a lower TEAC. This was also found with flavanols such as naringin and narirutin (data not shown), but not for the other compounds tested (Table $1)$.

\section{Lipophilic antioxidants}

To investigate whether more lipophilic compounds could also be assessed in the modified TEAC assay, we tried to find a compatible solvent to solubilize these compounds in the aqueous assay medium. We tested several solvents, such as tetrahydrofuran (THF), acetone and Triton X-100 (TX-100). To assess the effect of these solvents, $\alpha$-tocopherol and $\beta$-carotene were used as typical lipophilic compounds and quercetin as an amphiphilic compound.

As expected, the TEAC of $\alpha$-tocopherol was around 1, since tocopherol has the same antioxidant moiety (the chroman ring) as Trolox, and was not affected by the solvent used to solubilize tocopherol in the aqueous assay medium (Fig. 3A).

The TEAC of quercetin, measured in the various solvents at a $1.0 \mu \mathrm{M}$ (final) concentration, also appeared not to depend on the solvent used, except when dissolved in TX-100 (Fig. 3B). Results for $\beta$-carotene were, however, quite variable when using different solvents (Fig. 3C). With THF, $\beta$-carotene showed the highest TEAC, whereas no significant antioxidant capacity could be demonstrated if dissolved in acetone. These results show that measurement of lipid-soluble compounds in the TEAC assay can be troublesome. To overcome this solvent dependence of the TEAC, standardized procedures should be used.

The use of different solvents for solubilizing the lipid-soluble compounds in the assay did not affect the antioxidant capacity of the water-soluble antioxidants, such as vitamin C (data not shown). 
A

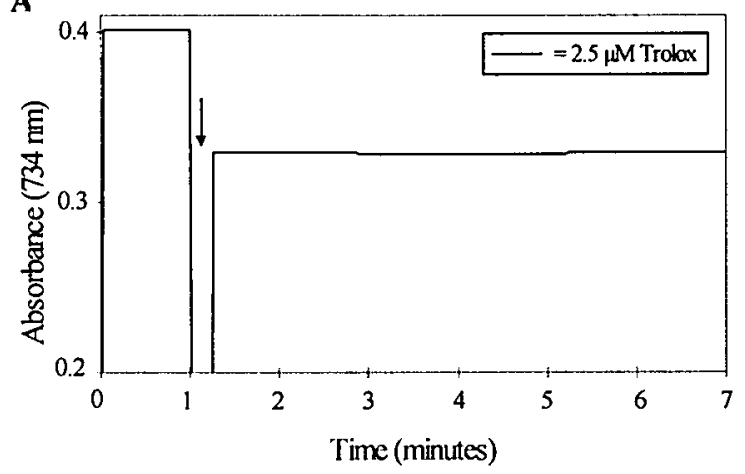

B

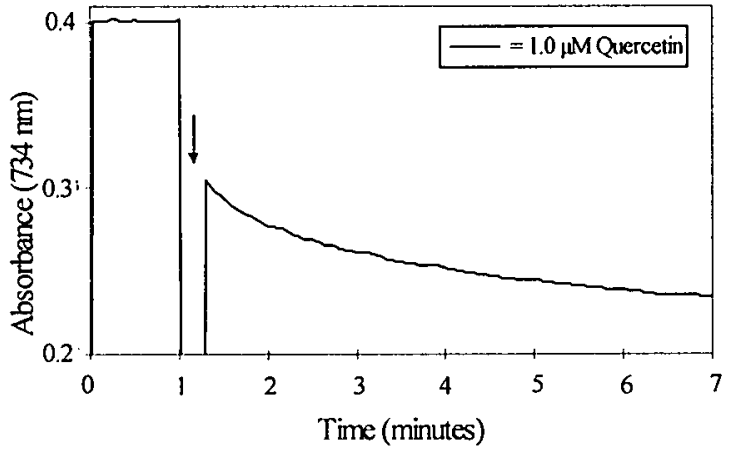

C

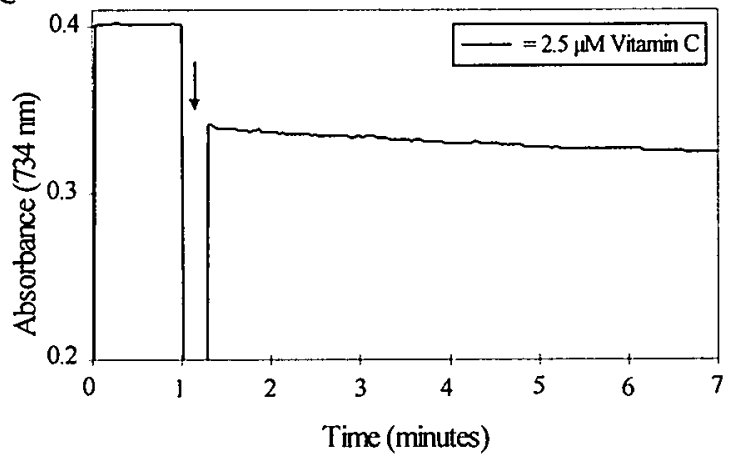

Figure 1. Reaction of Trolox $(A)$, quercetin $(B)$ and vitamin $C(C)$ with the ABTS". Trolox $(2.5 \mu \mathrm{M}$ final concentration) and quercetin (1.0 $\mu \mathrm{M}$ final concentration) dissolved in ethanol and vitamin $C(2.5 \mu \mathrm{M}$ final concentration) dissolved in PBS buffer were added at the timepoint indicated by the arrow. 


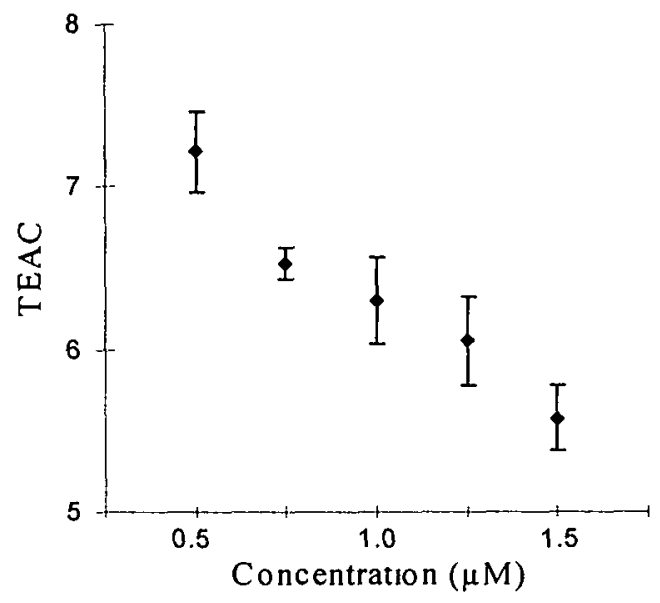

Figure 2. The TEAC of quercetin measured after 6 min in different concentrations.

Table 1. The TEACs of various antioxidants

\begin{tabular}{|c|c|c|c|}
\hline & Original assay & Modified & assay \\
\hline & $\begin{array}{c}\text { TEAC at } \\
6 \mathrm{~min}\end{array}$ & $\begin{array}{c}\text { TEAC at } \\
10 \mathrm{~s}\end{array}$ & $\begin{array}{c}\text { TEAC at } \\
6 \mathrm{~min}\end{array}$ \\
\hline Trolox & 1.00 & 1.00 & 1.00 \\
\hline$\alpha$-Tocopherol & $0.97 \pm 0.01^{a}$ & $0.95 \pm 0.02$ & $0.97 \pm 0.05$ \\
\hline Vitamin $C^{*}$ & $0.99 \pm 0.04^{a}$ & $0.86 \pm 0.02$ & $1.14 \pm 0.04$ \\
\hline Dehydroascorbate* & $0.00^{8}$ & $0.00 \pm 0.01$ & $0.25 \pm 0.05$ \\
\hline Quercetin & $4.72 \pm 0.10^{f}$ & $3.49 \pm 0.33$ & $6.43 \pm 0.27$ \\
\hline Hesperidin & $1.0 \pm 0.03^{d}$ & $0.16 \pm 0.02$ & $1.21 \pm 0.01$ \\
\hline Naringin & $0.24 \pm 0.02^{d}$ & $0.01 \pm 0.01$ & $1.08 \pm 0.01$ \\
\hline Narirutin* & $0.8 \pm 0.5^{d}$ & $0.01 \pm 0.01$ & $1.22 \pm 0.03$ \\
\hline$\beta$-Carotene & $" 1.9 \pm 0.10^{\circ}$ & ${ }^{\mathrm{s}} 0.88 \pm 0.08$ & $s_{1.61} \pm 0.07$ \\
\hline Lycopene & ${ }^{\#} 2.9 \pm 0.15^{e}$ & ${ }^{\$} 1.59 \pm 0.07$ & $s_{2.31} \pm 0.07$ \\
\hline Zeaxantine & ${ }^{\sharp} 1.4 \pm 0.04$ & $\mathrm{~s}_{0.88} \pm 0.13$ & ${ }^{s} 1.70 \pm 0.05$ \\
\hline$\beta$-Cryptoxantine & ${ }^{\#} 2.0 \pm 0.02$ & $s_{0.95} \pm 0.08$ & $s_{1.65 \pm 0.02}$ \\
\hline
\end{tabular}

TEACs are means $\pm \mathrm{SD}, n=3-6$. The listed compounds were dissolved in ethanol.

*Dissolved in PBS buffer, "Dissolved in hexane/acetone, ${ }^{5}$ Dissolved in THF.

Due to concentration dependency of the TEAC the given value was the TEAC measured at standardised final concentrations; quercetin $(1.0 \mu \mathrm{M})$, narigin $(5.0 \mu \mathrm{M})$ and narirutin $(5.0 \mu \mathrm{M}) .{ }^{a}$ Data from Miller et al. 1993. ${ }^{b}$ Data from Miller et al. 1995. 'Data from Salah et al. 1995. 'Data from Rice-Evans et al. 1997. ${ }^{\circ}$ Data from Miller et al. 1996. 

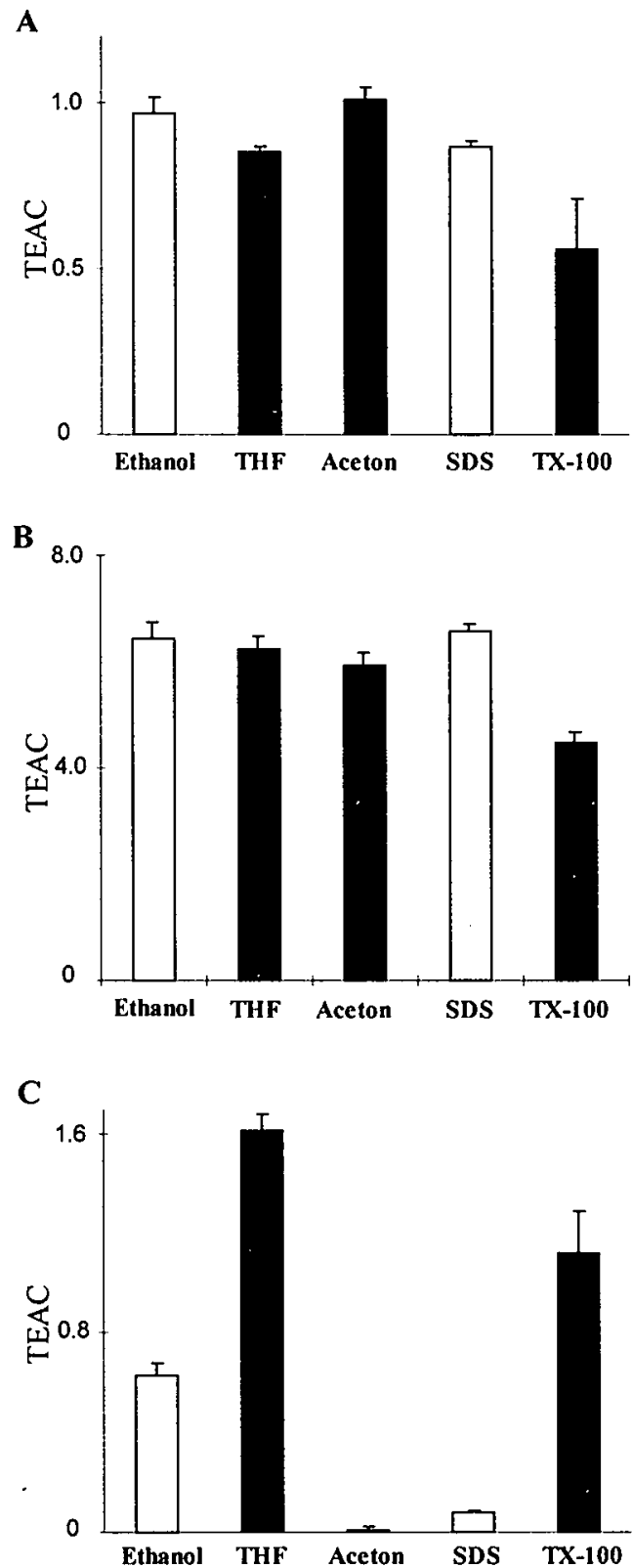

Figure 3. The effect of different solvents on the TEAC of $\alpha$-tocopherol (A) quercetin (B) and $\beta$-carotene (C). The TEAC was calculated 6 min after addition of 2.5-7.5 $\mu M \alpha$-tocopherol, $1.0 \mu M$ quercetin and $1.0 \mu M \beta$-carotene, respectively $(n=3)$. 


\section{Evaluation of antioxidant mixtures}

The previous section described measurement of TEACs for single compounds. However, the TEAC assay is often used to assess the antioxidant capacity of mixtures of antioxidants. To evaluate the modified TEAC assay for mixtures of antioxidants, a solution of lipophilic and hydrophilic compounds was prepared in ethanol.

When using ethanol instead of THF (Table 1), the TEAC of $\beta$-carotene was 0.63 rather than 1.61. Under these conditions, the TEAC, at 6 minutes, for a mixture of vitamin $C$, $\alpha$-tocopherol and $\beta$-carotene was found to be additive (Fig. 4).

The applicability of the protocol was tested for a soft drink and some fruit juices. For the TEAC of these solutions, it should be noted that a constant dilution factor was applied because of the concentration dependence of the TEAC. To standardize the procedure, 'pure' drinks were diluted with PBS buffer to a $5 \%$ solution. The results are listed in Table 2.

Between the drinks, considerable differences in TEAC were found. In all the cases, the measured TEAC was higher than could be explained on the basis of vitamin $\mathrm{C}$ and flavanones (measured as hesperidin, naringin and narirutin) contents. Vitamin $C$, the main known antioxidant in the fruit juices, can largely explain the antioxidant capacity measured. The contribution of the flavanones is too small to explain the remaining antioxidant capacity. Thus, other unidentified antioxidants appear to be present as well.

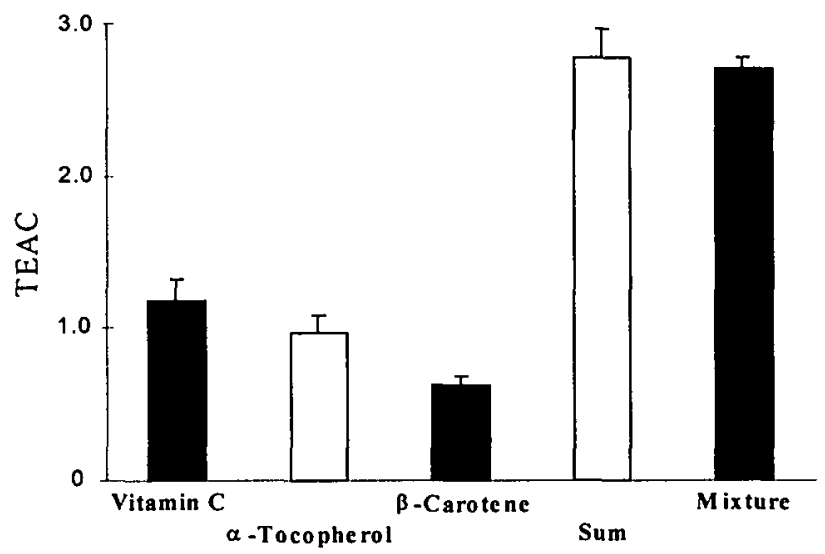

Figure 4. The TEAC of the separate antioxidants vitamin $C, \alpha$-tocopherol and $\beta$-carotene and of the mixture $(n=6)$. 
Table 2. Antioxidant capacity of some fruit/soft drinks in relation to antioxidant contents

\begin{tabular}{lccccc|cc}
\hline $\begin{array}{l}\text { Vitamin-C } \\
(\mathrm{mM}) \\
\text { analysed }\end{array}$ & $\begin{array}{c}\text { Vitamin-E } \\
(\mathrm{mM}) \\
\text { analysed }\end{array}$ & $\begin{array}{c}\text { Hesperidin } \\
(\mathrm{mM}) \\
\text { analysed }\end{array}$ & $\begin{array}{c}\text { Naringin } \\
(\mathrm{mM}) \\
\text { analysed }\end{array}$ & $\begin{array}{c}\text { Narirutin } \\
(\mathrm{mM}) \\
\text { analysed }\end{array}$ & calculated & measured \\
\hline $\begin{array}{l}\text { Orange- } \\
\text { juice 1 }\end{array}$ & 2.67 & n.f. & 0.77 & n.f. & 0.12 & 4.13 & 6.63 \\
$\begin{array}{l}\text { Orange- } \\
\text { juice 2 }\end{array}$ & 1.11 & n.f. & 0.36 & n.f. & 0.06 & 1.77 & 3.19 \\
$\begin{array}{l}\text { Grape } \\
\text { fruit juice }\end{array}$ & 1.73 & n.f. & n.f. & 0.69 & 0.21 & 2.97 & 5.57 \\
Soft-drink & 0.91 & 0.06 & n.f. & n.f. & n.f. & 1.10 & 1.74 \\
\hline
\end{tabular}

The TEAC of the drinks were measured at 6 minutes after addition to the assay. Calculation of the theoretical TEAC is the sum of the concentrations of the single compounds multiplied by their own TEAC (determined at the concentration present in the drinks, to overcome the concentration dependency of the TEAC); $n$.f.= not found, this means below the lower limit of quantification.

\section{Discussion}

Radical scavenging assays, such as the TEAC assay, are increasingly used for screening compounds, food products and extracts on their antioxidant capacity, but also to assess antioxidant status in biological fluids such as plasma.

In this report we describe a modification of the original TEAC assay as described by the group of Miller and Rice-Evans. In their original assay ABTS" were generated in the presence of the test compounds, which might result in overestimation of 'true' antioxidant capacity due to interference with the radical-generating system rather then scavenging (Strube et al. 1997). We generated ABTS“- separately before the test compound was introduced in the assay. Cyanide, which interfered in the original assay with ABTS" formation, indeed did not show any antioxidant capacity in the modified assay.

\section{The modified TEAC assay}

To evaluate our modified TEAC assay we determined the TEAC of some hydrophilic and lipophilic compounds with well established antioxidant values, using various assay conditions and solvents. Table 1 shows the TEACs obtained with the original and the modified assay. For some well known antioxidants such as vitamin $\mathrm{C}$ and quercetin we observed a biphasic reaction with a 'fast' and a 'slow' scavenging rate. This may be explained by the formation of reaction products that react slowly with ABTS $^{*}$ resulting in a biphasic reaction pattern. For example, if vitamin $\mathrm{C}$ reacts with $\mathrm{ABTS}^{*-}$, the reaction product dehydroascorbate is generated, which can be slowly 
autoxidized yielding vitamin $\mathrm{C}$, giving the slow reaction. Also slow intramolecular rearrangement of antioxidants may cause biphasic reactions.

Table 1 shows that the 'fast' TEACs of vitamin C and quercetin were slightly lower, while the 'total' TEACs were higher than the TEAC reported by Miller et al. (1995). It should therefore be realized that in comparing TEACs from different reports, the time interval used should be taken into account. Miller et al. (1997) also reported on a modification of their TEAC assay, including pre-formed ABTS radicals. Surprisingly, no difference was found between the TEAC at $1 \mathrm{~min}$ and the TEAC at 6 minutes after addition of vitamin C and quercetin. In contrast, Schofield et al. (1996), using the same type of assay as Miller et al. report that there is indeed a time dependency in the TEAC. Our results show that most antioxidants with ABTS"- exhibit a slow reaction as well. Trolox only displays a fast reaction. It can be concluded, therefore, that the TEAC of most antioxidants has to depend on the time interval used in the assay. This was indeed found in our modified assay.

Whether such a 'fast' and 'slow' radical scavenging mechanism also occurs in vivo is unclear. Free radical species occurring in vivo have short half-lives and react very rapidly, which might suggest that especially the fast reaction is important.

As shown in Figure 3, quercetin exhibits a concentration-dependent response. This also holds for the flavanones naringin and narirutin (data not shown). This indicates that the TEAC of phenolic compounds like quercetin depends on the concentration used in the assay, which complicates interpretations of the assay results.

\section{TEAC of lipophilic compounds}

A practical relevant question is whether the TEAC assay can also be applied to lipophilic compounds such as $\alpha$-tocopherol and $\beta$-carotene. Miller et al. (1996) have reported TEACs of carotenoids. In their procedure compounds dissolved in hexane/acetone were shaken with the ABTS radical solution. Scavenging might, in this case, occur at the interface between the aqueous and the organic phase, but whether the observed decrease in absorption is representative of total antioxidant capacity remains questionable.

In this study we compared several solvents compatible with water to solubilize lipophilic compounds in the assay mixture. Our results show that the TEAC of lipidsoluble compounds, such as $\beta$-carotene, strongly depends on the solvent used. Because of its limited solubility, $\beta$-carotene could only be measured at low concentrations (1.0 
$\mu \mathrm{M}$ final concentration) which resulted in a small decrease in absorption and therefore a high variability.

Because of the variable TEACs found for $\beta$-carotene, the question remains: What is the 'true' antioxidant capacity of $\beta$-carotene? The singlet oxygen quenching ability of $\beta$-carotene has well been established (DiMascio et al. 1989), but whether $\beta$-carotene acts in vivo as an antioxidant is still controversial (ATBC, 1994; Hennekens et al. 1994). The results of the present study show that not only the intrinsic reactivity with radicals, such as ABTS", is important, but that also other factors, like the solvent, play an important role in the antioxidant capacity of $\beta$-carotene.

Solubilization of lipophilic compounds, such as $\beta$-carotene, in the aqueous TEAC assay medium remains a problem; a low TEAC might reflect either limited scavenging or limited solubility.

\section{Evaluation of the antioxidant capacity of mixtures}

Under standardized conditions, the TEAC of a mixture of water and lipid-soluble compounds can be additive, i.e. equal to the sum. This might allow application of the assay for screening of mixtures, as we illustrated with some fruit juices (Table 2).

Comparing the theoretical TEAC, based on product composition, with the actually measured TEAC may indicate the presence of other, 'unknown' antioxidants. However, standardization of the assay is extremely important and concentration dependence and solvent dependence should be taken into account. This approach has been reported before for apple juices. However, in that report (Miller et al. 1995), the TEAC of the individual compounds measured at 6 min were used, while the TEAC of the juice was calculated after $2 \mathrm{~min}$ and $50 \mathrm{~s}$.

In conclusion, the modified TEAC assay described in this report is faster than the originally described assay and less sensitive to artefacts because of pre-generation of the ABTS" before addition of the test compounds. However, for most of the antioxidants, a biphasic reaction pattern was found and both a 'fast' and a 'total' TEAC are determined. Under standard conditions, lipid-soluble compounds could be measured in the assay. In the case of mixtures of lipid-soluble and water-soluble compounds, additive results could be obtained.

Application of the assay to fruit juices is complicated. In spite of these complications, we feel confident that the TEAC is a useful tool in screening the antioxidant capacity of both pure antioxidants and mixtures. For application of the assay to (solid) food 
products, more research is needed, especially regarding the extraction of water- and lipid-soluble antioxidants and solubilization of the latter compounds in the assay.

Based on the data presented in the present study, one should be very careful in interpretation of the results of the TEAC assay. We believe that quantitative evaluation of antioxidant capacity using the TEAC can be troublesome or even impossible, but it can be used to provide a ranking order of antioxidants.

\section{Abbreviations used}

The frequently used term ABTS radical anions (ABTS ${ }^{\circ}$ ) is usually termed $\mathrm{ABTS}$ radical cations in other publications.

\section{Acknowledgement}

Dr Hans Verhagen, Dr Geert van Poppel and Dr Gerard Oostenbrug are gratefully acknowledged for stimulating discussions and suggestions.

\section{References}

Arnao, M.B., Cano, A., Hernandez-Ruiz, J., Garcia-Canovas, F., Acosta, M. (1996) Inhibition by $\mathrm{L}$-ascorbic acid and other antioxidants of the 2.2'-azino-bis (3-ethylbenzthiazoline-6sulfonic acid) oxidation catalyzed by peroxidase: a new approach for determining total antioxidant status of foods. Anal. Biochem. 236, 255-261.

ATBC The $\alpha$-tocopherol, $\beta$-carotene cancer prevention study group (1994) The effect of Vitamin $E$ and $\beta$-carotene on the incidence of lung cancer and other cancers in male smokers. New England Journal of Medicine. 330, 1029-1035.

Campos, M.D.A.M., Lissi, E.A. (1996) Total antioxidant potential of Chilean wines. Nutrition. Research 3, 385-389.

DiMascio, P., Kaiser, S. , Sies, H. (1989) Lycopene as the most efficient biological carotenoid singlet oxygen quencher. Arch. Biochem. Biophys. 274, 532-538.

Halliwell, B., Gutteridge, J.M.C. (1985) Free Radicals in Biology and Medicine, Clarendon Press, Oxford.

Halliwell, B, Aeschbach, R, Loliger, J, Aruoma, O.I. (1995) The characterization of antioxidants. Food Chem. Toxicol. 33, 601-617.

Hennekens, C.H., Buring, J., Manson, J.E., Stampfer, M., Rosner, B., Cook, R., Belanger, C., La Motte, F., Gaziano, J.M., Ridber, P.M., Willet, W. , Peto, R. (1994) New England Journal of Medicine 334, 1145-1149.

Miller, N.J., Rice-Evans, C.A., Davies, M.J., Gopinathan, V., Milner, A. (1993) A novel method for measuring antioxidant capacity and its application to monitoring the antioxidant status in premature neonates. Clinical Science 84, 407-412.

Miller, N.J., Diplock, A.T., Rice-Evans C.A. (1995) Evaluation of the total antioxidant activity as a marker of the deterioration of apple juice on storage. J. Agric. Food Chem. 43, 1794-1801.

Miller, N.J., Sampson, J., Candeias, L.P., Bramly, P.M., Rice-Evans, C.A. (1996) Antioxidant activities of carotenes and xantophylls. FEBS Lett. 384, 240-242. 
Miller, N.J., Rice-Evans, C.A. (1997) Factors influencing the antioxidant activity determined by the ABTS.+ radical cation assay. Free Radic. Res. 26, 195-199.

Rice-Evans, C.A., Miller, N.J., Papaganga, G. (1997) Antioxidant properties of phenolic compounds. Trends in plant science. 4, 152-159.

Salah, N., Miller, N.J., Paganga, G., Tijburg, L., Bolwell, G.P., Rice-Evans, C.A. (1995) Polyphenolic Flavanols as Scavengers of Aqueous Phase Radicals and as Chain-Breaking Antioxidants. Arch. Biochem. Biophys. 322, 339-346.

Schofield, D., Braganza, J.M. (1996) Shortcomings of an automated assay for total antioxidant status in biological fluids. Clinical Chemistry 42, 1712-1714.

Scott, S.L., Chen, W., Bakac, A. and Espenson J.H. (1993) Spectroscopic Parameters, Electrode Potentials, Acid Ionisation Constants, and Electron Exchange Rates of the 2,2'Azinobis(3-ethylbenzothiazoline-6-sulfonate) Radicals and Ions. J. Phys. Chem. 97, 67106714.

Strube, M., Haenen, G.R.M.M., van den Berg, H., Bast, A. (1997) Pitfalls in a method for assessment of total antioxidant capacity. Free radical research $26,515-521$.

Wayner, D.D.M., Burton, G.W., Ingold, K.U., Barclay, L.R.C., Locke, S.J. (1987) The relative contributions of vitamin $\mathrm{E}$, urate, ascorbate and proteins to the total peroxyl radical-trapping antioxidant activity of human blood plasma. Biochimica et Biophysica Acta 924, 408-419. 


\section{Chapter 3}

The predictive value of the antioxidant capacity of structurally related flavonoids using the Trolox Equivalent Antioxidant Capacity (TEAC) assay

Robin van den Berg, Guido R.M.M Haenen, Henk van den Berg, Wim J.F. van der Vijgh and Aalt Bast

Food Chemistry 70 (3), 391-395 (2000) 


\section{Abstract}

The antioxidant capacity of a series of structurally related flavonoids is quantified by the amount of ABTS (2,2'-azinobis-(3-ethylbenzthiazoline-6-sulfonate)) radical anions ( $\mathrm{ABTS}^{\circ}$ ) ) that is able to react with the flavonoid and expressed as the Trolox equivalent antioxidant capacity (TEAC). To evaluate the predictive value of the TEAC, the antioxidant activity of this series of flavonoids was also assessed in other in vitro assays, measuring the effect on hydroxyl scavenging, lipid peroxidation and doxorubicin-induced toxicity as typical scavenging or damage assays. The flavonoids tested were mono HER, di HER, tri HER tetra HER and tri HEQ, differing in the number of aromatic hydroxyl groups. It was found that these compounds showed both a fast and slow scavenging effect in the TEAC assay and therefore the TEAC at 10 seconds ('fast' TEAC) and 6 minutes ('total' TEAC) was determined. Both this 'total' and 'fast' TEAC are negatively correlated with hydroxyl radical scavenging. The 'total' TEAC showed a better correlation than the 'fast' TEAC with the inhibition of lipid peroxidation and the protection against doxorubicin-induced toxicity. This indicates that beside the fast reaction of scavengers with the ABTS radical, also the slow reaction should be taken into consideration. It is concluded that the antioxidant capacity, assessed with the modified TEAC assay, can be useful to predict an in vitro antioxidant effect in a series of structurally related compounds. 


\section{Introduction}

An accumulating amount of data proves the pivotal role of free radicals in various (patho)physiological processes, like ageing, cancer and the toxicity of numerous compounds (Bast, 1994; Halliwell, 1987). This has stimulated research on the potential of intervening in these processes with antioxidants. Various in vitro tests to evaluate the efficacy of the antioxidants have been reported (for overview see Halliwell, Aeschbach, Löliger \& Aruoma, 1996). These tests can roughly be divided in chemical assays, for the evaluation of the scavenging capacity, i.e. determination of the rate constant of the scavenging reaction between the antioxidant and reactive oxygen species, and more 'biological' assays, in which free radical damage is measured, e.g. quantification of the ability of antioxidants to inhibit free radical processes such as the peroxidation of biomembranes.

Recently, much attention has been focussed on determination of the total antioxidant capacity of compounds using the TEAC assay. This assay was first described by Miller, Rice-Evans, Davies, Gopinathan \& Milner (1993), assessing the capacity of a compound to scavenge ABTS radicals. To circumvent interference in the radical generation process (Strube, Haenen, van den Berg \& Bast, 1997), a modified TEAC assay using pre-generated ABTS radicals, as recommended by Re, Pellegrini, Proteggente, Pannala, Yang \& Rice-Evans (1999) and van den Berg, Haenen, van den Berg \& Bast (1999), was used.

In this report we describe the results of a comparison study of the antioxidant capacity of a series of structurally related flavonoids using different methods. The different flavonoids have shown to give a wide variation in an antioxidative effect, i.e. the scavenging of peroxynitrite (Haenen, Paquay Korthouwer \& Bast, 1997). Next to the TEAC assay we measured the hydroxyl radical $\left(\mathrm{OH}^{*}\right)$ scavenging activity, the activity to protect biomembranes against lipid oxidation (microsomal lipid peroxidation) and the protection against doxorubicin-induced toxicity in isolated left atria of mice hearts of these compounds, by comparing the antioxidant activity of the different compounds in the various assays, the predictive value of the TEAC assay is evaluated.

\section{Materials and methods}

\section{Chemicals}

2,2'-Azobis-(2-amidinopropane) $\mathrm{HCl}$ (ABAP) was purchased from Polysciences (Warrington, USA). 2,2'-Azinobis-(3-ethylbenzthiazoline-6-sulfonate) obtained as 
sulfonic acid $\left(\mathrm{ABTS}^{2-}\right.$ ) was from Sigma (St. Louis, USA). The hydroxyethylrutosides (HER) and trihydroxyethyl quercetin (HEQ) were a gift from Zyma (Nyon, Switzerland). All other chemicals used were of analytical grade.

\section{Antioxidant capacity assay}

The ABAP modified TEAC assay was used as reported elsewhere (van den Berg et al. 1999). Briefly, an ABTS"- solution was prepared by mixing $2.5 \mathrm{mM}$ ABAP with 20 $\mathrm{mM} \mathrm{ABTS}{ }^{2-}$ stock solution in $100 \mathrm{mM}$ phosphate buffer (pH 7.4), containing $150 \mathrm{mM}$ $\mathrm{NaCl}$ (PBS). The solution was heated for $12 \mathrm{~min}$ at $60^{\circ} \mathrm{C}$, protected from light and stored at room temperature. To check ABTS ${ }^{*}$ formation the absorbance at $734 \mathrm{~nm}$ was determined (absorption had to be between 0.35 and 0.40 ).

For measuring antioxidant capacity $40 \mu$ of the sample was mixed with $1960 \mu l$ of the radical solution. Absorbance was monitored at $734 \mathrm{~nm}$ for $6 \mathrm{~min}$. The decrease in absorption at $734 \mathrm{~nm} 10 \mathrm{~s}$ ('fast' reaction) and $6 \mathrm{~min}$ ('total' reaction) after addition of a compound was used for calculating the TEAC. The antioxidant capacity of the compounds was expressed relative to that of Trolox. All compounds were dissolved in PBS.

\section{Hydroxyl radical scavenging}

Hydroxyl radical scavenging was determined according to the method described by Halliwell, Gutteridge \& Aruoma (1987). Hydroxyl radicals were generated by hydrogen peroxide, ascorbate and $\mathrm{FeCl}_{3}$, in the presence or the absence of $100-500$ $\mu \mathrm{M}$ of the test compound. The ability of the compound to compete with deoxyribose for scavenging hydroxyl radicals gives the rate constant of the reaction between hydroxyl radicals and the scavenger $(\mathrm{ks})$.

\section{Microsomal lipid peroxidation}

Untreated male Wistar rats (Harlan Olec C.P.B., Zeist, The Netherlands), 220-250 g, were killed by decapitation. Liver microsomes were prepared as previously described Haenen \& Bast (1983), and stored at $-80^{\circ} \mathrm{C}$. Before use, the microsomes were thawed, diluted 5-fold with ice-cold Tris buffer (50 mM Tris- $\mathrm{HCl}, 150 \mathrm{mM} \mathrm{NaCl}, \mathrm{pH} \mathrm{7.4)} \mathrm{and,}$ in order to remove potentially protective cytosolic contamination (e.g. endogenous GSH), subsequently washed twice with the Tris buffer by centrifugation (40 min, $115000 \mathrm{xg}$ at $4{ }^{\circ} \mathrm{C}$ ). Finally, the pellet was resuspended in the Tris buffer and the 
microsomes (final concentration $1-1.5 \mathrm{mg}$ microsomal protein $/ \mathrm{ml}$ ) were incubated at $37^{\circ} \mathrm{C}$. Lipid peroxidation was induced by a combination of vitamin $\mathrm{C}(0.2 \mathrm{mM})$ and $\mathrm{Fe}^{2+}(10 \mu \mathrm{M})$. The reactions were started with the addition of iron. Lipid peroxidation was measured with the thiobarbituric acid assay, as previously described (Haenen et al. $1983)$, and determined as the absorption at $535 \mathrm{~nm}$ vs $600 \mathrm{~nm}(\triangle \mathrm{A} 535-600)$.

\section{Doxorubicin-induced cardiotoxicity in the isolated left atrium}

Untreated male Balb/c mice (Harlan Olec C.P.B., Zeist, The Netherlands), 18-22 g, were killed by decapitation. The hearts were rapidly excised. The isolated left atria were mounted in water jacketed organ baths, thermostated at $37{ }^{\circ} \mathrm{C}$, containing a Krebs buffer gassed with a mixture of $95 \% \mathrm{O}_{2}$ and $5 \% \mathrm{CO}_{2}$, resulting in a pH of the solution of 7.4. The composition of the Krebs buffer was (mM): $\mathrm{NaCl}(117.5), \mathrm{KCl}$ (5.6), $\mathrm{MgSO}_{4}$ (1.18), $\mathrm{CaCl}_{2}$ (2.5), $\mathrm{NaH}_{2} \mathrm{PO}_{4}$ (1.28), $\mathrm{NaHCO}_{3}$ (25) and glucose (5.5). The tension was adjusted to $0.40 \mathrm{~g}$. Sixty min after mounting the atria, they were stimulated at a frequency of $4 \mathrm{~Hz}$ at a voltage of 1.5 , the threshold voltage. Doxorubicin, at a concentration of $35 \mu \mathrm{M}$, was added in the absence or presence of 0.5 $\mathrm{mM}$ of the test compound. For tri HEQ, a concentration of $0.1 \mathrm{mM}$ was used, due to the poor water solubility of this compound. After 1 hour of incubation, the inotropy was measured. The reduction in the contractile force relative to the contractile force at the beginning of the incubation with doxorubicin was determined. Doxorubicin at a concentration of $35 \mu \mathrm{M}$ induced a $50 \%$ reduction in contractile force ( $0 \%$ protection). The mean percentual protection provided by $0.5 \mathrm{mM}$ of the test compound is given $(n=2)$.

\section{Results}

The time-dependent ABTS* scavenging capacity for the structurally related flavonoids (Figure 1) tested is shown in Figure 2. Trolox reacts instantaneously with the ABTS*and within a few seconds the reaction is completed. In contrast, tri HER reacts relative slowly with the ABTS*- and the reaction takes several minutes. The other compounds (mono HER, di HER and tri HEQ) show combined effects and tetra HER displayed no antioxidant capacity. 


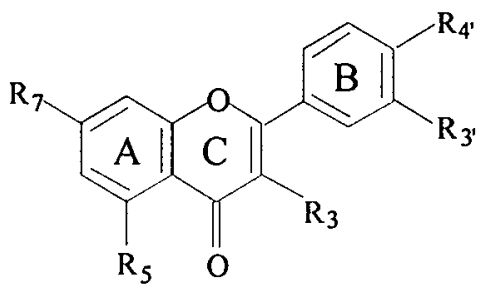

\begin{tabular}{|c|c|c|c|c|c|}
\hline Compound & R3 & R5 & $\begin{array}{l}\text { substituent } \\
\text { R7 } \\
\end{array}$ & R3' & R4' \\
\hline Mono HER & ORu & $\mathrm{OH}$ & $\mathrm{OEtOH}$ & $\mathrm{OH}$ & $\mathrm{OH}$ \\
\hline Di HER & $\mathrm{ORu}$ & $\mathrm{OH}$ & $\mathrm{OEtOH}$ & $\mathrm{OH}$ & OEtOH \\
\hline Tri HER & ORu & $\mathrm{OH}$ & OEtOH & OEtOH & OEtOH \\
\hline Tetra HER & ORu & OEtOH & $\mathrm{OEtOH}$ & OEtOH & OEtOH \\
\hline Tri HEQ & $\mathrm{OH}$ & $\mathrm{OH}$ & $\mathrm{OEtOH}$ & $\mathrm{OEIOH}$ & OEtOH \\
\hline
\end{tabular}

$\mathrm{Ru}=$ rutinose; $\mathrm{Et}=\mathrm{CH}_{2} \mathrm{CH}_{2}$

Figure 1. Chemical structures of the series of compounds tested.

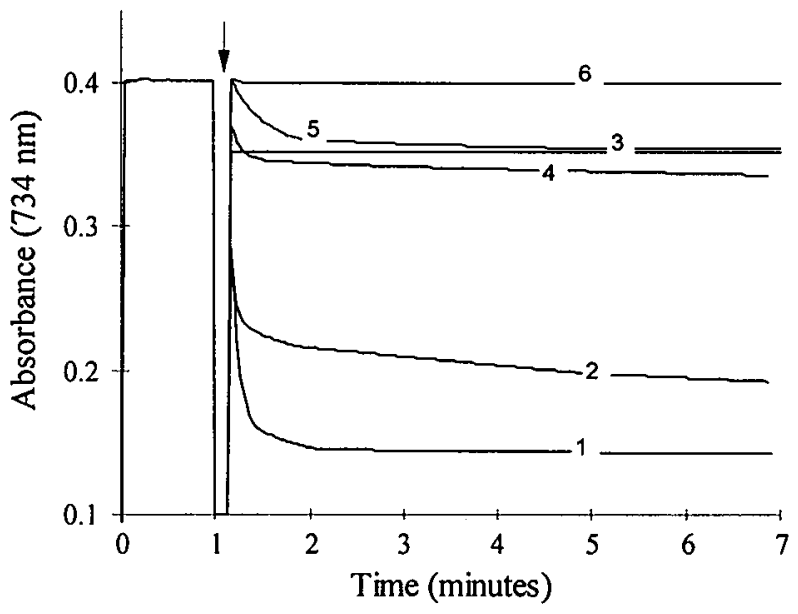

Figure 2. Reduction of the absorption at $734 \mathrm{~nm}$ by the addition of Trolox and flavonoids at the time-point indicated by the arrow. ABTS radicals were prepared using ABAP as radical source. The compounds were: (1) mono HER, (2) tri HEQ, (3) Trolox, (4) di HER, (5) tri HER and (6) tetra HER.. 
In Figure 3, the concentration-dependent effect of the compounds on the 'fast' reduction of the absorption measured at $10 \mathrm{~s}$ ('fast' TEAC), as well as the reduction of the absorption at 6 minutes ('total' TEAC) is depicted. It shows that at both timepoints scavenging capacity was lineary related to the concentrations examined. The capacity factors relative to Trolox are given in Table 1.

Results obtained with the hydroxyl radical scavenging assay, the inhibition of lipid peroxidation and the ability to protect against doxorubicin-induced cardiotoxicity in the isolated left atrium are summarized in Table 2. In the hydroxyl radical scavenging assay tetra HER shows the highest scavenging activity followed by tri HER, di HER and mono HER respectively. Scavenging activity could not be determined for tri HEQ because its poor water solubility. With the lipid peroxidation assay tri HEQ showed the highest protection followed by mono HER, di HER, tri HER and tetra HER respectively. In the assay assessing protection against doxorubicin-induced cardiotoxicitity mono HER shows the highest protection followed by di HER, tri HER and tetra HER. Tri HEQ could only be tested at a lower concentration $(0.1 \mathrm{mM})$ due to its poor water solubility. When mono HER was tested at the same concentration as tri HEQ a similar protection was found.

\section{Discussion}

The 'total' TEAC of the series of flavonoids tested correlated nicely with the number of aromatic hydroxyl groups. A similar relationship was found for another group of flavonoids (Rice Evans, Miller \& Paganga, 1997). The higher TEAC of tri HEQ compared to di HER - compounds with an equal amount of aromatic hydroxyl groups points at a higher contribution of the hydroxyl group at the 3-position compared to that of the hydroxyl group at the 3'-position. The same structure-activity relationship has also been found for other activities (Haenen, Paquay, Korthouwer \& Bast, 1997).

Free radicals formed in biological systems are usually very reactive and scavengers have to compete with vulnerable biological targets in the protection against free radical damage. Therefore, the fast scavenging reaction, as observed in the TEAC assay, seems more relevant than the slow scavenging reactivity. However, as the ABTS" has a relatively slow reactivity as compared to physiological important radicals, the slow scavenging reaction might also be relevant. 

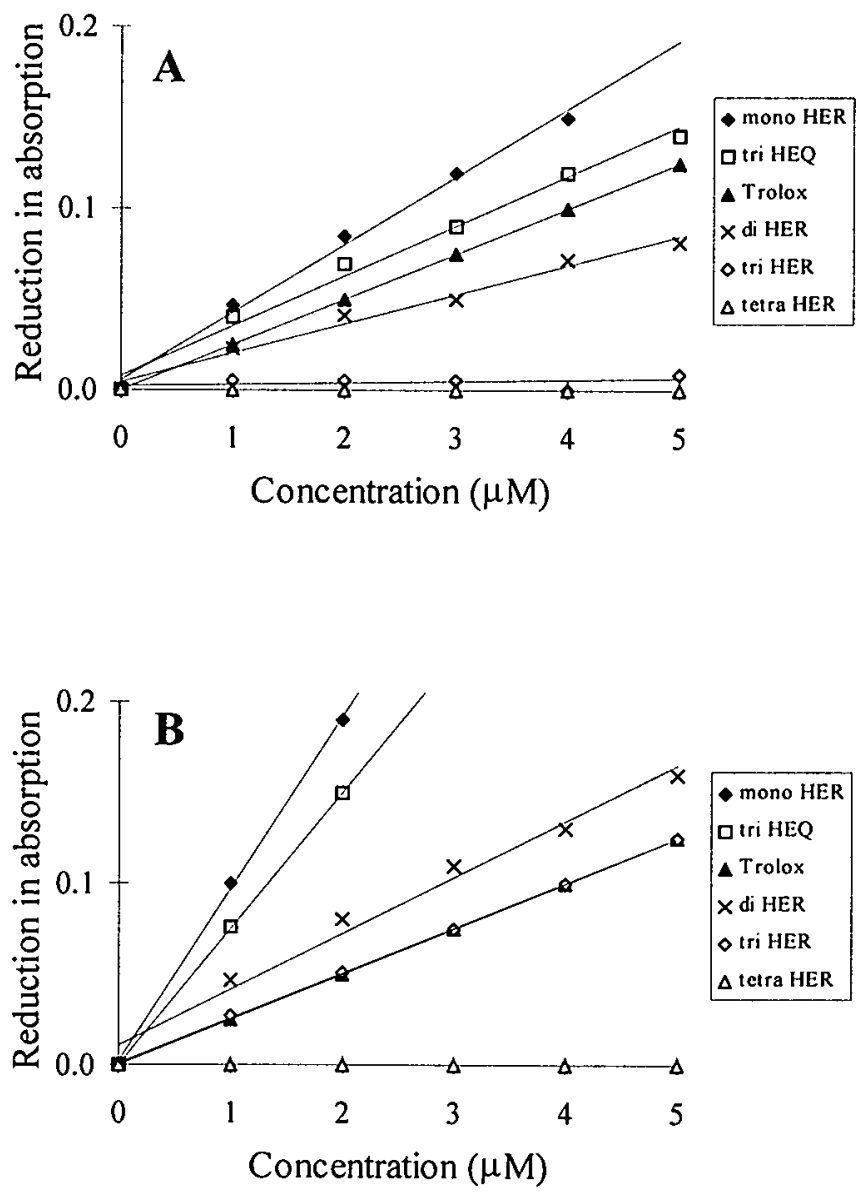

Figure 3. Concentration dependent reduction of the absorption determined at (A) $10 \mathrm{~s}$ ('fast' TEAC) or (B) 6 min ('total' TEAC) after the addition of the test compounds. ABTS' were generated using $A B A P$. The compounds were: ( ) mono HER, ( $\square)$ tri HEQ, (\) Trolox, $(x)$ di HER, ( $\diamond)$ tri HER and ( $(\Delta)$ tetra HER. 
Table 1. Antioxidant capacity (TEAC) of a series of hydroxyethylrutosides. The TEAC at 10 $s$ ('fast' TEAC) or at 6 min ('total' TEAC) after addition of the test compound to the solution containing the ABTS ${ }^{\circ}$.

\begin{tabular}{lcc}
\hline Compound & TEAC at $10 \mathrm{~s}$ & TEAC at $\mathbf{~ m i n}$ \\
\hline Tetra HER & $0.00 \pm 0.00$ & $0.00 \pm 0.00$ \\
Tri HER & $0.02 \pm 0.01$ & $1.0 \pm 0.1$ \\
Di HER & $0.7 \pm 0.1$ & $1.3 \pm 0.2$ \\
Mono HER & $1.3 \pm 0.2$ & $3.0 \pm 0.2$ \\
Tri HEQ & $1.1 \pm 0.2$ & $2.5 \pm 0.2$ \\
\hline
\end{tabular}

Table 2. Antioxidant parameters of a series of hydroxyethylrutosides.

\begin{tabular}{|c|c|c|c|}
\hline Compound & $\begin{array}{c}\text { Hydroxyl radical } \\
\text { scavenging } \\
\left(\mathbf{k}_{\mathbf{s}}, \mathrm{M}^{-1} \mathrm{~s}^{-1}\right) \\
\end{array}$ & $\begin{array}{c}\text { Inhibition of lipid } \\
\text { peroxidation } \\
\left(\mathrm{EC}_{50}, \mu \mathrm{M}\right)\end{array}$ & $\begin{array}{l}\text { Protection against } \\
\text { doxorubicin } \\
\text { cardiotoxicity }(\%)^{a}\end{array}$ \\
\hline Tetra HER & $11.1 \pm 2.2$ & $6200 \pm 200$ & 25 \\
\hline Tri HER & $10.2 \pm 2.9$ & $290 \pm 24$ & 28 \\
\hline Di HER & $8.2 \pm 3.5$ & $210 \pm 12$ & 66 \\
\hline Mono HER & $3.9 \pm 2.2$ & $15 \pm 1.8$ & 93 \\
\hline Tri HEQ & n.d. ${ }^{b}$ & $13 \pm 1.4$ & $41^{c}$ \\
\hline
\end{tabular}

To evaluate the predictive value of the antioxidant capacity, measured as the TEAC, we compared both the TEAC at 10 seconds (fast reaction) as well as the TEAC at 6 minutes (total reaction) of a series of structurally related compounds, with variable antioxidant effect, to other antioxidant activities obtained in another screening assay or in a more biological system.

Hydroxyl radicals are likely to be produced in vivo and are therefore physiological more relevant than $\mathrm{ABTS}^{*}$. In the present study, it was found that the TEAC at $10 \mathrm{~s}$ and $6 \mathrm{~min}$ was negatively correlated with the hydroxyl radical scavenging activity, indicating that substituting the aromatic hydroxyl groups with hydroxyethyl groups increases the hydroxyl radical scavenging activity. This is not unexpected because the hydroxyl radical is a much stronger oxidant than ABTS*- and is capable of $\mathrm{H}$ - 
abstraction from the hydroxyethyl group. The ABTS*- does not react with the hydroxyethyl group. This is in line with the finding that ABTS*- does not react with ethanol.

The negative correlation between hydroxyl radical scavenging and the TEAC could indicate that the ABTS*- scavenging does not reflect physiological relevant scavenging. However, also a negative correlation was found between hydroxyl radical scavenging and protection against doxorubicin-induced toxicity in the atrium model was found. This might suggest that hydroxyl scavenging plays a minor role in the protection of flavonoids against doxorubicin toxicity. There is also a negative correlation found between hydroxyl scavenging and the protection against lipid peroxidation, suggesting that hydroxyl radical scavenging also plays a minor role in this protection. Previously it has been shown that hydroxyl radical scavengers do not affect lipid peroxidation (Bast \& Steegs, 1986). Therefore, screening with the hydroxyl radical scavenging assay appears not to be an useful tool to predict the antioxidant effect of the flavonoids for these activities.

Free radical mediated damage to biological systems is often studied using lipid peroxidation. With this assay tri HEQ showed the highest protection followed by mono HER, di HER, tri HER and tetra HER respectively. This shows that, with exception of tri HEQ, the compound with the highest number of aromatic hydroxyl groups shows the best protecting against lipid peroxidation and substituting these hydroxyl groups decreases the $\mathrm{EC}_{50}$ of the flavonoids. Tri HEQ that has no rutinose group, had a higher activity then expected on the basis of the number of aromatic hydroxyl groups. The lipophilicity of HEQ is expected to be higher than that of the other compounds, since tri HEQ is the only one that does not contain the hydrophilic rutinose moiety. A higher lipophilicity will result in a higher partition of tri HEQ into lipid membranes, which may explain the higher activity of tri HEQ.

By using an isolated organ, the effect on a more integrated system can also be assessed. The results with this assay show that the compound with the highest number of aromatic hydroxyl groups shows best protection against doxorubicin-induced cardiotoxicity and substituting these hydroxyl groups decreases the protection of the compounds.

We have chosen the atrium model because there is a good correlation between the clinically observed cardiotoxicity and the protection against the doxorubicin-induced negative inotropic effect in the atrium (de Jong, Schoofs, Snabilie, Bast \& van der 
Vijgh, 1993). The isolated left atrium model has been validated using a range of compounds with known cardiotoxicity (van den Acker, submitted). The TEAC at $10 \mathrm{~s}$ as well as the TEAC at 6 min correlated with the protection against lipid peroxidation and doxorubicin-induced cardiotoxicity.

Here again tri HEQ appeared to be an exception. For tri HER, there was a remarkable difference between the fast TEAC and the total TEAC. Tri HER only reacts slowly with the ABTS*. Therefore, its fast TEAC is almost zero, whereas it has a substantial total TEAC. Tri HER displays a considerable antioxidant effect on lipid peroxidation and the cardiotoxicity induced by doxorubicin. These antioxidant effects are similar to those of di HER, a compound that has a substantial 'fast' TEAC. When only the fast TEAC is considered, tri HER is - erroneously - classified as having no antioxidant activity, comparable to tetra HER. The total TEAC predicts the right antioxidant potential of tri HER, i.e. an antioxidant activity comparable to that of di HER. From these data it can be seen that beside the fast reaction of scavengers with the ABTS*; also the slow reaction should be taken into consideration.

The results of our study indicate that the improved TEAC can be used to screen structurally related compounds to predict their antioxidant capacity, provided that the total TEAC is used.

Abbreviations used: ABAP, (2,2'-azobis-(2-amidinopropane) $\mathrm{HCl}$; ABTS, 2,2'-azinobis-(3-ethylbenzthiazoline-6-sulfonic acid); HER, hydroxyethyl rutoside; HEQ, hydroxyethyl quercetin; TEAC, Trolox equivalent antioxidant capacity.

\section{References}

Bast, A. and Steegs, M.H.M. (1986) Hydroxyl radicals are not involved in NADPH dependend microsomal lipid peroxidation. Experimentia 42, 555-556.

Bast, A. (1994) Antioxidant pharmacotherapy. Drug News \& Perspectives 7, 465-472.

De Jong, J., Schoofs, P.R., Snabilie A.M., Bast A., van der Vijgh W.J. (1993) The role of biotransformation in anthracycline-induced cardiotoxicity in mice. J. Pharmacol. Exp. Ther. $266(3), 1312-1320$.

Haenen, G.R.M.M., Bast, A. (1983) Protection against lipid peroxidation by a microsomal glutathione-dependent labile factor. FEBS Lett. 159, 24-28.

Haenen, G.R.M.M., Paquay, J.B.G., Korthouwer, R.E.M., Bast, A. (1997) Peroxynitrite scavenging by flavonoids. Biochem. Biophys. Res. Commun. 236, 591.

Halliwell, B. (1987) Oxidants and human disease: some new concepts. FASEB J. 1, 358-364.

Halliwell, B., Gutteridge, J.M.C., Aruoma, A.I: (1987) The deoxyribose method: a simple "test tube" assay for the determination of rate constants for reactions of hydroxyl radicals. Anal. Biochem. 165, 215-219. 
Halliwell, B., Aeschbach, R., Löliger, J., Aruoma, O.I. (1995) The characterization of antioxidants. Fd. Chem. Toxic. 33 (7), 601-617.

Miller, N.J., Rice-Evans, C.A., Davies, M.J., Gopinathan, V., Milner, A. (1993) A novel method for measuring antioxidant capacity and its application to monitoring the antioxidant status in premature neonates. Clinical Science 84, 407-412.

Re, R., Pellegrini, N., Proteggente, A., Pannala, A., Yang, M., Rice-Evans, C. (1999) Antioxidant activity applying an improved ABTS radical cation decolorization assay. Free radical Biology \& Medicine 26 (9/10), 1231-1237.

Rice-Evans, C.A., Miller, N.J., Paganga G. (1997) Antioxidant properties of phenolic compounds. Trends in Plant Science 2 (4) 152-159.

Strube, M., Haenen, G.R.M.M., van den Berg, H., Bast, A. (1997) Pitfalls in a method for assessment of total antioxidant capacity. Free radical research 26, 515-521.

Van den Berg, R., Haenen, G.R.M.M., van den Berg, H., Bast, A. (1999) Applicability of an improved TEAC assay for evaluation of antioxidant capacity measurements of mixtures. Food Chemistry 66, 511-517. 
Chapter 4

Transcription factor NF- $\mathrm{kB}$ as a potential biomarker for oxidative stress

R. van den Berg, G.R.M.M. Haenen, H. van den Berg and A. Bast British Journal of Nutrition 85, SI-S8 (2001) - modified 


\section{Introduction}

Reactive oxygen species (ROS) are likely implicated in the pathogenesis of a wide variety of human diseases such as cancer and cardiovascular diseases (Halliwell \& Gutteridge, 1985; Bast, 1994). ROS are very reactive and may inflict direct damage to vital cell constituents such as lipids, proteins and DNA. ROS are also involved in the regulation of gene expression (Sen \& Packer, 1996). For a better understanding of ROS-associated disorders, recent studies have focussed on the regulation of gene expression by intracellular reduction-oxidation (redox) state.

A well defined transcription factor, nuclear factor (NF) $\mathrm{kB}$, has been identified to be regulated by the intracellular redox state. Transcription factors are proteins that bind to regulatory sequences, usually in the $5^{\prime}$ upstream promoter region of target genes, to increase the rate of gene expression. This may affect protein synthesis, which could result in altered cellular function. Sen and Baltimore (1986) first identified NF- $\mathrm{KB}$ as an apparently tissue-restricted B-cell nuclear factor that activated the immunoglobulin $\kappa$-light chain intron enhancer during B-lymphocyte development. Since then, NF-кB has been identified in numerous cell types and is found to be activated by a wide variety of inducers, such as ultraviolet radiation, cytokines or bacterial and viral products (Baeurele \& Baltimore, 1996; Siebenlist et al. 1994).

The transcription factor NF-KB is of considerable interest to the field of free radical biology because it is activated by ROS and this enhanced activity can be modulated by antioxidants. Because ROS are generated under numerous pathological conditions, measurement of NF- $\mathrm{kB}$ activation could provide important insight into the etiology of these disorders and also offers the potential of NF- $\mathrm{KB}$ as a functional biomarker for oxidative stress.

\section{Activation of $N F-\kappa B$}

In quiescent cells, NF-kB is located in the cytosol as a dimer of protein components (p50/p65) bound to an inhibitor (IKB). NF- $\mathrm{kB}$ can be activated by different stimuli such as cytokines (e.g. TNF- $\alpha$, IL-1), phorbol esters, lipopolysaccharide (LPS) and in some cell types by hydrogen peroxide $\left(\mathrm{H}_{2} \mathrm{O}_{2}\right)$, enhancing specific IkB-kinases which phosphorylate $\mathrm{I} \kappa \mathrm{B}$, subsequently leading to a rapid ubiquination which results in degradation of $\mathrm{I} \kappa \mathrm{B}$ in the proteasome. Degradation of $\mathrm{I} \kappa \mathrm{B}$ uncovers nuclear localisation signals on the p65/p50 complex, resulting in a rapid translocation to the nucleus where it binds to specific $\mathrm{\kappa B}$ recognition elements in the promoter region of 
target genes (Figure 1). In this way NF- $\mathrm{kB}$ enhances the expression of inflammatory genes encoding for cytokines (e.g. IL-1), chemokines, growth factors, cell adhesion molecules (e.g. ICAM) or some acute phase proteins. NF-kB also regulates the expression of inflammatory enzymes, including the inducible form of nitric oxide synthetase (iNOS) (Xie et al. 1994) and inducible cyclooxygenase (COX-II) (Crofford et al. 1997). Inappropriate activation of NF- $\mathrm{KB}$ has been linked to inflammatory events associated with autoimmune arthritis, asthma, atherosclerosis, AIDS, cancer and diabetic complications (Chen et al. 1999).

\section{Inhibition of $N F-\kappa B$ activation}

Recent in vitro studies have shown that NF- $\mathrm{\kappa B}$ activation can be inhibited by antioxidants such as vitamin C (Bowie \& O'Neill, 1997), vitamin E (Islam et al. 1998) and flavonoids (Musonda \& Chipman, 1998) as well as the thiol containing compounds glutathione (Droge et al. 1994), $\alpha$-lipoic acid (Suzuki et al. 1992) and Nacetylcysteine (Schreck \& Baeuerle, 1994).

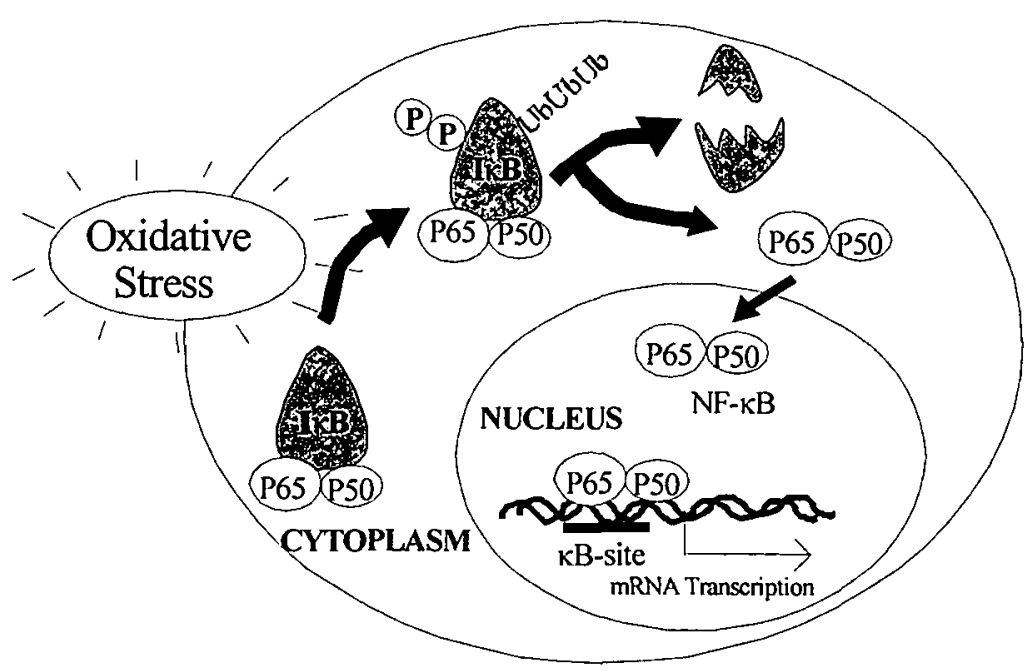

Figure 1. Cascade of $N F-\kappa B$ activation - In unstimulated cells, $N F-\kappa B$ is located in the cytosol as a dimer of protein components (p50/p65) bound to an inhibitor (IKB). NF- $\kappa B$ can be activated by oxidative stress, resulting in phosphorylation of $I \kappa B$ by $I \kappa B$-kinases, subsequently leading to a rapid ubiquination and degradation of $I \kappa B$ in the proteasome. Degradation of $I K B$ uncovers nuclear localisation signals on the p65/p50 complex, resulting in a rapid translocation to the nucleus where it binds to specific $\kappa B$ recognition elements in the promoter region of target genes. 
Reduction of enhanced NF- $\mathrm{KB}$ activation by antioxidants indeed confirms the involvement of ROS in the activation process, but the exact redox sensitive sites, the localisation of antioxidant action, and signalling events responsible for NF-kB activation remains elusive. Many antioxidants inhibit NF-kB by blocking upstream signalling that leads to phosphorylation of $I \kappa B$. Antioxidants can potentially prevent oxidation of redox sensitive cysteins in kinases or phosphatases (Schulze-Osthoff et al. 1995). Studies with glucocorticoids have shown that the anti-inflammatory effects of these compounds are achieved either by glucocorticoid receptor mediated blocking of NF-KB DNA binding (Scheinman et al. 1995) or enhancing the synthesis of IKB, which lead to inhibition of the nuclear translocation of NF-KB (Aupan et al. 1995).

\section{Measurement of NF- $\mathrm{KB}$ activation}

To clarify the role of NF- $\mathrm{KB}$ in various aspects of cell function, inflammatory processes and pathologies, clinical studies have to be performed using NF- $\kappa$ B activity as a target for intervention with drugs or food components. Because of the involvement of NF-KB in numerous pathophysiological processes an unequivocal NF$\kappa \mathrm{B}$ determination might be useful in order to be able to use $\mathrm{NF}-\kappa \mathrm{B}$ as a functional biomarker.

The most widely applied method to establish NF- $\mathrm{KB}$ activation is the electromobility shift assay (EMSA). In EMSA, differences in concentration of NF- $\mathrm{KB}$ proteins that have been translocated to the nucleus can be detected. Because of the complications in transcriptional analysis in primary cell cultures or tissues it is important to point out the critical steps in EMSA, i.e. (i) cell isolation (ii) preparation of nuclear extracts (iii) NF- $\kappa B$ determination by EMSA and (iiii) quantitative measurement of NF- $\kappa B$ activity.

\section{(i) Cell isolation}

The first step is to select the best available target cells. In vitro this is relatively easy since one can pick a cell line of the target organ or cells. In vivo (human) experiments there are more restrictions because the number of target tissues is limited. EMSA using either alveolar macrophages obtained by fibreoptic bronchoscopy (Farver et al. 1998) or peripheral mononuclear cells obtained by venipuncture (Hofmann et al. 1999) are the two most commonly used (available) cell types. Peripheral cells have the advantage that they can be obtained relatively easy and are less sensitive to artefacts produced by stress during the isolation procedure. 
During isolation it is essential to avoid false stress signals by working under standardized conditions at low temperatures $\left(4^{\circ} \mathrm{C}\right)$. To assess NF-kB activity in humans, $10-20 \mathrm{ml}$ whole blood has to be used to prepare 1-10 $\times 10^{6}$ peripheral blood mononuclear cells (PBMCs), immediately after venipuncture, by separation on a Ficoll-Isopaque( gradient. After PBMC isolation it is advisable to isolate the nuclear proteins directly to circumvent freezing and thawing of the cells which introduces additional stress.

\section{(ii) Preparation of nuclear extracts}

Nuclear extracts are prepared by using 1-10 × $10^{6}$ cells (freshly isolated or from cell culture). Again during the protein extraction it is important that all solutions are kept cold $\left(4^{\circ} \mathrm{C}\right)$ to avoid substantial protein degradation by proteases or false stress signals. Cells are washed three times in ice cold phosphate buffered saline (PBS) and lysed using an ice-cold lysis buffer as described by Hofmann et al. (1999). The use of $1 \%$ $(\mathrm{v} / \mathrm{v})$ mammalian protease inhibitor cocktail (Sigma, MO, USA) containing a mixture of 4-(2-aminoethyl)benzenesulfonyl fluoride, pepstatin A, trans-epoxysuccinyl-Lleucylamido(4-guanidino)butane, bestatin, leupeptin, and aprotinin is recommended to circumvent additional NF-KB protein degradation. The cell suspension has to be incubated on ice for 15 minutes to complete the lysis of the cell membrane and centrifuged at $4{ }^{\circ} \mathrm{C}$. This results in a pellet of nuclei. The supernatant is discarded and the nuclear pellet resuspended in an ice-cold (high salt) extraction buffer. To facilitate the extraction of the nuclear proteins, the nuclear suspension is shaken every 5 minutes for a total period of 20 minutes at $4{ }^{\circ} \mathrm{C}$. The nuclear lysates are centrifuged at $4{ }^{\circ} \mathrm{C}$ and the supernatant, containing the nuclear proteins, must immediately be collected and stored at $-80^{\circ} \mathrm{C}$ until further use. Protein concentrations can be determined according to the method of Bradford (BioRad, Veenendaal, The Netherlands), yielding sample concentrations of approximately $1 \mu \mathrm{g} / \mathrm{ml}$. Nuclear extracts should not be thawed more than twice and are at least stable for one year at $-80^{\circ} \mathrm{C}$.

\section{(iii) $N F-\kappa B$ determination by EMSA}

EMSA is a traditional and simple method to determine the inducible (p65/50) and the constitutive (p50/50) NF- $\mathrm{kB}$ in nuclei. A double-stranded NF- $\mathrm{kB}$ oligonucleotide (5'GAT CCA AGG GGA CTT TCC ATG GAT CCA AGG GGA CTT TCC AGT-3', Isogen, Maarsen, The Netherlands) containing a tandem repeat of the consensus 
sequence for the NF- $k B$ binding site (-GGGGACTTTCC-) or sp1 (5'...ATT CGA TCG GGG CGG GGC GAG C...3', Promega, MD, USA) is incubated with [ $\gamma^{32}{ }^{3}$ P]ATP (Amersham Pharmacia, Roosendaal, The Netherlands) in the presence of T4polynucleotide kinase (Beuringer, Mannheim, Germany) at $37^{\circ} \mathrm{C}$ for 45 minutes. The ${ }^{32} \mathrm{P}$-end labeled oligonucleotide is separated from the non-incorporated ${ }^{32} \mathrm{P}$ by a Sephadex G-50 (Sigma, MO, USA) column filtration. Incubation of $1 \mathrm{ng}$ radiolabeled $\mathrm{NF}-\mathrm{kB}$ oligonucleotide with $10 \mu \mathrm{g}$ nuclear extract containing the NF- $\mathrm{KB}$ proteins for 20 minutes at room temperature results in binding of NF-KB proteins to the oligonucleotide. Such a binding results in retardation ('shift') of the electromobility of the oligonucleotide on a $5 \%$ non-denaturating polyacryl amide gel (Biozym, Landgraaf, The Netherlands). These shifts can be visualized by phosphor imaging using a Cyclone (Packard, Meriden, USA) phosphor-imager. For the DNA binding reaction it is important that the volume of high-salt extraction buffer present in each binding assay is equal, to avoid differences in binding kinetics of the protein to the oligonucleotide This can be achieved by diluting the more concentrated nuclear protein extracts in the same extraction buffer. Specificity of NF- $\mathrm{B}$ DNA binding is ascertained by competition with a 150 -fold molar excess of unlabeled consensus oligonucleotides, displacing all radiolabeled oligonucleotides, resulting in a disappearance of all NF-KB complexes. Characterization can be done by so called 'supershifting' using specific antibodies for the NF- $\mathrm{kB}$ subunits $\mathrm{p} 65$ and $\mathrm{p} 50$ proteins (Janssen \& Sen, 1999).

\section{(iiii) Quantitative measurement of $N F-\kappa B$ activity}

To quantitate the NF- $\mathrm{KB}$ signal, a constant amount of HeLa nuclear extract that is included on each gel as a control can be used. Alternatively the transcription factor $\mathrm{sp} 1$ can also be used to quantitate the NF- $\mathrm{KB}$ signal, including the extraction quality of the nuclear extract. The intensity of the resulting NF- $\mathrm{kB}$ signals are determined by densitometry (Optiquant) for each gel. Spl is widely regarded as a housekeeping-type of nuclear transcription factor with constitutive activity and ubiquitous occurrence. The constant expression levels of $\mathrm{spl}$ can therefore be used to observe an increase in NF- $\kappa \mathrm{B}$ activity.

To compare the results obtained from different gels, the NF- $\kappa B$ signal has to be related either to the sp1 signal of the same sample or to the NF- $\mathrm{kB}$ signal of the HeLa extract 
that is run as a control on each gel. The densitometric value for the NF- $\mathrm{kB}$ signal can then be converted into spl equivalents or HeLa equivalents / $10 \mu \mathrm{g}$ protein.

\section{NF-KB as a potential 'new' biomarker of oxidative stress?}

Regulation and control of NF- $\mathrm{KB}$ activation can be a powerful therapeutic strategy for reducing tissue damage or other complications as a consequence of the releases of inflammatory mediators. Therefore NF- $\mathrm{KB}$ activity in humans is a 'new' target of interest to establish increased activity in several inflammatory diseases.

Recent studies show that NF- $\kappa B$ binding activity is increased in patients suffering from leprosy (Zea et al. 1998), sepsis (Böhrer et al. 1997), unstable angina pectoris (Ritchie, 1999) and diabetic nephropathy (Hofmann et al. 1999). The study with diabetic patients performed by Hofmann et al. showed that compared to the control group, the patients with diabetes mellitus and albuminuria had an increased NF- $\mathrm{KB}$ activity. More interestingly was that when they treated the patients with diabetic nephropathy with $600 \mathrm{mg}$ for three days with the antioxidant $\alpha$-lipoic acid, this resulted in a $38 \%$ decrease of NF- $\mathrm{kB}$ activity.

\section{$N F-\kappa B$ as biomarker of oxidative stress in vitro}

In Figure 2 an example of an in vitro study using $\mathrm{sp} 1$ as a standard is shown. The experiment demonstrates that NF- $\mathrm{kB}$ binding activity is increased in a rat macrophage cell line (NR8383) by an 1 hour incubation with $0.1 \mu \mathrm{g} / \mathrm{ml}$ lipopolysaccharide (LPS, Escherichia coli, Sigma, St. Louis, MO, USA) at $37^{\circ} \mathrm{C} / 5.0 \% \mathrm{CO}_{2}$ (Figure 2A). LPS are fragmental membranes of bacteria that activate the macrophage cell line. The transcription factor NF- $\mathrm{KB}$ concentration is indeed increased, whereas LPS does not influence the sp1 binding activity in NR8383 cells. Sp1 can be used both as a control to assess the efficiency of the nuclear extraction as well an internal standard to relate the NF- $\mathrm{KB}$ concentration to. Pre-incubation of the cells with the antioxidants vitamin $\mathrm{C}(100 \mu \mathrm{M}$, Merck, Darmstadt, Germany), Trolox (100 $\mu \mathrm{M}$, Aldrich, Milwaukee, WI, USA) and quercetin ( $10 \mu \mathrm{M}$, Fluka, Bio Chemica, Buchs, Switserland) followed by a 1 hour incubation with $0.1 \mu \mathrm{g} / \mathrm{ml}$ LPS resulted in a decrease in NF- $\mathrm{KB}$ binding activity (Figure $2 \mathrm{~B}$ ). This confirms that antioxidants can influence the activity of NF- $\mathrm{KB}$ in the nucleus of macrophages and that drugs or food components can be screened on potential antioxidant activity. 


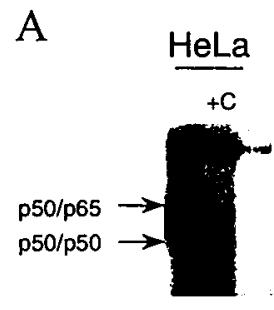

NR8383 (macrophage cell line)

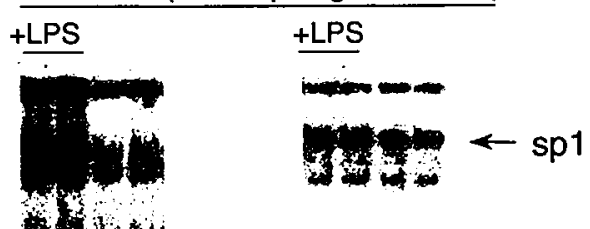

123

$\begin{array}{llll}4 & 5 & 6 & 7\end{array}$

8991011

$\mathrm{B}$

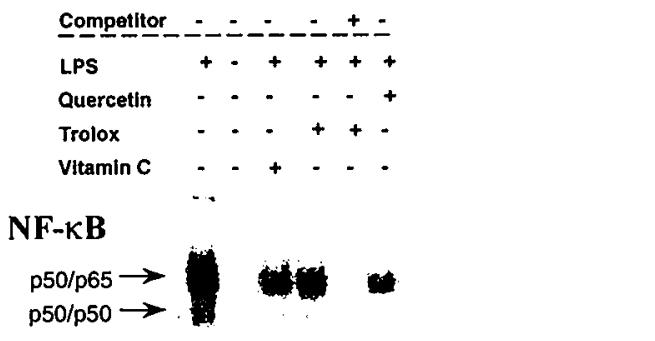

$\begin{array}{llllll}1 & 2 & 3 & 4 & 5 & 6\end{array}$

Figure 2. $N F-\kappa B$ and spl activity of rat macrophages with LPS. (A) Nuclear extracts were prepared in duplicate from cells treated with $0.1 \mu \mathrm{g} / \mathrm{ml} \mathrm{LPS} \mathrm{(lane} \mathrm{4,} \mathrm{5,} 8$ and 9) or without LPS (lane 6, 7, 10 and 11). Nuclear extracts were incubated with either the NF-KB probe (lane 1-7) or the spl probe (lane 8-11), followed by EMSA. As a control HeLa nuclear extract without (lane 1), with 150 fold excess competitor ( $+C$, lane 2) and free probe (lane 3) is used. (B) Nuclear extracts were prepared from cells treated with $0.1 \mu \mathrm{g} / \mathrm{ml} \mathrm{LPS} \mathrm{(lane} \mathrm{1);} \mathrm{LPS} \mathrm{and}$ vitamin C (100 $\mu \mathrm{M}$, lane 3); LPS and Trolox (100 $\mu \mathrm{M}$, lane 4); LPS, Trolox (100 $\mu \mathrm{M})$ and competitor (150-fold molar excess, lane 5) and LPS and quercetin (10 $\mu \mathrm{M}$, lane 6), followed by EMSA. Free probe is shown in lane 2.

$N F-\kappa B$ as biomarker of oxidative stress in vivo

The determination of the basal activity of PBMCs of healthy subjects, expressed as spl equivalents, is depicted in Figure $3 \mathrm{~A}$ and $3 \mathrm{~B}$. The EMSA (Figure $3 \mathrm{~A}$ ) clearly shows two specific bands in which the upper band represents the inducible p65/50 complex and the lower band the constitutive $\mathrm{p} 50 / 50$ complex. There is a very low $\mathrm{sp} 1$ activity and when NF- $\mathrm{kB}$ is expressed as spl equivalents only a $50 \%$ increase in NF$\kappa B$ activation is found (Fig. $3 B$ ).

The use of $\mathrm{spl}$ activity to relate NF- $\mathrm{KB}$ activity to is theoretically very elegant, because it includes the extraction efficiency. The nuclear concentration of $\mathrm{spl}$ is constant in healthy volunteers, but in sarcoidosis a distinct increase in sp1 binding activity is seen (unpublished data van den Berg et al.). This limits the use of spl and therefore the HeLa nuclear extract is used as an external standard to relate NF- $\mathrm{kB}$ activity to (Figure 3C). 
A

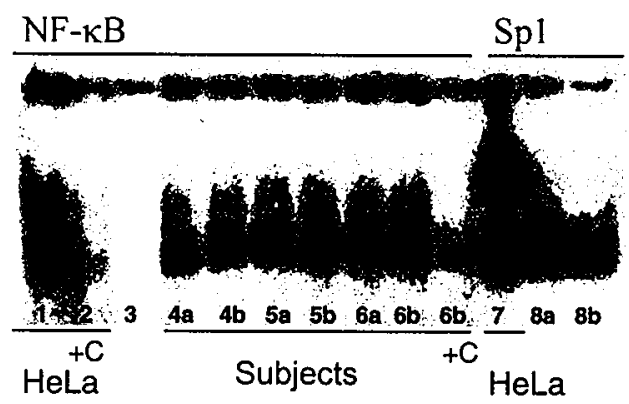

B

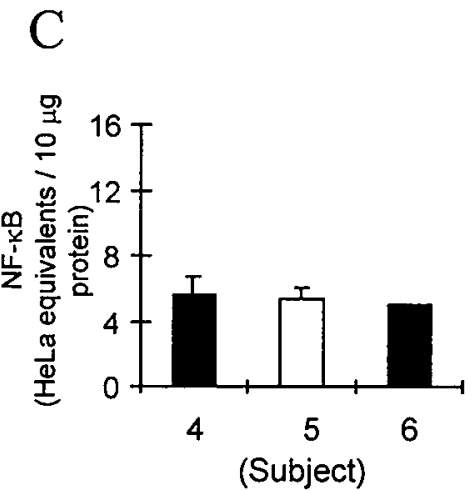

Figure 3. Basal $N F_{-\kappa B}$ and spl activity in peripheral blood mononuclear cells of healthy subjects. (A) Nuclear extracts from PBMCs of three healthy subjects were prepared in duplicate, followed by EMSA with the $N F-\kappa B$ probe $(4 a+4 b, 5 a+5 b$ and $6 a+6 b)$. Lane 1 represents the HeLa muclear extract, lane 2 Hela plus a 150-fold molar excess competitor $(+C)$ and lane 3 the free probe. A muclear extract from PBMCs of one of the healthy subjects prepared in duplicate, followed by EMSA with the spl probe (lane $8 a+8 b)$. Lane 7 represents the control HeLa nuclear extract with the $s p 1$ probe. The $N F-\kappa B$ activity is related either to the transcription factor spI (B) or to the HeLa nuclear extract $(C)$.

\section{Conclusion and perspectives}

The redox-controlled transcription factor NF- $\mathrm{KB}$ has for some years been recognized as an important mediator in the regulation of the inflammatory genes and is likely to be involved in the pathophysiology of several diseases. Using the EMSA procedure as described in this overview, measurement of NF- $\mathrm{KB}$ offers the possibility to evaluate both the activation of $\mathrm{NF}-\mathrm{kB}$ various pathologies, as well as the strategy used to reduce $\mathrm{NF}-\kappa \mathrm{B}$ activation.

The function of NF- $\mathrm{KB}$ in clinical studies can be assessed in isolated human PBMCs. However, care has to be taken to avoid false stress signals or early degradation of 
nuclear proteins during the isolation procedure. This can be achieved by using protease inhibitors, working at low temperatures, as fast as possible, following a standardised protocol.

To compare results obtained from different gels or different studies, a standard has to be used. Using another transcription factor, such as the 'housekeeping' transcription factor sp 1, as a standard has the advantage that also a correction for the loss of nuclear proteins during the isolation procedure can be made. However, we found that the activity of transcription factor $\mathrm{spl}$ is altered during sarcoidosis (unpublished results van den Berg et al.), which limits the use of $\mathrm{sp} 1$ as standard. In stead of a transcription factor we used a commercial available HeLa nuclear extract (Promega, Madison, USA). This nuclear extract could serve as a control to check the EMSA, as well as a standard to relate the NF- $\mathrm{kB}$ signal on each gel to. Unfortunately, no correction for the extracting efficiency is made when the HeLa extract is used.

Several clinical studies have shown that NF- $\mathrm{KB}$ binding activity is increased in different diseases (Böhrer et al. 1997; Hofmann et al. 1999; Ritchie, 1999; Zea et al. 1998). Indications have been found that antioxidants can inhibit NF-kB activation both in vitro and in vivo (Hoffmann et al. 1999). Our observations with EMSA on a macrophage cell line, healthy subjects and sarcoidosis patients confirm that NF- $\mathrm{kB}$ could be used as a marker of oxidative stress. However, more experiments are needed to validate this marker and to fully unveil the role of this important nuclear factor in pathogenesis and the effect of antioxidants on human health.

Fundamental research in this rapidly developing area is focussed on elucidating the exact role of NF- $\mathrm{KB}$ in oxidative stress related processes and the molecular mechanism of action of antioxidants. This may lead to new pharmacotherapeutic strategies. Applied research is directed towards the development of new probes and methods for the evaluating the role of NF- $\mathrm{kB}$ and the efficacy of clinical treatment schedules.

\section{References}

Aupan N, Di Donato J, Rosette C, Helmberg A \& Karin M (1995) Immunosupression by glucocorticoids: inhibition of NF-KB activity through induction of IKB synthesis. Science 270, 286-290.

Baeurele AP \& Baltimore D (1996) NF-kB: Ten years after. Cell 87, 13-20.

Bast A (1994) Antioxidant pharmacotherapy. Drug News \& Perspectives 7, 465-472.

Böhrer H, Qui F, Zimmermann T, Zhang Y, Jllmar T, Männel D, Böttiger BW, Stern DM, Waldherr R, Saeger HD, Ziegler R, Bierhaus A, Martin E \& Nawroth P (1997) Role of NF$\kappa B$ in the mortality of sepsis. Journal of Clinical Investigation 100, 972-985. 
Bowie A \& O'Neill LAJ (1997) Vitamin C inhibits NF-KB activation in endothelial cells. Biochemical Society Transactions 25, $131 \mathrm{~S}$.

Chen F, Castranova V, Shi X \& Demers LM (1999) New insights into the role of nuclear factor- B, a ubiquitous transcription factor in the initiation of diseases. Clinical Chemistry 45, 7-17.

Crofford LJ, Tan B, McCarthy CJ \& Hla T (1997) Involvement of nuclear factor $\mathrm{\kappa B}$ in the regulation of cyclooxygenase- 2 expression by interleukin-1 in rheumatoid synoviocytes. Arthritis Rheumat. 40, 226-236.

Droge W, Schulze-Osthoff K, Mihm S, Galter D, Schrenck H, Eck HP, Roth S \& Gmunder H (1994) Functions of glutathione and glutatione disulfide in immunology and immunopathology. FASEB Journal 8, 1131-1138.

Farver CF, Raychaudhuri B, Buhrow LT, Connors, MJ \& Thomassen MJ (1998) Constitutive $\mathrm{NF}-\mathrm{KB}$ levels in human alveolar macrophages from normal volunteers. Cytokine 10, 868871 .

Halliwell B \& Gutteridge JMC (1985) Free radicals in biology and medicine. Oxford: Clarendon Press.

Hofmann MA, Schiekofer S, Isermann B, Kanitz M, Henkels M, Joswig M, Treusch A, Morcos M, Weiss T, Borcea V, Abdel Kalec AKM, Amiral J, Trischler H, Ritz E, Wahl P, Ziegler R, Bierhaus A \& Nawroth PP (1999) Peripherial blood mononuclear cells isolated from patients with diabetic nephropathy show increased activation of the oxidative-stress sensitive transcription factor NF- $\mathrm{BB}$. Diabetologia 42, 222-232.

Islam KN, Devaraj S \& Jialal I (1998) $\alpha$-Tocopherol enrichment of monocytes decreases agonist-induced adhesion to human endothelial cells. Circulation 98, 2255-2261.

Janssen YMW \& Sen CK (1999) Nuclear factor $\kappa B$ activity in response to oxidants and antioxidants. Methods in Enzymology 300, 363-374.

Musonda CA \& Chipman JK (1998) Quercetin inhibits hydrogen peroxide (H2O2)-induced NF- $\kappa B$ DNA binding activity and DNA damage in HepG2 cells. Carcinogenesis 19, 15831589.

Ritchie ME (1999) Nuclear factor- $\mathrm{B}$ is selectively and markedly activated in humans with unstable angina pectoris. Circulation 98, 1707-1713.

Scheinman RI, Gualberto A, Jewell CM, Cidlowski JA \& Balwin AS Jr (1995) Characterization of mechanisms involved in transrepression of NF-kB by activated glucocorticoid receptors. Molecular Cell Biology 15, 943-953.

Schreck R, Baeuerle PA (1994) Assessing oxygen radicals as mediators in activation of inducible eukaryotic transcription factor NF-kappa B. Methods in Enzymology 234, 151163.

Schulze-Osthoff K, Los M \& Baeuerle PA (1995) Redox signalling by transcription factors NF-KB and AP-1 in lymphocytes. Biochemical Pharmacology 50, 735-741.

Sen CK \& Packer L (1996) Antioxidants and redox regulation of gene transcription. FASEB Journal 10, 709-720.

Sen R \& Baltimore D (1986) Multiple nuclear factors interact with the immunoglobulin enhancer sequences. Cell 46, 705-716.

Siebenlist U, Franzoso G \& Brown K (1994) Structure, regulation and function of NF-KB. Annual Review of Cell Biology 10, 405-455.

Suzuki YJ, Aggarwal BB, Packer L (1992) Alpha-lipoic acid is a potent inhibitor of NF-kB activation in human $\mathrm{T}$ cells. Biochemical and Biophysical Research Communictions 189 , 1709-1715. 
Xie QW, Kashiwabara Y \& Nathan C (1994) Role of transcription factor NF- $\mathrm{KB} / \mathrm{Rel}$ in induction of nitric oxide synthetase. Journal of Biological Chemistry 269, 4705-4708.

Zea AH, Ochoa, MT, Ghosh P, Longo DL, Alvord WG, Valderrama L, Falabella R, Harvey LK, Saravia N, Moreno LH \& Ochaoa AC (1998) Changes in expression of signal transduction proteins in $\mathrm{T}$ lymphocytes of patients with leprosy. Infection and Immunity 66, 499-504. 


\section{Chapter 5}

Reduction of oxidative stress in chronic hepatitis $\mathrm{C}$ by glycyrrhizin

Robin van den Berg, Tekla G.J. van Rossum, Guido R.M.M. Haenen, Henk van den Berg, Solko W. Schalm and Aalt Bast 


\begin{abstract}
Generation of reactive oxygen species (ROS) due to the chronic inflammatory responses is suggested to be involved in the etiology of liver injury observed in patients infected with hepatitis $C$. This can eventually lead to cirrhosis and hepatocellular carcinoma. Glycyrrhizin, as supposed an antioxidant and in Japan commonly administered to patients with chronic hepatitis $\mathrm{C}$, is reported to reduce serum alanine aminotransferase (ALT) levels and to improve liver histology. However, the molecular mechanism of its action remains unclear.

The aim of this study was to evaluate the antioxidant action of glycyrrhizin by investigating the effect of 6 times/week $200 \mathrm{mg}$ glycyrrhizin given as Stronger NeoMinophagen C (SNMC; $0.2 \%$ glycyrrhizin, $0.1 \%$ cysteine, $2.0 \%$ glycine). Fifteen patients with chronic hepatitis $\mathrm{C}$ received intravenously 6 times/week $200 \mathrm{mg}$ glycyrrhizin for 4 weeks. Serum ALT, plasma TEAC and MDA levels and NF- $\mathrm{BB}$ activity in mononuclear cells were determined before and after treatment and after a wash-out period of 4 weeks.

The results show that serum ALT and plasma MDA levels significantly decreased after treatment with glycyrrhizin and increased, again, after the wash-out period. Plasma TEAC remained stable. NF-kB activity, assessed in peripheral blood mononuclear cells, decreased after glycyrrhizin treatment, but did not increase after the wash-out period.
\end{abstract}

The results suggest that glycyrrhizin could act as a 'specific' antioxidant and that reduction of NF- $\mathrm{KB}$ activation is, at least, partly involved in the mechanism of action. 


\section{Introduction}

Oxidative stress is suggested to play an important role in the pathogenesis hepatitis $\mathrm{C}$ virus (HCV) infection. This oxidative stress is probably caused by the generation of reactive oxygen species (ROS). Generation of ROS due to the chronic inflammatory responses may account for a variety of pathophysiological pathways, which could lead to liver injury and fibrosis. These pathological alterations, caused by sustained injury, could eventually lead to cirrhosis or even degenerate to hepatocellular carcinoma (Sharara et al. 1996).

In patients infected with HCV, elevated markers of oxidative stress, i.e. serum thiobarbituric acid (TBARS) (Farinati et al. 1995), protein carbonyl groups (De Maria et al. 1996) and hepatic 8-hydroxydeoxyguanosine levels (Shimoda et al. 1994) were found. These observations could lead to the suggestion that provide a rationale for antioxidant therapy in reducing oxidative stress and subsequently for the treatment of chronic hepatitis $\mathrm{C}$.

Houglum et al. (1997a, 1997b) showed that the antioxidant $D$ - $\alpha$-tocopherol reduced oxidative stress in chronic hepatitis $\mathrm{C}$ patients which was accompanied by a decreased transcription rate of fibrosis genes and lower serum levels of oxidative stress markers (e.g. TBARS). However, 8-weeks of $D$ - $\alpha$-tocopherol treatment did not significantly affect serum alanine aminotransferase (ALT) levels, hepatitis $C$ virus titers, or histological degree of hepatocellular inflammation or fibrosis.

Also the aqueous extract of the licorice root, glycyrrhizin appears to have a hepatoprotective effect. Glycyrrhizin which is already clinically used for the treatment of chronic hepatitis in Japan (Suzuki et al. 1983) has been reported that it improves liver function by decreasing elevated serum transaminase levels (ALT and AST) (Suzuki et al. 1983). Besides decreasing ALT (alanine aminotransferase) levels, glycyrrhizin has also been shown to improve histological changes in either acute or chronic liver injury as well as to decrease the collagen content of the liver (Suzuki et al. 1977).

The molecular mechanism by which glycyrrhizin improves the biochemistry and histology has not been elucidated. In vitro and in vivo (rat) studies suggest that glycyrrhizin (and/or its metabolite glycyrrhetinic acid) acts as an antioxidant (Kiso et al. 1984, Nagai et al. 1991, 1992).

In the present study $200 \mathrm{mg}$ glycyrrhizin, in the form of a preparation Stronger NeoMinophagen C (SNMC) consisting of $0.2 \%$ glycyrrhizin, $0.1 \%$ cysteine and $2.0 \%$ 
glycine in physiological saline solution, was administered 6 times/week for 4 weeks to 15 patients with chronic hepatitis $\mathrm{C}$. To establish liver damage in these patients serum ALT levels were determined. Besides serum ALT, plasma TEAC and MDA were also determined. Plasma TEAC was used as a general marker to assess the contribution of glycyrrhizin to the total endogenous antioxidant capacity. Plasma MDA was assessed as a marker of free radical mediated lipid damage (lipid oxidation). Subsequently, to elucidate the underlying mechanism of action, activity of the transcription factor NF$\kappa \mathrm{B}$ in mononuclear cells was also assessed.

\section{Materials and Methods}

Study design and sample collection

Fifteen patients with chronic hepatitis $\mathrm{C}$ and serum ALT at least 1.5 times the upper limit of normal (ULN) were treated intravenously with glycyrrhizin 6 x week $200 \mathrm{mg}$ for 4 weeks followed by a wash-out period of 4 weeks. Glycyrrhizin was given in the form of Stronger Neo-Minophagen $\mathrm{C} \otimes$ (SNMC $\otimes$, Minophagen Pharmaceutical Co., Ltd., Tokyo, Japan). This preparation is a clear solution for intravenous use, consisting of $2 \mathrm{mg}$ glycyrrhizin, $1 \mathrm{mg}$ cystein and $20 \mathrm{mg}$ glycine per $\mathrm{ml}$ in physiological saline solution. Blood samples were collected before treatment, at the end of the treatment and at the end of the wash-out period. Serum ALT was directly measured after venipuncture by standard methodology using a Hitachi 917 (Hitachi, Roche, Almere, the Netherlands; reference values: male $41 \mathrm{IU} / \mathrm{L}$, female $31 \mathrm{IU} / \mathrm{L}$ ) and converted into upper limit of normal (ULN) values. For TEAC and MDA measurement EDTA blood samples were stored as plasma at $-80^{\circ} \mathrm{C}$ until further use. Ficoll heparin tubes were used to prepare mononuclear cell suspensions and stored below $-135^{\circ} \mathrm{C}$.

The study was conducted according to the Declaration of Helsinki and Good Clinical Practice. The Medical Ethical Committee of the University Hospital Rotterdam approved the protocol and all patients gave their written informed consent.

\section{Measurement of MDA in plasma}

To measure the thiobarbituric reactive material, $50 \mu \mathrm{L}$ of plasma was added to $950 \mu \mathrm{L}$ reagent which consisted of $0.102 \mathrm{M}$ 2-thiobarbituric acid, $0.32 \mathrm{M} \mathrm{H}_{3} \mathrm{PO}_{4}$ and $0.01 \%$ EDTA. This was heated for 1 hour at $100{ }^{\circ} \mathrm{C}$. After cooling, the samples were centrifuged. The fluorescence of the samples was determined using an excitation wavelength of $532 \mathrm{~nm}$ and an emission wavelength of $553 \mathrm{~nm}$ (Karsdorp et al. 1998). 


\section{Measurement of TEAC in plasma}

The total antioxidant capacity of deproteinated blood was determined with a spectrophotometrical assay that was based on the ability of antioxidants to neutralize the free radical of 2,2'-azinobis-(3-ethylbenzothiazoline-6-sulfonate) (ABTS). The ABTS radicals were prepared by heating a solution of $2 \mathrm{mM} \mathrm{2,2'-azobis-(2-}$ amidinopropane)dihydrochloride (ABAP) and $225 \mu \mathrm{M}$ ABTS in a $200 \mathrm{mM}$ phosphate buffer $(\mathrm{pH}=7.4)$ at $70^{\circ} \mathrm{C}$ for 20 minutes. First the plasma was deproteinized by adding an equal volume of $10 \%$ trichloroacetic acid. After centrifugation, an aliquot of the supernatant $(50 \mu \mathrm{L})$ was added to a solution of ABTS radicals $(0.950 \mathrm{~mL})$. The reduction of the absorption at $734 \mathrm{~nm}$, which reflects ABTS radical consumption, was determined. This reduction was related to that of a series of Trolox calibration solutions. The antioxidant capacity of the deproteinated plasma is expressed as the concentration of the Trolox solution that has a similar antioxidant capacity as the deproteinated plasma sample (van den Berg et al. 1999).

\section{Isolation of peripheral blood mononuclear cells}

For peripheral blood mononuclear cells (PBMCs) isolation, approximately $20 \mathrm{~mL}$ heparinized blood was transferred into a leucosep tube containing Ficoll Paque (Pharmacia) and diluted with a balanced salt solution. PBMCs were collected using density separation. Samples were centrifuged 30-60 min after collection for $30 \mathrm{~min}$. at $1850 \mathrm{rpm}$ and $4{ }^{\circ} \mathrm{C}$. After centrifugation PBMCs were collected, washed two times and divided over the aliquots needed. Cell concentrations were determined. Samples were stored at below $-135^{\circ} \mathrm{C}$.

\section{Preparation of nuclear extracts}

Nuclear extracts are prepared according to the method described by Hoffman et al. (1999) using 1-10 x 106 PBMCs. Cells are washed three times in ice cold phosphate buffered saline (PBS) and lysed using an ice-cold lysis buffer. Briefly, the cell suspensions are incubated on ice and centrifuged at $4{ }^{\circ} \mathrm{C}$. The supernatant is discarded and the nuclear pellet resuspended in an ice-cold (high salt) extraction buffer. The nuclear lysates are centrifuged at $4{ }^{\circ} \mathrm{C}$ and the supernatant, containing the nuclear proteins, are immediately collected and stored at $<-70{ }^{\circ} \mathrm{C}$ until further use. Protein concentrations are be determined according to the method of Bradford (BioRad). 


\section{$N F-\kappa B$ determination with the electromobility shift assay (EMSA)}

EMSA is used to determine the inducible (p65/50) NF- $\mathrm{KB}$ in nuclei. A doublestranded NF- $\mathrm{kB}$ oligonucleotide (5'-GAT CCA AGG GGA CTT TCC ATG GAT CCA AGG GGA CTT TCC AGT-3', Isogen, Maarssen, The Netherlands) containing a tandem repeat of the consensus sequence for the NF-kB binding site (GGGGACTTTCC-) is labeled with $\left[\gamma^{32}\right.$ P]ATP (Amersham Pharmacia, Roosendaal, The Netherlands). Incubation of $1 \mathrm{ng} \gamma^{32} \mathrm{P}$-end labeled NF- $\mathrm{KB}$ oligonucleotide with 10 $\mu \mathrm{g}$ nuclear extract containing the NF- $\mathrm{KB}$ proteins for 20 minutes at room temperature results in binding of NF-KB proteins to the oligonucleotide. Such a binding results in retardation ('shift') of the electromobility of the oligonucleotide on a $5 \%$ nondenaturating polyacryl amide gel (Biozym, Landgraaf, The Netherlands). These shifts can be visualized by phosphor imaging using a Cyclone (Packard, Meriden, USA) phosphor-imager. Specificity of NF-kB DNA binding is ascertained by competition with a 150-fold molar excess of unlabeled consensus oligonucleotides, displacing all radiolabeled oligonucleotides, resulting in a disappearance of all NF-KB complexes.

\section{Statistical analysis}

Data analyses were performed using the statistical software package SAS/STAT version 6 (SAS Institute, Cary, NC, USA, paired T-Test procedure).

\section{Results}

To elucidate if oxidative stress is involved in hepatitis $\mathrm{C}$ and that glycyrrhizin could act as an antioxidant, 15 chronic hepatitis $C$ patients were treated with $200 \mathrm{mg}$ glycyrrhizin 6 times/week for 4 weeks and blood samples were collected before treatment, at the end of the treatment and at the end of the wash-out period. To detect improvement of liver damage in these patients serum alanine aminotransferase (ALT) levels were determined. The results, summarized in Figure 1A, show that glycyrrhizin therapy significantly reduces serum ALT levels $(p<0.0001, n=15)$. These levels were markedly increased before treatment with ALT $>1.5$ times upper limit of normal range (ULN). At the end of the wash-out period serum levels were, again, increased as compared to the end of the treatment.

Plasma antioxidant capacity can be assessed using a synthetic radical (ABTS) and measuring the capacity to scavenge this radical compared to Trolox (van den Berg et al. 1999). The total antioxidant capacity measured in deproteinated plasma as the 
'common' TEAC (Trolox equivalent antioxidant capacity) before treatment, at the end of the treatment and at the end of the wash-out period remained stable (Figure 1B). This indicates that there is no significant contribution of glycyrrhizin to the overall 'endogenous' antioxidant capacity of plasma.

To assess a more specific antioxidant effect plasma MDA, expressed as TBARS, was measured to detect protection against free radical mediated damage. Plasma MDA significantly decreased after $6 \times$ week SNMC treatment $(p<0.05 ; n=14)$ (Figure 1C). At the end of the wash-out period plasma MDA levels were, again, increased as compared to the end of the treatment.

We also studied whether the NF- $\mathrm{kB}$ pathway is involved. NF- $\mathrm{kB}$ activity was determined by electromobilty shift on a $5 \%$ non-denaturation polyacryl amide gel. Nuclear extracts, of mononuclear cells isolated from whole blood, before treatment, at the end of the treatment and at the end of the follow-up were used. As demonstrated in Figure 2, treatment of patients with $\mathrm{HCV}$ with SNMC reduced the NF-kB activity, but at the end of the wash-out period the activity was still reduced. However, only a limited number of patients $(n=3)$ could be evaluated because of low peripheral blood mononuclear cell concentrations of most of the samples which was too low for the measurement of NF-kB activity.

\section{Discussion}

Recently several studies have suggested that oxidative stress is involved in the pathogenesis of patients with chronic hepatitis C (Farinati et al. 1995, De Maria et al. 1996, Shimoda et al. 1994). The therapeutic effect of glycyrrhizin has also been reported (Suzuki et al. 1977, Hino et al. 1986, Yasuda et al. 1991). However, the underlying mechanism of action remains elusive.

Chronic hepatitis $\mathrm{C}$ is a slowly progressive liver disease that may evolve into cirrhosis with its potential complications of liver failure or hepatocellular carcinoma. In randomized controlled trails, glycyrrhizin induced a significant reduction of serum alanine aminotransferases and an improvement in liver histology compared to placebo. To elucidate the involvement of the antioxidant capacity of glycyrrhizin in its therapeutic effect, a study with 15 chronic hepatitis C patients was performed, receiving 6 × $200 \mathrm{mg}$ glycyrrhizin (given as Stronger Neo-Minophagen C; SNMC) / week for 4 weeks. At the end of the treatment, liver damage, measured as serum ALT, was significantly decreased. 

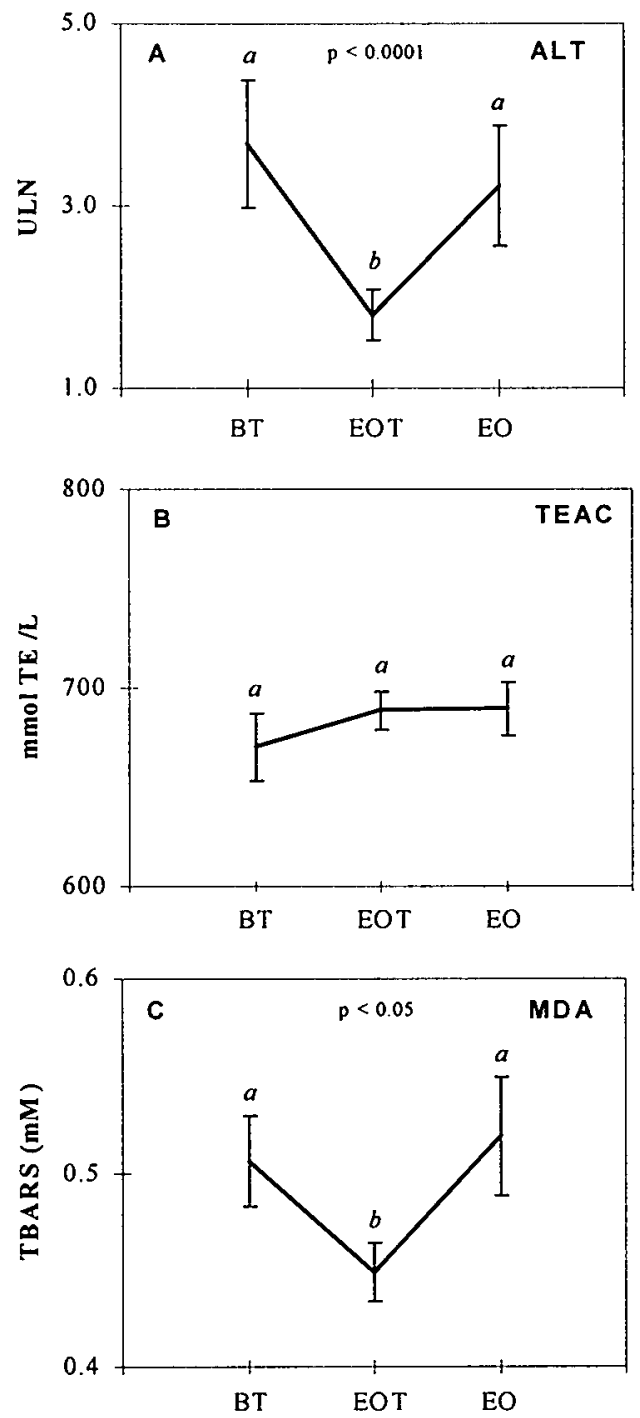

Figure 1. Effect of 4 weeks 6 times/week $200 \mathrm{mg}$ glycyrrhizin on (A) serum ALT, (B) plasma $T E A C$ and $(C)$ plasma $M D A$ in patients with chronic hepatitis $C$, measured before treatment (BT), at the end of treatment (EOT) and after a wash-out period of 4 weeks (EOF) (mean \pm SD). ${ }^{a, b}$ Common symbols indicate that responses of treatment are not significantly different from each other according to the paired T-Test. 


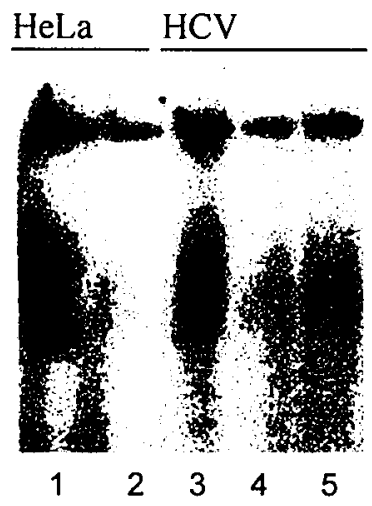

Figure 2. Representative electromobility gel shift using $a{ }^{32} P$-end labeled $N F-\kappa B$ oligonucleotide and a nuclear extract of peripheral mononuclear cells of a patient with chronic hepatitis C. Lane 1-2: Positive controls Hela nuclear extract without and with a 150fold molar excess of unlabeled consensus oligonucleotides, respectively. Lane 3-5: $N F-\kappa B$ activity before treatment, after treatment and after the wash-out period, respectively.

However, plasma TEAC remained stable. Thus glycyrrhizin does not contribute to the total antioxidant capacity measured with the general TEAC assay, indicating that there is no significant contribution of glycyrrhizin to the overall 'endogenous' antioxidant capacity of plasma. This means that not a general, aspecific antioxidant effect e.g. radical scavenging is involved, but more likely a 'specific' antioxidant effect.

To further investigate the antioxidant effect of glycyrrhizin, the end products of lipid peroxidation were quantified in blood plasma. Lipid peroxidation is a free radical mediated process that is often associated with cellular damage as a result of oxidative stress. Plasma MDA in hepatitis $C$ patients decreased after treatment with glycyrrhizin. This shows the protecting action of glycyrrhizin against free radical mediated damage, an antioxidant activity that is not found in the less specific TEAC assay.

We also tested the effect of glycyrrhizin on a very specific target i.e. the redoxregulated transcription factor NF-kB. Previously it has been reported that the inhibition of the activation of NF-kB is involved in the protective effect of glycyrrhizin on $\mathrm{CCl}_{4}$ and alcohol induced liver injury in rats (Wang et al. 1998). NF$\kappa \mathrm{B}$, a transcription factor that plays a key role in the activation of genes involved in immune and acute phase responses is likely to be a protagonist candidate for playing a 
role in $\mathrm{HCV}$ pathogenesis. This transcription factor increases the expression of genes for many cytokines, enzymes and adhesion molecules involved in chronic inflammatory diseases e.g. TNF- $\alpha$, IL-1 and iNOS (Barnes \& Karin 1997). NF- $\mathrm{kB}$ activity is regulated through various distinct mechanisms such as phosporylation, ubiquitination of $\mathrm{I} \mathrm{KB}$ and translocation of the remaining p50/65 heterodimer to the nucleus (Schottelius \& Baldwin 1999). NF-kB can be induced by e.g. ROS, bacteria, bacterial products and several viruses and inhibited by antioxidants and glucocorticoids (Chen et al. 1999).

Measurement of NF- $\mathrm{KB}$ activity before treatment, at the end of the treatment and at the end of the wash-out period showed that NF- $\mathrm{KB}$ might be involved. NF- $\mathrm{\kappa B}$ activity is increased in PBMCs of patients with chronic hepatitis $\mathrm{C}$ and decreased after treatment with glycyrrhizin, although the number of patients is low and the activity is still decreased after the wash-out period of 4 weeks. This decrease indicates that glycyrrhizin could act as a 'specific' antioxidant that protects a particular target. An aspecific antioxidant effect is not likely to be involved as indicated by the TEAC that is not influenced by glycyrrhizin administration. Glycyrrhizin might exert antioxidant actions in vivo by inhibiting generation of ROS, but not by directly scavenging free radicals as indicated by having no major contribution to the TEAC. NF- $\mathrm{\kappa B}$ activity is regulated by intracellular ROS levels. Increased generation of ROS, increases NF- $\mathrm{KB}$ activity which can be inhibited by antioxidants (Schreck et al. 1992). The decrease in activity, after treatment with glycyrrhizin, could indicate that glycyrrhizin acts as an antioxidant. Therefore inhibition of NF- $\mathrm{KB}$ activity by glycyrrhizin may ultimately lead to a decrease in liver damage mediated by the NF-KB pathway, which is established by the lower serum ALT levels.

Because of the glucocorticoid-like structure of glycyrrhizin it also seems possible that it acts by activation glucocorticoid receptors which directly interact with and inhibit NF- $\mathrm{KB}$ subunits. This mechanism plays an important role in glucocorticoids mediated repression of cytokine transcription (Mukaida et al. 1994). It has also been demonstrated that glucocorticoids act by activation of the IKB gene, thus by upregulating I $\mathrm{KB}$ levels blocking the translocation of NF- $\mathrm{KB}$ and subsequently DNA binding (Auphan et al. 1995).

However, it seems reasonable to speculate that glycyrrhizin could act as an antioxidant, as indicated by reducing the MDA levels, and therefore might prevent activation of NF-kB. The significant decrease in serum ALT and MDA indicates that 
glycyrrhizin protects the liver from free radical induced injury and subsequently fibrosis but also by liver-injury caused by hepatitis virus infection. To our knowledge, this is the first time that it is shown that NF- $\mathrm{KB}$ is activated in patients with chronic Hepatitis $\mathrm{C}$ and that glycyrrhizin can, at least partly, inhibit this NF- $\mathrm{KB}$ activity. Additional in vitro studies have to be performed to further elucidate its mechanism of action, but the results that show that NF- $\mathrm{kB}$ is involved might optimize the strategy in the search for a specific therapy for patients with chronic hepatitis $\mathrm{C}$.

\section{References}

Auphan N, Di Donato J, Rosette C et al. (1995) Immunosuppression by glucocorticoids: Inhibition of NF- $\kappa B$ activity through induction of IאB synthesis. Science 270: 286-290.

Barnes PJ, Karin M. (1997) Nuclear factor-kB - A pivotal transcription factor in chronic inflammatory diseases. New Engl. J. Med. 366: 1066-1077.

Chen F, Castranova V, Shi X et al. (1999) New insights into the role of nuclear factor-kB, a ubiquitous transcription factor in the initiation of diseases. Clincal Chemistry 45: 7-17.

De Maria N, Colantoni A, Fagiuoli S et al. (1996) Association between reactive oxygen species and disease activity in chronic hepatitis C. Free. Rad. Biol. Med. 21: 291-295.

Farinati F, Cardin R, De Maria N et al. (1995) Iron storage, lipid peroxidation and glutathione turnover in chronic anti-HCV positive hepatitis. J. Hepatol. 22: 449-56.

Hino L, Miyakawa H, Takahashi J et al. (1986)Effect of large dose of SNMC on the liver histology of chronic active hepatitis [in japanese]. Kan-Tansui 13: 797.

Hoffman MA, Schiekofer S, Isermann B et al. (1999) Peripheral blood mononuclear cells isolated from patients with diabetic nephropathy show increased activation of the oxidative-stress sensitive transcription factor NF- $\kappa$ B. Diabetologia 42: 222-232.

Houglum K, Ramm G, Crawford D et al. (1997a) Excess iron induces oxidative stress and transforming growth factor 1 in genetic hemochromatosis. Hepatology 26: 605-610.

Houglum K, Venkataramani A, Lyche K et al. (1997b) A pilot study of the effects of D-alphatocopherol on hepatic stellate cell activation in chronic hepatitis C. Gastroenterology 113: 1069-1073.

Karsdorp VHM, Dekker GA, Bast A et al. (1998) Maternal and fetal plasma concentrations of endothelin, lipidhydroperoxides, glutathione peroxidase and fibronectin in relation to abnormal umbilical artery velocimetry. European $\mathrm{J}$ of Obstetrics \& Gynecology and Reproductive Biology 80: 39-44.

Kiso $\mathrm{Y}$, Tohkin M, Hikino $\mathrm{H}$ et al. (1984) Mechanism of antihepatotoxic activity of glycyrrhizin, I: effect on free radical generation and lipid peroxidation. Planta Medica 298302.

Mukaida N, Morita M, Ishikawa Y et al. (1994) Novel mechanism of glucocorticoid-mediated gene repression: NF-KB is a target for glucocorticoid-mediated IL-8 gene repression. J. Biol. Chem. 269: 289-295.

Nagai T, Egashira T, Yamanaka Y et al. (1991) The protective effect of glycyrrhizin against injury of the liver caused by ischemia-reperfusion. Arch Environ Contam Toxicol 20: 432436.

Nagai T, Egashira T, Kudo $Y$ et al. (1992) Attenuation of disfunction in the ischemiareperfused liver by glycyrrhizin. Japan J Pharmacol 58: 209-218. 
Schottelius AJG, Baldwin Jr AS. (1999) A role for transcription factor NF- $\mathrm{KB}$ in intertinal inflammation. Int. J. Colorect. Dis. 14: 18-28.

Schreck R, Albermann K, Baeuerle PA. (1992) Nuclear factor kappa B: an oxidative stressresponsive transcription factor of eukaryotic cells (a review). Free Rad. Commun. 17: 221237.

Sharara A, Hunt C, Hamilton J. Hepatitis C. (1996) Ann. Intern. Med. 125: 658-668.

Shimoda R, Nagashima M, Sakamoto $M$ et al. (1994) Increased formation of oxidative DNAdamage 8-hydroxydeoxyguanosine in human livers with chronic hepatitis $\mathrm{C}$. Cancer Res. 54: $3171-3172$.

Suzuki H, Otha T, Takino $\mathrm{T}$ et al. (1977) The therapeutic effects of Stronger NeoMinophagen $C$ for chronic hepatitis. Igaku no Ayumi 102: 562-568.

Suzuki $\mathrm{H}$, Otha T, Takino $\mathrm{T}$ et al. (1983) Effect of glycyrrhizin on biochemical tests in patients with chronic hepatitis - Double blind trial. Asian Med. J. 26: 423-438.

Van den Berg R, Haenen GRMM, van den Berg H et al. (1999) Applicability of an improved TEAC assay for evaluation of antioxidant capacity measurements of mixtures. Food Chemistry 66: 511-517.

Wang JY, Guo JS, Li $\mathrm{H}$ et al. (1998) Inhibitory effect of glycyrrhizin on NF- $\mathrm{B}$ binding activity in CCl4-plus ethanol-induced liver cirrhosis in rats. Liver 18: 180-185.

Yasuda K, Hino K, Fujioka S et al. (1991) Effect of high dose therapy with Stronger NeoMinophagen (SNMC) on hepatic histograhpy in non-B chronic active hepatitis. Elsevier Science Publishers B.V. (Biomedical Division): 205-209. 
Chapter 6

$\mathrm{NF}-\mathrm{\kappa B}$ activation in sarcoidosis

Marjolein Drent, Robin van den Berg, Guido R.M.M. Haenen, Henk van den Berg, Emiel F.M. Wouters and Aalt Bast

Sarcoidosis Vasculitis and Diffuse Lung disease 18, 50-56 (2001) - modified 


\begin{abstract}
Sarcoidosis is an inflammatory disorder of unknown origin. The nuclear regulatory factor- $\mathrm{KB}(\mathrm{NF}-\mathrm{\kappa B})$ appears to play a key role in immune and inflammatory processes such as asthma, rheumatoid arthritis and inflammatory bowel disease. We hypothesized that NF- $\mathrm{kB}$ activation might be involved in the pathological process of sarcoidosis.

Twelve sarcoidosis patients, biopsy proven, and five healthy control subjects, all nonsmokers, were studied. Blood samples were taken and routinely analysed for several parameters including the serum angiotensin converting enzyme (SACE) level. Mononuclear cells were isolated from these patients in order to quantify the NF- $\kappa B$ contents in the nuclear extract of the mononuclear cells.

Mononuclear cells NF-kB expressed per $\mu \mathrm{g}$ protein was twice as high in both untreated $(n=5)$ and treated $(n=7)$ patients with sarcoidosis compared to the control subjects $(p<0.001)$. In contrast, the sACE level appeared to be low in the treated patients compared to the untreated patients $(p<0.01)$. These results indicate that the inflammation in sarcoidosis is associated with NF- $\mathrm{kB}$ activation. Moreover, the suppression of the activated NF- $\mathrm{kB}$ response by glucocorticoids seems less successful than the suppression of the SACE activity. Future studies should focus on the clinical relevance of this observation and establish the possible therapeutic consequences of the increased NF-kB activation in sarcoidosis.
\end{abstract}




\section{Introduction}

Although the cause of sarcoidosis still remains unknown, the list of possible causative agents has continuously expanded. Genes may determine a patient's susceptibility to the disease and the disease's severity, but environmental factors often unknown, may determine its course (Hunninghake et al. 1999). Some of the proposed agents are viruses (herpes, Epstein-Barr, retrovirus, coxsackie B virus, and cytomegalovirus), Mycobacteria, inorganic agents (beryllium, aluminum, zirconium, talc and man-mademineral fibres (MMMF)) and organic agents (pine tree pollen and cotton dust). Oxidative stress inducing the production of free radicals and other reactive oxygen species occurs in many inflammatory diseases (Halliwell \& Gutteridge 1992, Poli \& Parola 1996, Donaldson 1998). Free radical activity at the surface of the particles has been suggested a common factor for the ability to cause inflammation (Halliwell and Gutteridge 1992, Poli \& Parola 1996, Donaldson 1998). The effects of surface free radicals could result in oxidative damage to cells (Halliwell and Gutteridge 1992, Poli \& Parola 1996, Donaldson 1998). Additionally, free radicals can also induce more subtle effects on cells that can cumulate in gene expression. Gene expression is mediated by transcription factors, proteins that bind to DNA in the promotor enhancergene region of genes and could initiate its transcription (Halliwell and Gutteridge 1992, Newman et al. 1997, Hunninghake et al. 1999). The activation of transcription factors, particularly those that are involved in immune responses, such as $\mathrm{NF}-\mathrm{\kappa B}$, can be activated in response to oxidative stress, cytokines, ionizing radiation, UV light, and chemicals. NF-KB is important in the activation of transcription of many cytokine genes encoding cytokines, as well as other proinflammatory genes, such as tumour necrosis factor $\alpha$ (TNF $\alpha$ ), which is mostly increased in sarcoidosis (Newman et al. 1997, Hunninghake et al. 1999). Interestingly, TNF- $\alpha$ amplifies the inflammation by stimulating the NF- $\mathrm{kB}$ pathway. NF- $\mathrm{kB}$ present in the cytoplasm is bound to its inhibitor $I \kappa B$. When the cell comes under oxidative stress, particularly when there is

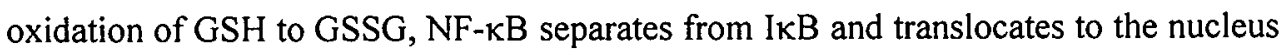
to bind to the NF- $\mathrm{KB}$ motif in the promotor region. Binding of the transcription factor than leads to transcription. Direct activation of these transcription factors may be anticipated to occur in the case of particles with free radical activity (Poli \& Parola 1996, Donaldson 1998). Gilmour et al. (1995) showed the ability of MMMF to generate free radicals at the fibre surface. Previously, we observed the association of MMMF exposure and a sarcoidlike granulomatous reaction (Drent et al. 2000). 
Moreover, Driscoll et al. (1995) described the activation of NF-kB by a range of pneumoconiotic particles. In line with this, Brown et al. found that also nonpathogenic (not carcinogenic) fibres such as MMMF cause increased NF- $\mathrm{KB}$ activity initiating inflammation (Brown et al. 1999). Furthermore, NF- $\mathrm{KB}$ has been assumed to be a biomarker to detect mild oxidative stress. Barnes et al. reported a pivotal role for NF$\mathrm{KB}$ in asthma and other chronic inflammatory diseases, such as inflammatory bowel disease and rheumatoid arthritis (Barnes \& Adcock 1997; Barnes \& Karin, 1997). Giri et al. (1998) demonstrated that Mycobacterium avium-intracellulare complex (MAC) activates NF-KB and they suggested that this interaction may play a pivotal role in the pathogenesis of the disease.

We speculated that the inflammation in sarcoidosis -among others- is associated with activation of the transcription factor NF- $\mathrm{KB}$. To assess the possible role of the transcription factor NF- $\mathrm{KB}$ in the pathogenesis of sarcoidosis this activity was measured in a sarcoidosis patient population and compared to a healthy control group.

\section{Materials and methods}

\section{Subjects}

Twelve non-smoking out-patients with symptomatic sarcoidosis were enrolled in this study. These patients were recruited from those visiting our out-patient clinic for a regular check-up at the day of the experiment. Patients had been diagnosed with sarcoidosis based on consistent clinical features, together with bronchoalveolar lavage (BAL) fluid analysis results (Drent et al. 1996). Moreover, all patients had a biopsy confirmation of sarcoidosis. The clinical symptoms of the respective patients included more or less severe respiratory symptoms such as dyspnea, coughing and chest pain, and occasionally erythema nodosum and arthralgia. None of the subjects participating had any significant medical history or co-morbidity. At the moment this study was performed seven patients had been treated with corticosteroids for three months, e.g. prednison orally (initial dose $50 \mathrm{mg}$ daily, decreased by $10 \mathrm{mg}$ a month). Initially, five of these patients were referred to our hospital for a second opinion and demonstrated a more or less chronic course of the disease. The clinical records of these cases were carefully reviewed. Five other patients were not treated.

The control group consisted of five non-smoking healthy volunteers (age 36.1 $1 \pm 5.8$ ) without any pulmonary history, having normal chest radiography and lung function tests. Written informed consent was obtained from all participating subjects. 


\section{Serological measurements}

In the course of the initial diagnosis among others the serological parameters serum angiotensin-converting enzyme (SACE) and serum $\mathrm{C}$-reactive protein (CRP) were assessed. ACE was measured with a colorimetric method using a testkit from Fujirebio inc. (Tokyo, Japan). SACE acts upon the substrate p-hydroxybenzoyl-glycyl-Lhistidyl-L-leucine whereafter $\mathrm{p}$-hydroxybenzoyl-glycine and L-histidyl-L-leucine are formed. Hippuricase transforms p-hydroxybenzoyl-glycine into p-hydroxybenzoic acid and glycine. Quinoneimine dye is produced by oxidation and condensation of the phydroxybenzoic acid using 4-aminoantipyrine and sodium metaperiodate $\left(\mathrm{NalO}_{4}\right)$. Finally, the concentration of quinoneimine dye is quantitatively measured at its absorbance maximum at $505 \mathrm{~nm}$ to evaluate the activity of ACE. The reference normal range under this test method is 9 to $25 \mathrm{U} / \mathrm{L}$.

$\mathrm{C}$-reactive protein (CRP) was measured using a turbidimetric method performed on the Beckman synchron CX-7 system (Mijdrecht, the Netherlands, kit 465231). In this test CRP combines with a specific antibody to form in soluble antigen-antibody complexes. The detection limit for CRP of the used turbimetry assay was $2 \mu \mathrm{g} / \mathrm{ml}$ with a normal range of 2 to $9 \mu \mathrm{g} / \mathrm{ml}$.

Quantitative measurement of $N F-\kappa B$ activation in human peripheral blood mononuclear cells

In order to assess NF- $\mathrm{kB}$ activation in humans we employed the electro mobility shift assay (EMSA) as described by van den Berg et al. (2000). In EMSA, differences in concentration of NF-KB proteins that have been translocated to the nucleus can be detected.

Briefly, to assess NF- $\mathrm{KB}$ activity in humans $20 \mathrm{ml}$ whole blood is used to prepare $1 \times 10^{7}$ peripheral blood mononuclear cells (PBMCs), immediately after venipuncture, by separation on a Ficoll-Isopaque gradient using leucosep tubes (Greiner).

Nuclear extracts were prepared by using $1 \times 10^{7}$ cells. Cells were washed and lysed using an ice-cold lysis buffer as described by Hofmann et al. (1999). The cell suspension was incubated on ice and centrifuged at $4{ }^{\circ} \mathrm{C}$. The nuclear pellet resuspended in an ice-cold extraction buffer (Hofmann et al. 1999). The nuclear lysates were centrifuged at $4{ }^{\circ} \mathrm{C}$ and the supernatant, containing the nuclear proteins, was immediately collected and stored at $-80^{\circ} \mathrm{C}$ until further use. 
Protein concentrations can be determined according to the method of Bradford (Biorad), yielding sample concentrations of approximately $1 \mu \mathrm{g} / \mathrm{ml}$.

EMSA was used to determine the inducible (p50/65) and the constitutive (p50/50) NF$\kappa B$ in nuclei. $\mathrm{A}^{32} \mathrm{P}$-end labeled double-stranded NF- $\mathrm{KB}$ oligonucleotide (5'-GAT CCA AGG GGA CTT TCC ATG GAT CCA AGG GGA CTT TCC AGT-3', Isogen, Maarssen, The Netherlands) containing a tandem repeat of the consensus sequence for the NF- $\mathrm{KB}$ binding site (-GGGGACTTTCC-) was used to detect NF- $\mathrm{kB}$ activity. Binding of NF- $\mathrm{KB}$ to the oligonucleotide results in 'shift' on a $5 \%$ non-denaturating polyacryl amide gel (Biozym, Landgraaf, The Netherlands). These shifts were visualized by phosphor imaging using a Cyclone phosphor-imager (Packard, Meriden, USA). Specificity of NF-kB DNA binding was ascertained by competition with a 150fold molar excess of unlabeled consensus oligonucleotides, displacing all radiolabeled oligonucleotides, resulting in a disappearance of all NF- $\kappa B$ complexes.

To quantitate the NF- $\mathrm{KB}$ signal, a constant amount of HeLa nuclear extract was included on each gel as a control. The intensity of the resulting NF-KB signals was determined by densitometry (Optiquant) for each gel. The NF- $\mathrm{KB}$ signal was related to the NF- $\mathrm{KB}$ signal of the HeLa extract that is run as a control on each gel. The densitometric value for the NF- $\mathrm{KB}$ signal was converted into HeLa equivalents / $10 \mu \mathrm{g}$ protein (van den Berg et al. 2001).

\section{Lung function and respiratory muscle strength}

Lung function measurements included $\mathrm{FEV}_{1}$ and IVC measured with a pneumotachograph. The DLCO was measured by the single-breath method (Masterlab, Jaeger, Würzburg, Germany). Values were expressed as a percentage of those predicted (Quanjer et al. 1993).

Inspiratory and expiratory muscle strength were assessed by measuring maximal respiratory mouth pressures using the method of Black and Hyatt (Winsberger et al. $1997)$ as previously reported. Maximal inspiratory mouth pressure $(P \mathrm{I}, \max )$ was measured at residual volume (RV), whilst maximal expiratory mouth pressure ( $P \mathrm{E}$, $\max$ ) was measured at total lung capacity (TLC). The equipment used was a pressure transducer (model MP 45-30; Validyne Engineering Corp., Northridge, CA, USA). All signals were recorded on a strip chart (type BD 31; Kipp \& Zonen, Delft, The Netherlands). Values are expressed as absolute terms and as percentage of predicted values according to Wilson (Winsberger et al. 1997). 


\section{Exercise capacity}

Patients performed a symptom limited incremental exercise test on an electronically braked cycle ergometer (Cornival 400, Lode, Groningen, The Netherlands). After a period of rest and 2 minutes of unloaded pedalling, a progressively increasing work rate test was started in order to determine peak work rate $\left(\mathrm{W}_{\text {peak }}\right)$ and oxygen uptake $\left(\mathrm{VO}_{2 \text { peak }}\right)$ of the subject. The work rate increase was set at $10 \mathrm{Watts} / \mathrm{min}$ for each patient and 15-30 watts/min for the healthy volunteers, depending upon their training status. Pedalling frequency was selected by the subjects between 60 and $70 \mathrm{rpm}$ and held constant throughout the test. Breath-by-breath gas exchange was measured throughout the test by a ventilated hood system (Oxyconbeta, Jaeger, Bunnik, The Netherlands). An infrared electrode was placed on a finger to measure oxygen saturation (Fasttrac, Sensor Medics Co., Anaheim, California). Heart rate was measured throughout the test using a sport tester (PE3000, Polar Electro cy, Kempele, Finland). In rest and during maximal exercise arterial blood samples were taken and arterial bloodgas analyses were performed.

\section{Chest radiographs}

Chest radiographs were made in the posterior-anterior and lateral projections, and were classified by a single experienced reader, blinded to the patients' clinical history, in a standard manner according to the radiographic stage (0 to IV).

\section{High-resolution CT}

Thin section scans with $1 \mathrm{~mm}$ collimation were obtained at $10-\mathrm{mm}$ intervals through the chest. The scanning parameters included $137 \mathrm{kVp}, 255 \mathrm{~mA}$, and 1 -second scanning time. Both mediastinal (width, $400 \mathrm{HU}$; level, $40 \mathrm{HU}$ ) and lung (width, 1,600 $\mathrm{HU}$; level, $-800 \mathrm{HU}$ ) window images were obtained. Scans were reconstructed with a highfrequency reconstruction algorithm. A single experienced reader, blinded to the patient's clinical history classified the scans. The typical patterns of parenchymal involvement were qualitatively registered as thickening or irregularity of the bronchovascular bundle (BVB), intraparenchymal nodules (ND), septal and nonseptal lines (LS) and parenchymal consolidation (including ground glass opacifications) (PC) as well as the volume affected which was quantified by a visual score: 0 no lesions found; $1=$ up to $33 \% ; 2=$ up to $66 \% ; 3=$ more than $66 \%$ of the volume affected. Similarly, the quantification of the focal pleural thickening (PL) respectively the 
enlargement of the lymph nodes (LN) was done: $0=$ no pathologic findings, $1=$ minor, $2=$ moderate, and $3=$ pronounced changes (Oberstein et al. 1997). The total score was obtained by counting the individual scores (BVB, ND, LS, PC, LN, and PL) together.

\section{Statistical analysis}

The data of the control subjects and sarcoidosis patient groups were compared using one way analyses of variance (ANOVA) for ordinal values and Chi-square tests for nominal values. In all tests a probability value of less than 0.05 was considered to be statistically significant. All analyses were performed using the Statistical Package for Social Science (SSPS) for Windows.

\section{Results}

All 12 cases suffered from fatigue, dry cough, and dyspnea during exercise, chest pain, and occasionally arthralgia, weight loss, night sweats, and fever. Histologic examination of lung biopsy specimen revealed a submucosal, interstitial and occasionally subpleural location of non-confluent non-necrotizing granulomatous inflammation in all cases. In some granulomas multi nucleated giant cells of Langerhans or foreign body type were present. The demographic and clinical characteristics of the studied sarcoidosis patients are summarized in Table 1. Group A consisted of the five untreated patients and group B of seven treated patients. No significant differences were found between both sarcoidosis patient groups. In seven sarcoidosis patients oral corticosteroids (prednison orally: one month $50 \mathrm{mg}$, one month $40 \mathrm{mg}$ followed by one month $30 \mathrm{mg}$ ) were employed. This resulted in a decrease of the SACE levels within normal limits (Table 1). In contrast, the NF- $\mathrm{KB}$ activity appeared to be increased in the treated (group B) as well as the untreated (group A) sarcoidosis patients $(8.2 \pm 2.6)$ compared to the healthy control group $(4.4 \pm 0.6)(p<0.001$, Figure 1). Representative examples of three sarcoidosis patients as well as a control are depicted in Figure 2. Despite the corticosteroid treatment, the patients from group B suffered from persistent pulmonary symptoms and severe fatigue at the moment this study was performed. Moreover, the radiological findings and lung function test results did not improve significantly either. 
Table 1. Demographic and clinical characteristics of 12 sarcoidosis patients

\begin{tabular}{|c|c|c|}
\hline & $\begin{array}{c}\text { Group A } \\
\text { No treatment }\end{array}$ & $\begin{array}{c}\text { Group B } \\
\text { Prednisone }\end{array}$ \\
\hline Age, yrs & $36.0 \pm 8.7$ & $35.4 \pm 8.2$ \\
\hline Sex, female/male & $2 / 3$ & $1 / 6$ \\
\hline \multicolumn{3}{|l|}{ Imaging procedures } \\
\hline Radiographic stage II/III & $4 / 1$ & $3 / 4$ \\
\hline HRCT total score & $4.8 \pm 3.7$ & $8.0 \pm 3.8$ \\
\hline \multicolumn{3}{|l|}{ Laboratory characteristics } \\
\hline \multirow[t]{2}{*}{ sACE U/l (9-25) } & $33.6 \pm 13.0$ & $17.4 \pm 6.8^{*}$ \\
\hline & & $38.8 \pm 8.8^{* *}$ \\
\hline C-reactive protein $\mathrm{mg} / \mathrm{l}(2-9)$ & $27.6 \pm 25.7$ & $11.3 \pm 8.5$ \\
\hline Calcium mmol/l (2.10-2.60) & $2.34 \pm 0.05$ & $2.43 \pm 0.08$ \\
\hline Uric acid mmol/l $(0.20-0.42)$ & $0.33 \pm 0.06$ & $0.40 \pm 0.09$ \\
\hline NF- $\kappa$ B HeLa eq/10 $\mu$ g protein $(3-5)$ & $8.2 \pm 2.5$ & $8.4 \pm 2.5$ \\
\hline \multicolumn{3}{|l|}{ Lung function test results } \\
\hline $\mathrm{FEV}_{1}, \%$ predicted & $82.8 \pm 11.1$ & $75.1 \pm 16.6$ \\
\hline FVC, \% predicted & $89.8 \pm 12.2$ & $81.7 \pm 14.4$ \\
\hline DLco, $\%$ predicted & $78.4 \pm 13.6$ & $80.2 \pm 12.4$ \\
\hline$P_{1}, \max \mathrm{cm} \mathrm{H}_{2} \mathrm{O}$ & $-119.6 \pm 28.4$ & $-111.4 \pm 28.4$ \\
\hline Desaturation during exercise yes/no & $1 / 4$ & $4 / 3$ \\
\hline
\end{tabular}

Data are expressed as number or mean $\pm S D$. HRCT=high-resolution computed tomography; $s A C E=$ serum angiotensin converting enzyme; $N F-\kappa B=$ nuclear factor $-\kappa B$; Reference ranges of laboratory values in parentheses. ${ }^{*} p<0.01$ group $B$ during treatment with prednison versus before treatment**. 


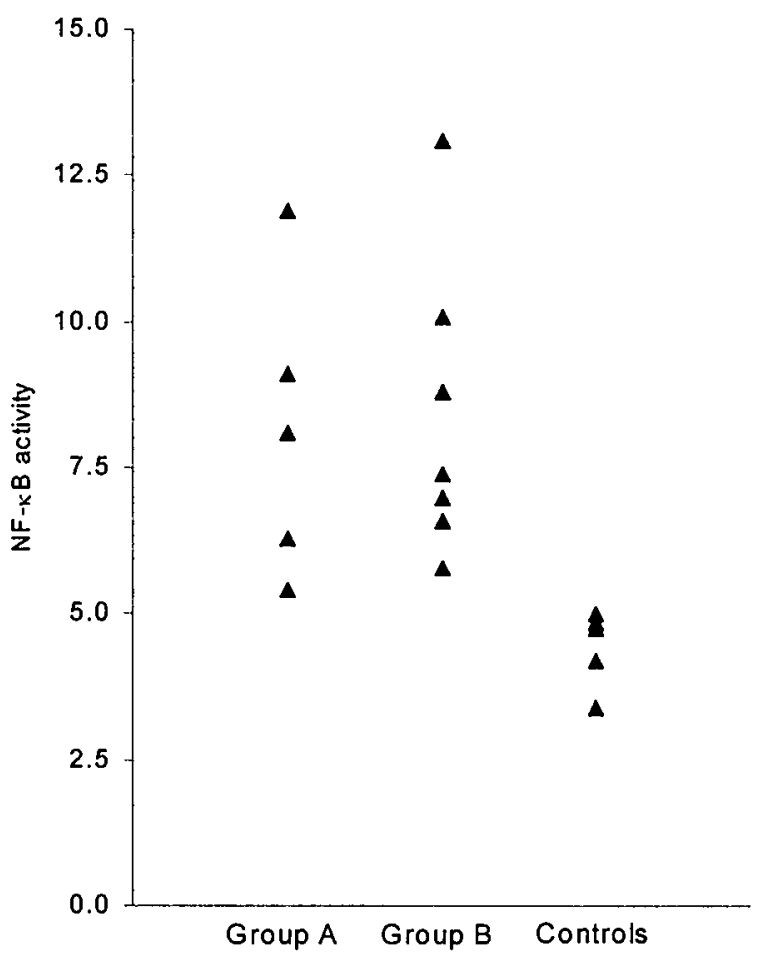

Figure 1. $N F-\kappa B$ activity in HeLa equivalents/lO $\mu$ grotein of the studied sarcoidosis patients: group A without treatment $(n=5)$, group $B$ after 3 months treatment with prednison orally $(n=7)$ and the healthy controls $(n=5)$.

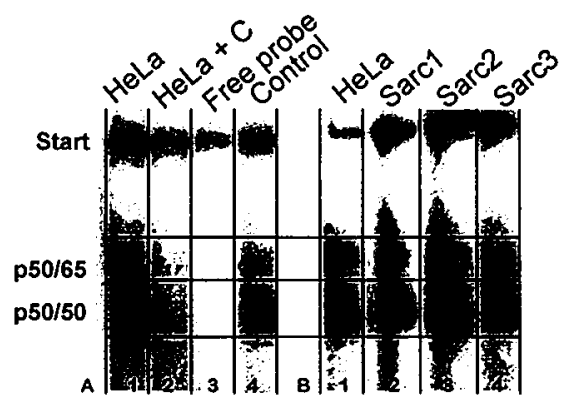

Figure 2. Representative Electro Mobility Shift Assays (EMSAs) using $10 \mu \mathrm{g}$ nuclear proteins (extract) from Peripheral Blood Mononuclear Cells (PBMCs) of a control (Control, lane A4) and three patients with sarcoidosis (Sarc, lane B2, B3, B4). The locations were the samples have been brought on the gels are indicated with Start. Lane AI and BI represent the HeLa nuclear extract. The specificity of the binding is checked with the HeLa nuclear extract plus a 150-fold molar excess competitor (HeLa $+\mathrm{C}$, lane A2) and with the free probe (Free probe, lane A3). The $N F-\kappa B$ activity is related the HeLa nuclear extract and expressed as HeLa equivalents / $10 \mu \mathrm{g}$ protein. 


\section{Discussion}

To the best of our knowledge, this is the first study to demonstrate an activation of the $\mathrm{NF}-\mathrm{KB}$ response in sarcoidosis. However, we realize that caution in the interpretation of the results of this study is warranted due to the rather small sample size of the study population. Many oxidative stress factors that stimulate NF- $\mathrm{kB}$ response are identified, such as oxidants (ozone, fibres, beryllium), viruses and activators of protein kinase $C$. All these stimuli also are reported to be possible inducers of sarcoidlike granulomatous reactions (Hunninghake et al. 1999). The disease results from an interplay of genetic and environmental factors. Therefore, it is obvious that there is no single causative agent of sarcoidosis, but that many oxidative agents - infectious and (in)organic - may trigger the granulomatous response in susceptible persons.

Serum ACE levels and other markers of cell activation in sarcoidosis (Gottlieb et al. 1997, Müller-Quernheim 1998) in general have a poor predictive value (Halliwell et al. 1992, Rizzato et al. 1998, Hunninghake et al. 1999). Moreover, an elevated sACE is not exclusive to sarcoidosis, and a low SACE activity does not exclude sarcoidosis. In the present study the SACE levels were high in the sarcoidosis patients. In the treated patients the SACE levels returned within normal limits during prednison treatment, whereas the clinical features still remained. In contrast, the NF- $\mathrm{kB}$ activity did not differ between the treated and non treated patients. However, no data about the NF- $\mathrm{KB}$ activity before treatment with corticosteroids are available. So, we cannot exclude that the NF- $\mathrm{kB}$ activity even was higher before treatment. Studdy and Bird (1989) suggested that the SACE level parallels the progress of sarcoidosis and that the dose of the glucocorticoids may be titrated on the SACE levels. Regarding the effectivity of glucocorticoids it has been suggested that glucocorticoids only suppress the disease activity, making things look better than they actually are (Selroos 1996). This suggestion coincides with our observation that SACE activity is reduced while $\mathrm{NF}-\mathrm{\kappa B}$ activity is not affected by glucocorticoid treatment. It has been suggested that glucocorticoids inhibit the action of transcription factors such as NF- $\mathrm{KB}$ in chronic inflammation. However, others found no effect of corticosteroids on NF- $\mathrm{KB}$ activity (Newton 2000). In patients with asthma that are resistant to the anti-inflammatory effects of glucocorticoids, there appears to be a reduction of availability of glucocorticoid receptors to inhibit the activated NF-kB response (Barnes \& Adcock 1997; Barnes \& Karin, 1997). Moine et al. (2000) demonstrated an increased activation of NF- $\mathrm{KB}$ in alveolar macrophages of patients with established ARDS. They 
suggested that fundamental abnormalities in transcriptional mechanisms involving NF$\kappa \mathrm{B}$, and important in the inflammatory response occur in the lungs of patients with ARDS. In contrast to our study population, no patient received corticosteroids before or at the time of the study. Due to the rather complicated and pitfall-prone procedure of the NF- $\mathrm{KB}$ measurement, this is not yet useful in a clinical setting.

Sarcoidosis is often acute and self-limiting, but may also have a chronic pattern, waxing and waning over a long period (Hunninghake et al. 1999). The high NF- $\mathrm{KB}$ response presumably results in the observed elevated levels of cytokines in sarcoidosis (Müller-Quernheim 1998, Hunninghake et al. 1999). Previously, an increase of the polymorphonuclear neutrophil (PMN) count in BAL fluid obtained from sarcoidosis patients appeared to be associated with more advanced disease (Drent et al. 1999). This highlights that PMNs - but not lymphocytes - seem to play a crucial role in the outcome of sarcoidosis and evolution of the inflammatory process toward pulmonary fibrosis. Moreover, PMNs contribute to oxidative stress, cytokine production and cell damage (Henderson et al. 1991, Cobben et al. 1999). Car and coworkers (1994) demonstrated significantly elevated interleukin-8 (IL-8) levels in BAL fluid of sarcoidosis patients and idiopathic pulmonary fibrosis (IPF) patients. The coordinated stimulation of the expression of the genes for the inflammatory protein IL-8 is regulated by NF- $\mathrm{KB}$ resulting in recruitment and activation of neutrophils (Barnes \& Karin 1997, Desai et al. 1999) like in ARDS (Moine et al. 2000). Kilgore et al. (1997) hypothesized that neutrophils and neutrophil-derived products $\left(\mathrm{H}_{2} \mathrm{O}_{2}\right)$ influence granuloma formation through induction of local monocyte chemoattractant protein-1 (MCP-1) expression. In line with this, Ichiyasu et al (1999) demonstrated an important role of MCP-1 in the development of granuloma in a rabbit model. It is tempting to speculate that the neutrophil component of the inflammation - including mediators such as collagenase (Ward et al. 1990), toxic oxidant radicals and proteases - has the potential to contribute to alveolar wall injury in sarcoidosis also (Roth et al. 1981, Lin et al. 1985). Blackwell et al (1996) suggested that limiting NF-kB-dependent gene transcription represents an attractive therapeutic target for strategies to control neutrophilic inflammation and lung injury caused by excessive production of inflammatory mediators (Blackwell \& Christman 1997). To determine potential mechanisms, through which neutrophils may participate in granuloma formation, Kilgore et al. (1998) administered the antioxidant enzymes superoxide dismutase and catalase to neutrophil-sufficient rats with glucan-induced granulomas. Superoxide 
dismutase treatment did not reduce granuloma formation, whereas catalase treatment resulted in decreased granuloma size, suggesting that $\mathrm{H}_{2} \mathrm{O}_{2}$ plays an important role in this process. In this context, although more data supporting the importance of the neutrophil in the pathogenesis of sarcoidosis are really needed, it is reasonable to assume that NF- $\mathrm{KB}$ might be a target for new types of anti-inflammatory treatment. Therefore, the search for potent and long-lasting antioxidants that inhibit the activation of NF- $\mathrm{kB}$ or direct inhibitors of NF- $\mathrm{KB}$ is substantial and might prove beneficial for the treatment of cytokine-mediated inflammatory diseases (Blackwell and Christman 1997, Kilgore et al. 1998, Brown et al. 1999, Moine et al. 2000).

Major alterations in the expression of signal transduction molecules in $\mathrm{T}$ cells, including NF-KB, have been demonstrated in other granulomatous disorders such as leprosy by Zea et al. (1998). A selective decrease in Thl function and a predominance of a Th2 response lead to the loss of cellular immunity, including a decreased expression of NF- $\mathrm{KB}$, and an enhanced antibody production. In contrast, the presence of the NF- $\mathrm{KB}$ p65-p50 heterodimer is associated with increased production of interferon- $\gamma$, a Thl response. In the present study, an increased NF- $\mathrm{kB}$ activity was demonstrated in the sarcoidosis patient population. This observation might provide more substantial evidence that sarcoidosis is a Th1 mediated disorder. A shift in the Th1/Th2 balance has been considered in the course of sarcoidosis. Presumably, this is reflected by the NF-KB expression as well. Moreover, it is tempting to speculate that alterations in NF- $\mathrm{KB}$ expression might be useful in distinguishing disorders considered as Th1 mediated such as sarcoidosis and Th2 mediated disorders such as extrinsic allergic alveolitis or drug-induced pneumonitis (Drent et al. 1997). Furthermore, detailed measurement of NF- $\mathrm{KB}$ expression might be of additional value in understanding the pathogenesis of various granulomatous disorders.

In conclusion, the NF-KB response appeared to be activated in sarcoidosis. It is tempting to speculate that oxidative stress plays a role in the pathogenesis of sarcoidosis too. The suppression of the activity of the NF- $\mathrm{KB}$ response seems nonequivalent to the suppression of the SACE activity. Future studies are warranted to evaluate the clinical relevance of this observation as well as to establish whether NF$\mathrm{KB}$ inhibitors may be useful in the treatment of sarcoidosis and whether antioxidants should be considered novel treatment for sarcoidosis. 


\section{References}

Barnes, P.J., Karin, M. (1997) Nuclear factor-kB - a pivotal transcription factor in chronic inflammatory diseases. New Engl. J. Med. 15: 1066-1071.

Barnes, J.P., Adcock, I.M. (1997) NF-кB: a pivotal role in asthma and a new target for therapy. New Engl. J. Med. 18: 46-50.

Blackwell, T.S., Blackwell, T.R., Holden, E.P., Christman, B.W., Christman, J.W (1996) In vivo antioxidant treatment suppresses nuclear factor-kappa $B$ activation and neutrophilic lung inflammation. J. Immunol. 157: 1630-1637.

Blackwell, T.S., Christman, J.W. (1997) The role of nuclear factor-kappa B in cytokine gene regulation. Am. J. Respir. Cell. Mol. Biol. 17: 3-9.

Brown, D.M., Beswick, P.H., Donaldson, K. (1999) Induction of nuclear translocation of NF$\kappa \mathrm{B}$ in epithelial cells by respirable mineral fibers. J. Pathol. 189: 258-264.

Car, B.D., Meloni, F., Luisetti, M., Semenzato, G., Gialdroni-Grassi, G., Walz, A. (1994) Elevated IL-8 and MCP-1 in the bronchoalveolar lavage fluid of patients with idiopathic pulmonary fibrosis and pulmonary sarcoidosis. Am. J. Respir. Crit. Care Med. 149: 655659.

Cobben, N.A.M., Drent, M., Jacobs, J.A., Schmitz, M.P.J., Mulder, P.G.H., Henderson R.F., Wouters, E.F.M., van Dieijen-Visser, M.P. (1999) Relationship between enzymatic markers of pulmonary cell damage and cellular profile: a study in bronchoalveolar lavage fluid. Exp. Lung Research 25: 99-111.

Desai, A., Huang, X., Warren, J.S. (1999) Intracellular glutathione redox status modulates MCP-1 expression in pulmonary granulomatous vasculitis. Lab. Invest. 79: 837-847.

Donaldson, K. (1998) Mechanisms of pneumoconiosis. In E. Banks E, and J.E. Parker, editors. Occupational lung disease, Chapman and Hall Medical, London. Pg. 139-160.

Drent, M., Nierop, M.A.M.F., van Gerritsen, F.A., Wouters, E.F.M., Mulder, P.G.H. (1996) Computer program using BALF analysis results as diagnostic tool in interstitial lung diseases. Am. J. Respir. Crit. Care Med. 153: 736-741.

Drent, M., Grutters, J.C., Mulder, P.G.H., van Velzen-Blad, H., Wouters, E.F.M., van den Bosch, J.M.M. (1997) Is the different $T$ helper cell activity in sarcoidosis and extrinsic allergic alveolitis also reflected by the cellular bronchoalveolar lavage fluid profile? Sarcoidosis Vasc. Diffuse Lung Dis. 14: 31-38.

Drent, M., Jacobs, J.A., Lamers, R.J.S., Liem, I.H., Wouters, E.F.M. (1999) Does the cellular bronchoalveolar lavage fluid profile reflect the severity of sarcoidosis? Eur. Respir. J. 13: 1338-1344.

Drent, M., Bomans, P.H.H., van Suyten, R.J., Lamers, R.J.S., Bast, A., Wagenaar, S.S. (2000) The association between sarcoidlike granulomatosis and man-made mineral fibre exposure. Respir. Med. 94: 815-820.

Driscoll, K.E., Howard, B.W., Carter, L.M., Hassenbein, D.G., Janssen, Y.M.W., Mossman, B.T. (1995) Oxidative stress and silica induced increases in nuclear, NF-AB binding activity in alveolar epithelial cells. Am. J. Respir. Crit. Care Med. 151: A712.

Gilmour, P., Beswick, P.H., Donaldson, K. (1995) Detection of surface free radical activity of respirable industrial fibres using supercoiled $\square$ x 174 plasmid DNA. Carcinogenesis 16: 2973-2979.

Giri, D.K., Mehta, R.T., Kansal, R.G., Aggarwal, B.B. (1998) Mycobacterium aviumintracellulare complex activates nuclear transcription factor-[] in different cell types through reactive oxygen intermediates. J. Immunol. 161: 4634-4841.

Gottlieb, J., Israel, H., Steiner, R., Triolo, J., Patrick, H. (1997) Outcome of sarcoidosis. Chest $111: 623-631$. 
Halliwell, B., Gutteridge, J.M.C., Cross, C.E. (1992) Free radicals, antioxidants, and human disease: where are we now? J. Lab. Clin. Med. 119:598-620.

Henderson, R.F., Harkema, J.R., Hotchkiss, J.A., Boehme, D.S. (1991) Effect of blood leukocyte depletion on the inflammatory response of the lung to quarts. Toxicol. Appl. Pharmacol. 109: 127-136.

Hoffman, M.A., Schiekofer, S., Isermann, B., et al (1999) Peripheral blood mononuclear cells isolated from patients with diabetic nephropathy show increased activation of the oxidative-stress sensitive transcription factor NF-[]B. Diabetologia 42: 222-232.

Hunninghake, G.W., Costabel, U., Ando, M., et al (1999) ATS/ERS/WASOG statement on sarcoidosis. Sarcoidosis Vasc. Diffuse Lung Dis. 16:149-173.

Ichiyasu, H., Suga, M., Matsukawa, A., Iyonaga, K., Mizobe, T., Takasahishi, T., Ando, M. (1999) Immunopathogenesis of granuloma formation induced by Propionibacterium acnes. Sarcoidosis Vasc. Diffuse Lung Dis. 16 (Suppl.1): 8.

Kilgore, K.S., Imlay, M.M., Szaflarski, J.P., Silverstein, S.F., Malani, A.N., Evans, V.M., Warren, J.S. (1997) Neutrophils and reactive oxygen intermediates mediate glucan-induced pulmonary granuloma formation through the local induction of monocyte chemoattractant protein-1. Lab. Invest. 76: 191-201.

Kilgore, K.S., Powers, K.L., Imlay, M.M., Malani, A., Allen, D.I., Beyer, J.T., Anderson M.B., Warren, J.S. (1998) The carbohydrate sialyl Lewis(x) (sLe(x)) sulfated glycomimetic GM2941 attenuates glucan-induced pulmonary granulomatous vasculitis in the rat. J. Pharmacol. Exp. Ther. 286: 439-446.

Lin, Y.H., Haslam, P.L., Turner-Warwick, M. (1985) Chronic pulmonary sarcoidosis: relationship between lung lavage cell counts, chest radiograph, and results of standard lung function tests. Thorax 40: 501-507.

Moine, P., McIntyre, R., Schwartz, M.D., et al (2000) NF- $\square$ B regulatory mechanisms in alveolar macrophages from patients with acute respiratory distress syndrome. Shock 13: 85-91.

Müller-Quernheim, J. (1998) Sarcoidosis: immunopathogeninetic concepts and their clinical appreciation. Eur. Respir. J. 11: 716-738.

Newman, L.S., Rose, C.S., Maier, L.A. (1997) Sarcoidosis. New Engl. J. Med. 336: 12241234.

Newton, R. (2000) Molecular mechanisms of glucocorticoid action: what is important? Thorax 55: 603-613.

Oberstein, A., Aitzewitz, H., von Schweden, F., Müller-Quernheim, J. (1997) Non invasive evaluation of the inflammatory activity in sarcoidosis with high-resolution computed tomography. Sarcoidosis Vasc. Diffuse Lung Dis. 14: 65-72.

Poli, G., Parola, M. (1996) Oxidative damage and fibrogenesis. Free Radical. Biol. Med. 22: 287-305.

Quanjer, P.H., Tammeling, G.J., Cotes, J.E., Pederson, O.F., Peslin, R., Yernault, J-C. (1993) Lung volumes and forced ventilatory flows. Report working party. Standardization of lung function tests. European Commission for Steel and Coal. Official statement of the European Respiratory Society. Eur. Respir. J. 6 (Suppl. 16): 5-40.

Rizzato, G., Montemurro, L., Colombo, P. (1998) The late follow-up of chronic sarcoid patients previously treated with corticosteroids. Sarcoidosis Vasc. Diffuse Lung. Dis. 15: 52-58.

Roth, C., Huchson, G.J., Arnoux, A., Staaslan-Lequern, G., Marsac, J.H., Chretien, J. (1981) Bronchoalveolar cells in advanced pulmonary sarcoidosis. Am. Rev. Respir. Dis. 124: 912.

Selroos, O. (1996) Glucocorticoids and pulmonary sarcoidosis. Thorax 51:229-230. 
Studdy, R.P., Bird, R. (1989) Serum angiotensin converting enzyme in sarcoidosis - its value in clinical practice. Ann. Clin. Biochem. 26: 13-18.

Van den Berg, R., Haenen, G.R.M.M., van den Berg, H., Bast, A. (2001) Nuclear factor-kB as a potential biomarker of oxidative stress. Br. J. Nutr. (in press).

Ward, K., O'Conner, M., Odlum, C., Power, C., Fitzgerald, M.X. (1990) Pulmonary disease progress in sarcoid patients with and without bronchoalveolar lavage collagenase. Am. Rev. Respir. Dis. 142: 636-641.

Wirnsberger, R.M., Drent, M., Hekelaar, N., Breteler, M.H.M., Drent, S., Wouters, E.F.M., Dekhuijzen, P.N.R. (1997) Relationship between respiratory muscle function and quality of life in sarcoidosis. Eur. Respir. J. 10: 1450-1455.

Zea, A.H., Ochoa, M.T., Ghosh, P., et al (1998) Changes in expression of signal transduction proteins in $\mathrm{T}$ lymphocytes of patients with Leprosy. Infect. Immun. 66: 499-504. 


\section{Chapter 7}

Nuclear factor- $\mathrm{\kappa B}$ activation is higher in peripheral blood mononuclear cells of male smokers

Robin van den Berg, Guido R.M.M. Haenen, Henk van den Berg and Aalt Bast

Environmental Toxicology and Pharmacology 9(4), 147-151 (2001) 


\begin{abstract}
Nuclear factor $-\kappa \mathrm{B}(\mathrm{NF}-\kappa \mathrm{B})$ is an oxidative stress sensitive transcription factor involved in the regulation of inflammatory genes. Activation of NF- $\kappa B$ results into increased expression of inflammatory genes such as for interleukins, endothelial cell leukocyte adhesion molecules and inducible NO synthase.

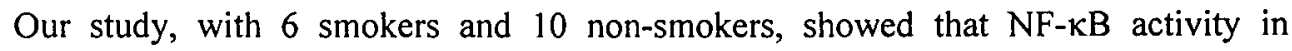
peripheral blood mononuclear cells of smokers compared to non-smokers is significantly higher $(\mathrm{p}<0.05)$ in smokers.

This indicates that NF- $\mathrm{kB}$ is involved in cigarette smoke induced inflammatory responses and that $\mathrm{NF}-\mathrm{KB}$ activation can be used as a functional marker of oxidative stress.
\end{abstract}




\section{Introduction}

Oxidative stress is implicated in cigarette smoke-induced airway diseases, such as chronic obstructive pulmonary disease (COPD) (Rahman and MacNee, 1999; Repine et al. 1997). It is suggested that oxidative stress is an important trigger in the upregulation of proinflammatory genes and protective mechanisms such as antioxidant enzymes (Keating et al. 1999; Gilks et al. 1998). Current research is directed to elucidate the exact role of oxidants, such as cigarette smoke, in the etiology of diseases, e.g. on disruption of key cell-cycle regulators and signal transduction cascades (Rahman and MacNee, 1998).

Cigarette smoke is a complex mixture of more than 4,700 chemical compounds, including benzo[a]pyrene, cadmium, nicotine, hydroquinone and high concentrations of free radicals and other oxidants (Church and Pryor, 1985). Nitric oxide (NO•) is present in cigarette smoke in concentrations of 500-1,000 ppm (Pryor and Stone, $1993)$ and also semiquinone radicals, hydroxyl radicals $(\bullet \mathrm{OH})$ and hydrogen peroxide $\left(\mathrm{H}_{2} \mathrm{O}_{2}\right)$ has been demonstrated in smoke ( $\mathrm{Zang}$ et al. 1995). These reactive oxygen/nitrogen species are able to generate oxidative stress in humans, which could lead to damage to proteins, lipids and DNA. Oxidative stress in smokers was already demonstrated by Rahmann and MacNee (1996a) using direct measurement of specific markers of oxidative injury with electron spin resonance (ESR). Indirect evidence of oxidative injury was also found, e.g. increased levels of TBARS in BAL fluid (Morrison et al. 1999), increased plasma-conjugated dienes (Duthie et al. 1991), increased levels of $F_{2}$-isoprostane (Morrow et al. 1995) as products from lipid peroxidation, depletion of major plasma antioxidants such as ascorbic acid, vitamin $E$, $\beta$-carotene and selenium (Rahmann and MacNee 1996b, review) and also a decreased plasma total antioxidant capacity (Morrison et al. 1999). All these markers indicate that oxidative stress has occurred, but they do not provide direct evidence that oxidative stress is involved in the etiology of smoke-induced pathologies.

The earliest events in the response of the lung to cigarette smoke are increased epithelial permeability (Morrison et al. 1999), a direct or indirect release of cytokines (Mikuniya et al. 1999), an increase in sequestration of neutrophils in the lungs (Rahmann and MacNee 1996b) and increased expression of adhesion molecules (Turato et al. 1995). Nuclear factor- $\mathrm{kB}(\mathrm{NF}-\mathrm{\kappa B})$ is an oxidative stress sensitive transcription factor and is involved in the expression of inflammatory genes (Barnes

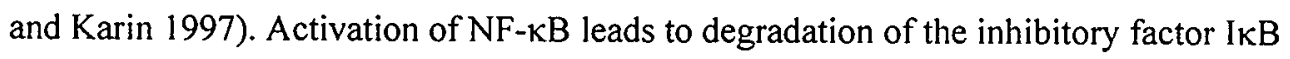


and subsequently rapid translocation of the 'active' p50/p65 heterodimer to the nucleus. In the nucleus NF- $\mathrm{KB}$ binds to promotor/enhancer regions of inflammatory genes such as interleukin (e.g. IL-1, IL-2, IL-8), endothelial cell leukocyte adhesion molecule (e.g. ELAM-1) and inducible NO synthase (iNOS). To determine if NF- $\mathrm{kB}$ activation is quantitatively different in smokers compared to non-smoking healthy subjects and whether NF- $\mathrm{KB}$ activation can be used as a functional marker of oxidative stress, we have examined the NF-KB activation in peripheral blood mononuclear cells (PBMCs).

\section{Material and Methods}

\section{Study subjects and methods}

Sixteen male subjects, both smokers ( $\mathrm{n}=6$, currently smoking at least 10 cigarettes per day for at least 1 year) and non-smokers $(n=10)$, aged $39.1 \pm 12.1$ years and apparently healthy were recruited among staff members of the laboratory. Clinical laboratory tests were performed to describe the two groups and to detect major deviations from the normal human values. The clinical tests that were performed included white blood cells, red blood cells, haemoglobin and hematocrite as blood parameters, aspartate aminotransferase, alanine aminotransferase, alkaline phosphatase as liver parameters, bilirubin and creatinin as kidney parameters and C-reactive protein to detect major inflammations. Informed written consent was obtained from all subjects and the study was approved by an external Medical Ethical Committee.

\section{Isolation of peripheral blood mononuclear cells (PBMCs)}

To assess NF- $\mathrm{KB}$ activity in humans, $20 \mathrm{~mL}$ whole blood was used to prepare approximately $1 \times 10^{7}$ PBMCs, immediately after venipuncture, by separation on a Ficoll-Isopaque ${ }^{\circledR}$ gradient using leucosep ${ }^{\circledR}$ tubes.

\section{Preparation of nuclear extracts}

Nuclear extracts were prepared by using $1 \times 10^{7}$ cells, as described by van den Berg et al. (2000). Briefly, cells were washed three times in ice cold phosphate buffered saline (PBS) and lysed using $400 \mu \mathrm{l}$ ice-cold lysis buffer (10 mmol/L HEPES-KOH, pH 7.9 at $4{ }^{\circ} \mathrm{C}, 1.5 \mathrm{mmol} / \mathrm{L} \mathrm{MgCl}_{2}, 10 \mathrm{mmol} / \mathrm{L} \mathrm{KCl}, 0.5 \mathrm{mmol} / \mathrm{L}$ dithiothreitol (DTT), 0.2 $\mathrm{mmol} / \mathrm{L}$ phenylmetyhlsulfonyl fluoride (PMSF) and $1 \%(\mathrm{v} / \mathrm{v})$ mammalian protease inhibitor cocktail (Sigma, MO, USA)). The cell suspension was incubated on ice for 15 minutes to complete the lysis of the cell membrane and centrifuged at $4{ }^{\circ} \mathrm{C}$. The 
supernatant was discarded and the nuclear pellet was resuspended in $100 \mu \mathrm{l}$ ice-cold (high salt) extraction buffer $\left(20 \mathrm{mmol} / \mathrm{L}\right.$ HEPES- $\mathrm{KOH}, \mathrm{pH} 7.9$ at $4^{\circ} \mathrm{C}, 25 \%$ glycerol, $1.5 \mathrm{mmol} / \mathrm{L} \mathrm{MgCl}, 420 \mathrm{mmol} / \mathrm{L} \mathrm{NaCl}, 0.5 \mathrm{mmol} / \mathrm{L} \mathrm{DTT}, 0.2 \mathrm{mmol} / \mathrm{L} \mathrm{PMSF}$ and $1 \%$ ( $v / v)$ mammalian protease inhibitor cocktail (Sigma, MO, USA)). The nuclear lysates were centrifuged at $4{ }^{\circ} \mathrm{C}$ and the supernatant, containing the nuclear proteins, were immediately collected and stored at $-80^{\circ} \mathrm{C}$ until further use. Protein concentrations were determined according to the method of Bradford (BioRad, Veenendaal, the Netherlands), yielding sample concentrations of approximately $1 \mu \mathrm{g} / \mathrm{ml}$.

\section{$N F-\kappa B$ determination with the electromobility shift assay (EMSA)}

EMSA was used to determine the inducible (p65/50) and the constitutive (p50/50) NF$\kappa B$ in nuclei. $A^{32} \mathrm{P}$-end labeled double-stranded NF- $\kappa B$ oligonucleotide (5'-GAT CCA AGG GGA CTT TCC ATG GAT CCA AGG GGA CTT TCC AGT-3', Isogen, Maarssen, The Netherlands) containing a tandem repeat of the consensus sequence for the NF- $\kappa$ B binding site (-GGGGACTTTCC-) was used to detect NF- $\kappa B$ activity. $1 \mathrm{ng}$ radiolabeled NF- $\mathrm{KB}$ oligonucleotide was incubated with $10 \mu \mathrm{g}$ nuclear extract containing the NF- $\kappa B$ proteins for 20 minutes at room temperature. Binding of NF- $\mathrm{KB}$ to the oligonucleotide results in retardation ('shift') of the electromobility of the oligonucleotide on a $5 \%$ non-denaturating polyacryl amide gel (Biozym, Landgraaf, The Netherlands). These shifts were visualised by phosphor imaging using a Cyclone (Packard, Meriden, USA) phosphor-imager.

Specificity of NF-kB DNA binding was ascertained by competition with a 150 -fold molar excess of unlabeled consensus oligonucleotides, displacing all radiolabeled oligonucleotides, resulting in a disappearance of the signal of all NF-KB complexes.

\section{Measurement of $N F-\kappa B$ activity}

To quantitate the NF-kB signal, a constant amount of HeLa nuclear extract was included on each gel as a control. The intensity of the resulting NF- $\mathrm{kB}$ signals were determined by densitometry (Optiquant, Packard, Meriden, USA) for each gel. The NF- $\mathrm{kB}$ signal of the samples was related to the NF- $\mathrm{kB}$ signal of the HeLa extract that is run as a control on each gel (van den Berg et al. 2001). The densitometric value for the NF- $\mathrm{KB}$ signal was converted into HeLa equivalents / $10 \mu \mathrm{g}$ protein. 


\section{Statistical analysis}

Data analysis was performed using the statistical software package SAS/STAT version 6 (SAS Institute, Cary, NC, USA, T-test procedure).

\section{Results}

\section{Clinical tests}

Clinical laboratory tests were performed to describe the group of smokers (aged, 41.3 $\pm 13.2, \mathrm{n}=6$ ) and non-smokers (aged, $37.7 \pm 11.9, \mathrm{n}=10$ ) and to detect major deviations from the normal human values. Table 1 shows that there is a significant difference $(p<0.05)$ in white blood cells in smokers as compared to non-smokers, but both groups within the normal human ranges $\left(4-10 \times 10^{9} / \mathrm{L}\right)$. With all other parameters, no significant differences between smokers and non-smokers were found.

In both groups only two subjects had CRP values above the detection limit of 0.30 $\mathrm{mg} / \mathrm{L}$. The two smokers had CRP values of 0.31 and $1.08 \mathrm{mg} / \mathrm{L}$ respectively and 0.84 and $1.18 \mathrm{mg} / \mathrm{L}$ for non-smokers. Increased CRP levels above $10 \mathrm{mg} / \mathrm{L}$ indicate a temporary acute phase reaction (Pepys 1995).

Table 1. Results of routine clinical laboratory tests in smokers and non-smokers

\begin{tabular}{lccc}
\hline & Smokers & Non-smokers & p-value \\
\hline Number of subjects & 6 & 10 & \\
Age $(\mathrm{y})$ & $41.3 \pm 13.2$ & $37.7 \pm 11.9$ & 0.59 \\
\hline White blood cells $\left(10^{9} / \mathrm{L}\right)$ & $7.3 \pm 1.2$ & $5.7 \pm 1.0$ & 0.02 \\
Red blood cells $\left(10^{12} / \mathrm{L}\right)$ & $5.01 \pm 0.26$ & $5.08 \pm 0.29$ & 0.64 \\
Haemoglobin $(\mathrm{mmol} / \mathrm{L})$ & $9.9 \pm 0.4$ & $9.7 \pm 0.5$ & 0.47 \\
Hematocrite $(\%)$ & $46.6 \pm 1.2$ & $45.2 \pm 2.0$ & 0.11 \\
\hline Aspartate aminotransferase $(\mathrm{IU} / \mathrm{L})$ & $21 \pm 4$ & $24 \pm 6$ & 0.20 \\
Alanine aminotransferase $(\mathrm{IU} / \mathrm{L})$ & $19 \pm 4$ & $26 \pm 12$ & 0.11 \\
Alkaline phosphatase $(\mathrm{IU} / \mathrm{L})$ & $100 \pm 26$ & $79 \pm 21$ & 0.58 \\
\hline Creatinin $(\mu \mathrm{mol} / \mathrm{L})$ & $89 \pm 8$ & $83 \pm 7$ & 0.19 \\
Bilirubin $(\mu \mathrm{mol} / \mathrm{L})$ & $4.5 \pm 0.9$ & $5.5 \pm 1.0$ & 0.06 \\
\hline C-reactive protein $(\mathrm{mg} / \mathrm{L})^{*}$ & $<1.2$ & $<1.2$ & \\
\hline
\end{tabular}

* The results on C-reactive protein are explained in the result section. 
$N F-\kappa B$ activity

The effect of smoking on NF- $\mathrm{KB}$ activity was investigated by EMSA on nuclear extracts of peripheral blood mononuclear cells of smokers and non-smokers. NF- $\mathrm{kB}$ activity was measured in one run and related to the NF- $\mathrm{kB}$ signal of the HeLa extract that is run as a control on the gel. The densitometric value for the NF- $\mathrm{BB}$ signal was converted into HeLa equivalents / $10 \mu \mathrm{g}$ protein. Figure 1 shows that there is a significant $(\mathrm{p}<0.05)$ difference in $\mathrm{NF}-\mathrm{kB}$ activity in smokers $(9.1 \pm 2.0 \mathrm{HeLa}$ equivalents / $10 \mu \mathrm{g}$ protein, mean $\pm \mathrm{SD}$ ) as compared to non-smokers smokers (7.3 \pm 1.8 HeLa equivalents / $10 \mu \mathrm{g}$ protein, mean $\pm \mathrm{SD}$ ).

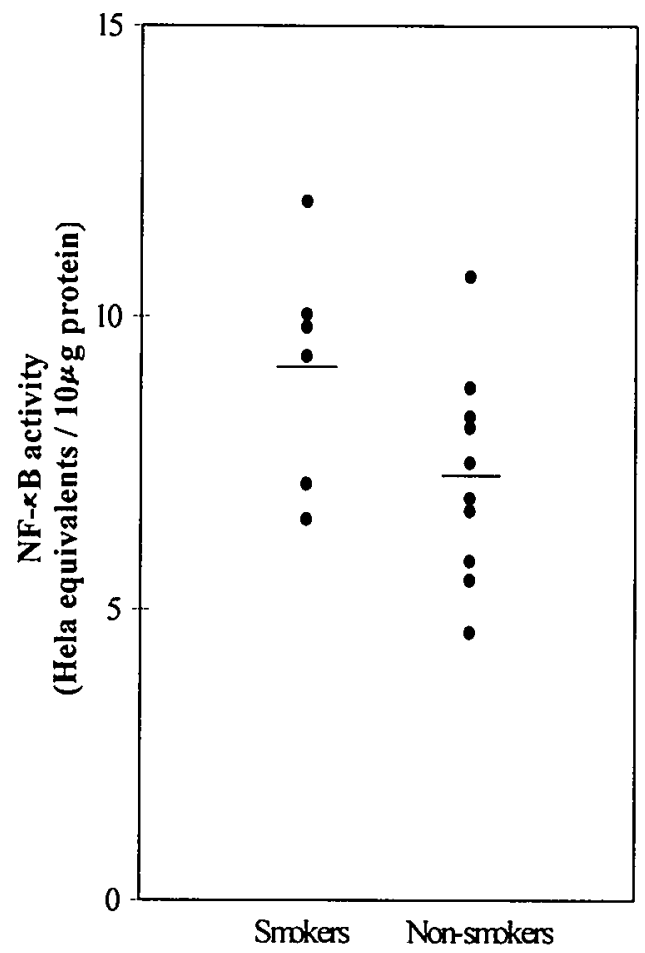

Figure 1. Effect of smoking on $N F-\kappa B$ activity in peripheral blood mononuclear cells ( $p<0.05 ;$ smokers compared with non-smokers). 


\section{Discussion}

Oxidative stress plays a critical in the inflammatory response to cigarette smoke through upregulation of redox-sensitive transcription factors and subsequently proinflammatory gene expression (Keating et al. 1999; Gilks et al. 1998). Inflammation itself also induces oxidative stress in the lungs and polymorphisms of genes for inflammatory mediators or antioxidant genes may have a role in individual susceptibility to the effects of cigarette smoke (Smith and Harrison 1997).

The redox-sensitive transcription factor NF- $\mathrm{kB}$, which can be activated by oxidants and inhibited by antioxidants (Sen and Packer 1996), plays an important role in the coordinated expression of inflammatory genes induced by cigarette smoke. To elucidate if NF- $\mathrm{KB}$ is involved, a study with 6 smokers and 10 non-smokers was performed. The higher concentration of NF- $\mathrm{KB}$ in the nucleus of freshly isolated PBMCs of these apparently healthy subjects indeed demonstrate that NF- $\mathrm{KB}$ is involved. Apparently, chronic cigarette smoking induces NF-KB activation, which might result via inflammatory cytokines into chronic inflammations. The increased white blood cells in smokers compared to non-smokers also indicate chronic inflammatory response.

Recently, Yan et al. (2000) showed that treatment of human and rat arterial smooth muscle cells with benzo[a]pyrene increased the binding of NF- $\mathrm{kB}$ to DNA and subsequently increased cyclooxygenase-2 gene expression (increased levels of COX-2 protein and mRNA). Shen et al. (1996) showed in human umbilical vein endothelial cells an increase in the binding activity of NF- $\mathrm{KB}$ to the consensus motif common to the cell adhesion molecule genes after treatment with a cigarette smoke condensate.

Also contradictory effects have been found. It has been reported that tobacco smoke (Vayssier et al. 1998), nicotine (Sugano et al. 1998) and hydroquinone (Pyatt et al. 1998) all inhibited of NF-KB activation. This discrepancy may be due to differences in experimental condition. A too high concentration or a too long incubation period with the noxious compounds present in cigarette smoke may be toxic to the cells, and this may give rise to false conclusions. Differences in the cell type used, possible differences in composition of the smoke used and experiments performed only with a single ingredient of smoke hamper a straightforward interpretation of the results and make a comparison between the studies almost impossible. For example hydroquinone has an antioxidant activity in vitro (Soucek et al. 2000) and this may explain its inhibitory effect on NF-KB activation. The potential antioxidant activity of 
hydroquinone will be overwhelmed by the great amount of oxidants present in cigarette smoke.

Data on the effect of smoke on NF-KB activation in vivo are scarce. Nishikawa et al. (1999) reported that acute exposure to cigarette smoke initiates NF- $\mathrm{kB}$ activation, IL-8 expression and infiltration of neutrophils in the airways in guinea pigs. It was also suggested that the alveolar macrophage is one potential source of NF- $\mathrm{KB}$ activation and IL-8 mRNA expression after acute exposure to cigarette smoke. A human volunteer study of Holscherman et al. (1999) also demonstrated enhanced procoagulant tissue factor (TF) expression in monocytes from smoking premenopausal woman. This was based on an increased TF gene transcription following activation of NF- $\mathrm{kB}$. However in the latter study also an effect of oral contraceptives was found.

The results of our human volunteer study indicate that NF- $\mathrm{KB}$ is involved in cigarette smoke induced inflammatory responses. Therefore the concentration of NF- $\mathrm{KB}$ in the cell nucleus of PBMCs could be used as a functional marker of oxidative stress. Antioxidants are known to prevent NF- $\mathrm{kB}$ activation (Hofmann et al. 1999). Besides stop smoking, increasing the antioxidant status might reduce smoke-induced toxicity.

\section{References}

Barnes, P.J., Karin, M. (1997) Nuclear factor-kB: a pivotal transcription factor in chronic inflammatory diseases. N. Engl. J. Med. 336, 1066-1071.

Church, T., Pryor, W.A. (1985) Free-radical chemistry of cigarette smoke and its toxicological implications. Environ. Health. Perspect. 64, 111-126.

Duthie, G.G., Arthur J.R., James, W.P.T. (1991) Effects of smoking and vitamin E on blood antioxidant status. Am. J. Clin. Nutr. 53, 1061S-1063S.

Gilks, C.B., Price, K., Wright, J.L., Churg, A. (1998) Antioxidant gene expression in rat lung after exposure to cigarette smoke. Am. J. Pathol. 152, 269-278.

Hofmann, M.A., Schiekofer, S., Isermann, B., Kanitz, M., Henkels, M., Joswig, M., Treusch, A., Morcos, M., Weiss, T., Borcea, V., Khalek, A.K.M.A., Amiral, J., Tritschler, H., Ritz, E., Wahl, P., Ziegler, R., Bierhaus, A., Nawroth, P.P. (1999) Peripheral blood mononuclear cells isolated from patients with diabetic nephropathy show increased activation of the oxidative-stress sensitive transcription factor NF-KB. Diabetologia 42, 222-232.

Holschermann, H., Terhalle, H.M., Zakel, U., Maus, U., Parviz, B., Tillmanns, H., Haberbosch, W. (1999) Monocyte tissue factor expression is enhanced in women who smoke and use oral contraceptives. Thromb. Haemost. 82, 1614-1620.

Keating, V.M., Collins, P.D., Scott, D.M., Barnes, P.J. (1999) Differences in interleukin-8 and tumor necrosis factor-induced sputum from patients with chronic obstructive pulmonary disease or asthma. Am. J. Respir. Crit. Care Med. 153, 530-534.

Mikuniya, T., Nagai, S., Tsutsumi, T., Morita, K., Mio, T., Satake, N., Izumi, T. (1999) Proinflammatory or regulatory cytokines released from BALF macrophages of healthy smokers. Respiration 66, 419-426. 
Morrison, D., Rahman, I., Lannan, S., MacNee, W. (1999) Epithelial permeability, inflammation, and oxidant stress in the air spaces of smokers. Am. J. Respir. Crit. Care Med. 159, 473-479.

Morrow, J.D., Frei, B., Longmire, A.W., Gaziano, J.M., Lynch, S.M., Shyr, Y., Strauss, W.E., Oates, J.A., Roberts II, L.J. (1995) Increase in circulating products of lipid peroxidation (F2-isoprostanes) in smokers. N. Engl. J. Med. 332, 1198-1203.

Nishikawa, M., Kakemizu, N., Ito, T., Kudo, M., Kaneko, T., Suzuki, M., Udaka, N., Ikeda, H., Okubo, T. (1999) Superoxide mediates cigarette smoke-induced infiltration of neutrophils into the airways through nuclear factor-kappa B activation and IL-8 mRNA expression in guinea pigs in vivo. Am. J. Respir. Cell Mol. Biol. 20, 189-198.

Pepys M.B. (1995) The acute phase response and C-reactive protein. In: Weatherall D.J., Ledingham J.G.G., Warrel D.A. (Eds.), Oxford textbook of medicine, third edition. Oxford: Oxford University press, p1527-1533.

Pryor, W.A., Stone, K. (1993) Oxidants in cigarette smoke: radicals, hydrogen peroxides, peroxynitrate and peroxynitrite. Ann. N.Y. Acad. Sci. 686, 12-28.

Pyatt, D.W., Stillman, W.S., Irons, R.D. (1998) Hydroquinone, a reactive metabolite of benzene, inhibits NF-kappa B in primary human CD4+ T lymphocytes. Toxicol. Appl. Pharmacol. 149, 178-184.

Rahman, I., MacNee, W. (1996a) Oxidant/antioxidant imbalance in smokers and in chronic obstructive pulmonary disease. Thorax 51, 348-350.

Rahman, I., MacNee, W., (1996b) Role of oxidants/antioxidants in smoking induced lung diseases. Free. Rad. Biol. Med. 21: 669-681.

Rahman, I., MacNee, W. (1998) Role of transcription factors in inflammatory lung diseases. Thorax 53, 601-612.

Rahman, I., MacNee, W. (1999) Lung glutathione and oxidative stress: implications in cigarette smoke-induced airway disease. Am. J. Physiol. Lung Cell Mol. Physiol. 277, L1067-L1088.

Repine, J.E., Bast, A., Lankhorst, I., de Backer, W., Dekhuijzen, R., Demedts, M., van Herwaarden, C., van Klaveren, R., Lammers, J.W., Larsson, S., Lundback, B., Petruzelli, S., Postma, D., Riise, G., Vermeire, P., Wouters, E., Yernault, J.C., van Zandwijk, N. (1997) Oxidative stress in chronic obstructive pulmonary disease. Am. J. Respir. Crit. Care Med. 156, 341-357.

Shen, Y., Rattan, V., Sultana, C., Kalra, V.K. (1996) Cigarette smoke condensate-induced adhesion molecule expression and transendothelial migration of monocytes. Am. J. Physiol. 270, H1624-H1633.

Sen, C.K., Packer, L. (1996) Antioxidants and redox regulation of gene transcription. FASEB J. 10, 709-720.

Smith, C.A.D., Harrison, D.J. (1997) Association between polymorphism in gene for microsomal epoxide hydrolase and susceptibility to emphysema. Lancet 350, 630-633.

Soucek, P., Ivan, G., Pavel, S. (2000) Effect of the microsomal system on interconversions between hydroquinone, benzoquinone, oxygen activation, and lipid peroxidation. Chem. Biol. Interact. 126, 45-61.

Sugano, N., Shimada, K., Ito, K., Murai, S. (1998) Nicotine inhibits the production of inflammatory mediators in U937 cells through modulation of nuclear factor-kappa B activation. Biochem. Biophys. Res. Commun. 252, 25-28.

Turato, G., Di Stefano, A., Maestrelli, P., Mapp, C.E., Ruggieri, M.P., Roggeri, A., Fabbri, L.M., Saetta, M. (1995) Effect of smoking cessation on airway inflammation in chronic bronchitis. Am. J. Respir. Crit. Care Med. 152, 1262-1267. 
Van den Berg, R., Haenen, G.R.M.M., van den Berg, H., Bast, A. (2001) Transcription factor NF- $\kappa$ B as a potential biomarker for oxidative stress. Br. J. Nutr. (in press).

Vayssier, M., Favatier, F., Pinot, F., Bachelet, N., Polla, B.S. (1998) Tobacco smoke induces coordinate activation of HSF and inhibition of NF kappa B in human monocytes: Effects on TNF alpha release. Biochem. Biophys. Res. Commun. 252, 249-256.

Yan, Z., Subbaramaiah, K., Camilli, T., Zhang, F., Tanabe, T., McCaffrey T.A., Dannenberg, A.J., Weksler, B.B. (2000) Benzo[a]pyrene induces transcription of cyclooxygenase-2 in vascular smooth muscle cells. Evidence for the involvement of extracellular signalregulated kinase and NF- $\mathrm{KB}$. J. Biol. Chem. 275, 4949-4955.

Zang, L.Y., Stone, K., Pryor, W.A. (1995) Detection of free radicals in aqueous extracts of cigarette tar by electron spin resonance. Free Rad. Biol. Med. 19, 161-167. 



\section{Chapter 8}

A vegetable/fruit concentrate with high antioxidant capacity has no effect of on biomarkers of antioxidant status in male smokers

Robin van den Berg, Trinette van Vliet, Wendy M.R. Broekmans, Nicole H.P. Cnubben, Wouter H.J. Vaes, Len Roza, Guido R.M.M. Haenen, Aalt Bast and Henk van den Berg 


\section{Abstract}

The potential benefits of a high fruit and vegetable intake on the antioxidant status and on relevant biomarkers of oxidative damage to lipids, proteins and DNA and on (functional) markers of oxidative stress were evaluated. A randomized, free living, open placebo-controlled cross-over trial of $3 \mathrm{wk}$, with a 2-wk wash out period between treatments, was performed in a group of 22 male smokers with a relatively low vegetable and fruit intake using a vegetable burger and fruit drink.

The vegetable burger and fruit drink increased serum levels of vitamin $\mathrm{C}, \alpha$-carotene, $\beta$-carotene, $\beta$-cryptoxanthin and zeaxanthin and plasma total antioxidant capacity. However, no effects were demonstrated on any marker of oxidative damage to lipids (malondialdehyde, $\mathrm{F}_{2}$-isoprostane), proteins (carbonyls) and DNA (Comet assay) and (functional) markers of oxidative stress (reduced/oxidized glutathione ratio, glutathione-S-transferase $\alpha$, glutathione-S-transferase $\pi$, nuclear transcription factor$\kappa B)$. Apparently, these increased levels of antioxidants in serum were not sufficiently high to show beneficial changes with the selected biomarkers. Alternatively, oxidative stress in male smokers with a relatively low fruit and vegetable intake might have been still too low to demonstrate a beneficial effect of antioxidants. 


\section{Introduction}

High consumption of fruit and vegetables has been associated with lower incidence and mortality rates of cancer, as found in several human cohort and case-control studies and for a number of common cancer sites (Block et al. 1992). This is in line with many animal experiments showing that vegetables that are common in human diets have antitumorigenic effects (Bresnick et al. 1990, Wattenberg \& Coccia 1991, Mahmoud et al. 2000).

Protection against cardiovascular disease by a high consumption of fruits and vegetables has also been suggested (Rimm et al. 1996, Gillman et al. 1995). Additional evidence comes from pre-clinical studies, such as in vitro or animal studies (Benzie 1996, review). However, such data are of limited value because of difficulties in extrapolating to the human situation, e.g. due to uncertainties with respect to bioavailability and tissue distribution, or, as in animal models, differences in metabolism and metabolic rate (Halliwell 1996).

The potential health benefits of fruits and vegetables have been attributed to the effects of specific ingredients in fruits and vegetables, such as vitamins, dietary fibre and a wide range of bioactive compounds, such as flavonoids. Antioxidant activity is considered to play an important role in the protective effects of fruits and vegetables (Pool-Zobel et al. 1997a; Porrini \& Riso, 2000; Young et al. 1999; Verhagen et al. 1995; van Poppel \& van den Berg 1997). This is in part based on the increasing evidence that oxidative damage is involved in the pathogenesis of atherosclerosis and in carcinogenesis (Loft \& Poulsen 1996, Baynes \& Thorpe 1999).

The aim of the present study was to evaluate the sensitivity of biomarkers of oxidative damage and (functional) biomarkers of oxidative stress, and the potential to demonstrate beneficial effects with these biomarkers in a potential risk group with a relatively low 'usual' vegetable and fruit consumption using 'natural' products. In this report we describe the results of a cross-over intervention study with antioxidants in a "natural" matrix and other bioactive compounds from fruit and vegetables in a group of male smokers with a relatively low "habitual" fruit and vegetable intake. We used a vegetable burger (VB) with commercially available lyophilized vegetables, containing the equivalent of $\sim 500 \mathrm{~g}$ mixed "fresh" vegetables (tomatoes, carrots, onions, broccoli and red sweet pepper) per daily portion and a fruit drink (FD) prepared from fruit (orange, blueberry, apple, lemon and lime) concentrate. The vegetables and fruits selected for preparation of the test products were considered to be significant sources 
of antioxidants associated with the beneficial health effects, as suggested in observational epidemiological and experimental studies (Hertog et al. 1996, Verhagen et al. 1995, Giovanucci 1999, Broekmans et al. 2000).

The effects of the VB/FD on the antioxidant status (vitamin $\mathrm{C}$ and $\mathrm{E}$, retinol, carotenoids), plasma total antioxidant capacity (TEAC) and selected biomarkers of oxidative damage (malondialdehyde (MDA), $\mathrm{F}_{2}$-isoprostane, protein carbonyls, DNA damage (Comet assay)) and oxidative stress (reduced/oxidized gluathione ratio (GSH/GSSG ratio), glutathione-S-transferases (GST $\alpha$, GST $\pi$ ) were assessed. Activity of the nuclear transcription factor- $\mathrm{KB}$ (NF- $\mathrm{KB}$ ) was determined in peripheral blood mononuclear cells (PBMCs). This factor is involved in carcinogenic and inflammatory processes and under redox control, i.e., activated under conditions of increased cellular oxidative stress (Sen \& Packer 1996) and therefore is considered as an early functional marker of oxidative stress.

\section{Subjects and Methods}

Subjects

The study was performed according to the guidelines for Good Clinical Practice (GCP) of the International Conference on Harmonisation of Technical Requirements for Registration of Pharmaceuticals for Human Use at the Department of Nutritional Physiology of TNO Nutrition and Food Research, Zeist, the Netherlands. The protocol was approved by the local medical ethics committee.

Smoking, male (aged 18-50 year) subjects were recruited from the pool of volunteers of the institute. The protocol was carefully explained to the volunteers and their written informed consent was obtained. Subjects were eligible if they fulfilled the following inclusion criteria: i) apparently healthy as indicated by a general medical questionnaire, physical examination and a "normal" clinical chemical blood profile, ii) currently smoking $\geq 10$ cigarettes/d for $\geq 1$ year and no intention to stop during the study period, iii) a body mass index [BMI; body weight $\left.(\mathrm{kg}) / \mathrm{height}\left(\mathrm{m}^{2}\right)\right] \leq 30$, iv) low use of vegetables, fruits and fruit drinks as assessed by a food frequency questionnaire (subjects with the lowest quantified vegetable/fruit intake were selected), v) moderate alcohol consumption $\leq 28 \mathrm{U} / \mathrm{wk}(1 \mathrm{U}=10 \mathrm{~g}$ alcohol), vi) regular (Dutch) food pattern and vii) no use of vitamin and/or food supplements.

Twenty-four men entered the study. Two subjects withdrew during the first treatment period of the study due to dislike of the test products. One subject withdrew on $\mathrm{d} 1$ and 
was replaced. Therefore data of 21 subjects were available on $\mathrm{d} 1$ and data of 22 subjects were available on $\mathrm{d} 22$ and 57 .

\section{Study design}

The study was designed as a randomized, free living, open placebo-controlled crossover trial. The study consisted of two treatment periods of 3 wk with a 2-wk wash out period between periods. Each subject received test products (VB/FD) and the respective control products (control burgers and control drinks $(C B / C D)$ ) in a randomized order. Subjects were instructed to maintain their usual diet and to use one portion of either test products or control products per day during $3 \mathrm{wk}$ at a selfselected moment but not replacing a meal. Half of the subjects started with the test products for $3 \mathrm{wk}$ and changed over after $2 \mathrm{wk}$ wash-out to the control products; the other half of the subjects did the opposite. Each week, volunteers were supplied with fresh products and instructed to store the products in a refrigerator.

At $d 1,22$ and 57 body weight was assessed with the subject wearing indoor clothing, without shoes, wallet and keys. Systolic and diastolic blood pressure and heart rate were measured oscillometrically in a sitting position and in the right arm after $\geq 5$ minutes rest. Blood samples were collected for analysis of various status, damage and stress variables as described later.

\section{Test products}

A VB was prepared using commercially available lyophilized vegetables, provided by Keizer Waalwijk BV, the Netherlands (lyophilized by Kerry Ingredients BV, the Netherlands) and a FD prepared from fruit juice concentrates (SVZ International, Etten-Leur, the Netherlands).

The VB of $\sim 100 \mathrm{~g}$, contained the equivalent of $\sim 500 \mathrm{~g}$ mixed "fresh" vegetables, consisted of $40 \mathrm{~g}$ mixed freeze-dried vegetables (equivalent to $\sim 85 \mathrm{~g}$ broccoli, $47 \mathrm{~g}$ tomato, $84 \mathrm{~g}$ carrot, $99 \mathrm{~g}$ red sweet pepper and $156 \mathrm{~g}$ onion), mixed with $39.5 \mathrm{~g}$ chicken meat, $5 \mathrm{~g}$ of palm oil carotenoids (in corn oil; Quest International, Maarssen, the Netherlands) and a mix of spices. The detailed composition of the burger is given in Table 1. The fruit drink (FD) of about $330 \mathrm{~mL}$, consisted of a mixture of tap water diluted juice concentrates of orange (30\%), blueberry (30\%), apple (30\%), lemon (5 $\%)$ and lime (5\%). 
The control product was a control burger (CB) of about $100 \mathrm{~g}$, consisted of $70.5 \mathrm{~g}$ chicken-meat, $11 \mathrm{~g}$ of corn-oil and a mix of spices (similar as in test product, Table 1). The $\mathrm{CB}$ had a similar energy content, macro nutrient composition and texture as the VB. The control drink (CD) was a drink of about $330 \mathrm{~mL}$ water and fructose $(0.2 \mathrm{~g} / \mathrm{L})$. The CD had a similar energy content as the FD. The ingredients of the VB and FD were selected for their high antioxidant contents and mixed in a ratio to achieve tasteful products.

\section{Blood samples}

On d 1, 22 and 57 blood samples were collected from fasting subjects, between 0800 and $0930 \mathrm{~h}$. For analysis of vitamins A, E, carotenoid profile, triglycerides, total cholesterol and HDL-cholesterol, blood was collected in tubes containing clot activator (Vacutainer systems, Becton Dickinson, Leiden, the Netherlands) and further prepared on ice under subdued light. Within 30 minutes, the tubes were centrifuged (10 minutes at $2000 \mathrm{~g}$ at $4{ }^{\circ} \mathrm{C}$ ). Serum samples for analysis of vitamins $\mathrm{A}, \mathrm{E}$ and carotenoid profile were stored $<-70^{\circ} \mathrm{C}$ until analysis.

Samples for analysis of triglycerides, total and HDL-cholesterol were stored $<-18{ }^{\circ} \mathrm{C}$ and analysed within 2 months. For analysis of 8-epi-prostaglandin $\mathrm{F}_{2 \alpha}\left(\mathrm{F}_{2}\right.$-isoprostane) blood was collected in tubes containing $3.8 \%$ sodium citrate (Vacutainer systems, Becton Dickinson). Directly after collection, indomethacin (14 $\mu \mathrm{mol} / \mathrm{L})$ and BHT (20 $\mu \mathrm{mol} / \mathrm{L}$ ) were added and the tubes were centrifuged ( 10 minutes at $2000 \mathrm{~g}$ at $4{ }^{\circ} \mathrm{C}$ ). Plasma was removed for analysis of $\mathrm{F}_{2}$-isoprostane, placed on ice and stored $<-70^{\circ} \mathrm{C}$. For all other parameters blood was collected in tubes containing lithium heparin (Vacutainer systems, Becton Dickinson). For analysis of vitamin C, directly after collection $0.5 \mathrm{~mL}$ blood was added to $2.0 \mathrm{~mL}$ metaphosphoric acid $(50 \mathrm{~g} / \mathrm{L}$; J.T. Baker, Deventer, The Netherlands) under continuous vortexing. This mixture was placed on dry-ice, stored $<-70^{\circ} \mathrm{C}$ and analysed within $5 \mathrm{~d}$. For analysis of TEAC, MDA, protein carbonyls and GST $\alpha$, within 15 minutes, blood was centrifuged (10 minutes at $2000 \mathrm{~g}$ at $4^{\circ} \mathrm{C}$ ).

Plasma samples were immediately placed on dry-ice and stored $<-70^{\circ} \mathrm{C}$. For analysis of DNA breakage, NF- $\mathrm{kB}$ activity and GST $\pi$, immediately after blood collection, PBMCs were isolated. Heparinized blood was transferred into Leucosep tubes containing Ficoll Paque and diluted with a balanced salt solution. 
Table 1. Composition of the test products

\begin{tabular}{|c|c|c|}
\hline \multirow[t]{3}{*}{ Ingredient } & \multicolumn{2}{|c|}{ Dosage } \\
\hline & $\begin{array}{c}\text { Vegetable } \\
\text { burger }\end{array}$ & $\begin{array}{l}\text { Control } \\
\text { burger }\end{array}$ \\
\hline & \multicolumn{2}{|c|}{$\mathrm{g} / 100 \mathrm{~g}$} \\
\hline Blanched broccoli, freeze dried & 9.3 & - \\
\hline Red sweet pepper, freeze dried & 8.4 & - \\
\hline Tomatoes, freeze dried & 2.8 & - \\
\hline Onions, freeze dried & 12.1 & - \\
\hline Blanched carrots, freeze dried & 7.4 & - \\
\hline Chicken breast & 39.5 & 70.5 \\
\hline Corn oil & - & 11 \\
\hline Corn oil + palm oil carotenoids ${ }^{1}$ & 5 & - \\
\hline Native potato starch & 2.8 & 5.8 \\
\hline White pepper & 0.3 & 0.3 \\
\hline Corn & 0.1 & 0.1 \\
\hline Lavas & 0.3 & 0.3 \\
\hline Phosphate (E450) & 0.3 & 0.3 \\
\hline Chicken tea & 0.7 & 0.7 \\
\hline Salt $(\mathrm{NaCl})$ & 1 & 1 \\
\hline \multirow[t]{2}{*}{ Water } & 10 & 10 \\
\hline & Fruit drink & Control drink \\
\hline Cloudy orange juice concentrate & 30 & $\cdot$ \\
\hline Clarified apple juice concentrate & 30 & - \\
\hline Clarified blueberry juice concentrate & 30 & - \\
\hline Cloudy lemon juice concentrate & 5 & - \\
\hline Cloudy lime juice concentrate & 5 & - \\
\hline Tartrazine (E 102) & - & 0.04 \\
\hline Sunset yellow (E110) & - & 0.02 \\
\hline Tap water & to $330 \mathrm{~mL}$ & $\overline{-}$ \\
\hline Tap water + fructose $(0.2 \mathrm{~g} / \mathrm{L})$ & - & to $330 \mathrm{~mL}$ \\
\hline
\end{tabular}

${ }^{\prime} 30 \%$ suspension in corn oil of natural carotene crystals which have been extracted and purified from the fruit of the oil palm, suspension contains predominantly $\alpha$ and $\beta$-carotene. 
Samples were centrifuged $\left(30 \mathrm{~min}\right.$. at $800 \mathrm{~g}$ and $4{ }^{\circ} \mathrm{C}$ ) and subsequently PBMCs were collected, washed two times and divided over the aliquots needed. Cell concentrations were determined and samples were directly used for analysis of GST $\pi$ and for isolation of nuclear proteins (NF- $\mathrm{kB}$ ) or stored $<-70{ }^{\circ} \mathrm{C}$ for analysis of DNA breakage. For analysis of GSH/GSSG ratio, blood was placed on ice, centrifuged ( 5 minutes at $5000 \mathrm{~g}$ ) and immediately used for determination of GSH/GSSG in erythrocytes. The resulting erythrocytes were washed and to $450 \mu$ lerythrocytes $1 \mathrm{~mL}$ $10 \mathrm{mmol} / \mathrm{L} \mathrm{HCl}+6.5 \% 5$-sulfosalicyl acid (SSA) was added, mixed and put on ice for 10 minutes. Samples were centrifuged $\left(15\right.$ minutes at $2000 \mathrm{~g}$ at $\left.4{ }^{\circ} \mathrm{C}\right)$ and the supernatant was rapidly frozen on dry-ice and stored $<-70^{\circ} \mathrm{C}$.

\section{Biochemical and chemical analysis}

Characterization of products

All study products (VB/FD and $\mathrm{CB} / \mathrm{CD}$ ) were characterized by chemical analysis of macronutrient composition and antioxidant contents. Protein, carbohydrate and total fat concentrations were analysed using standard methodology and energy values were calculated based on the results of macronutrient composition.

The antioxidant content was established by analyses of vitamin $\mathrm{C}$, total vitamin $\mathrm{E}$ (only burgers) and carotenoid concentrations. For vitamin $\mathrm{C}$ analyses, VB and $\mathrm{CB}$ were first extracted with trichloroacetic acid and FD and $\mathrm{CD}$ were deproteinated with metaphosphoric acid followed by filtration, oxidation to dehydro-L-ascorbic acid and condensation according to a method reported by Speek et al. (1984).

Total vitamin $\mathrm{E}$ and carotenoid profile were analysed after saponification with $\mathrm{KOH}$ followed by extraction with diisopropylether and HPLC with fluorometric detection for vitamin E (Speek et al. 1985) and spectrophotometric detection for carotenoids (van Vliet et al. 1991). The results of the macronutrient composition (protein, carbohydrate and fat), carotenoid profile (lutein, zeaxanthin, $\beta$-cryptoxanthin, lycopene, $\alpha$-carotene and $\beta$-carotene), vitamin $E$ and vitamin $C$ concentrations of the burgers and drinks (except for vitamin E) are summarised in Table 2.

In addition flavonoid analysis was performed using HPLC equipped with photodiode array detection according to a method described by Hertog et al. (1992). Briefly, before extraction, VB and CD were ground under nitrogen followed by lyophilization. Subsequently, the flavonoids were extracted and the extract was filtered. The filtrate was transferred onto a preconditioned SPE C18 cartridge and quantitatively eluted 
from the column. The eluate, containing the glycosylated flavonoids, and the drinks (FD, CD) was acidified with concentrated $\mathrm{HCl}$, and hydrolyzed for $2 \mathrm{~h}$ at an elevated temperature. Deglycosylated flavonoids were analyzed using an Alliance $2690 \mathrm{HPLC}$ system, equipped with a Hypersil BDS column $(4.6 \times 250 \mathrm{~mm})$ and photodiode array detection. Compounds were quantified at compound-specific absorption maxima.

The in vitro antioxidant capacity was measured as the Trolox equivalent antioxidant capacity (TEAC) as described by van den Berg et al. (1999). Briefly, VB and CB were extracted with $70 \%$ methanol. Samples of $\mathrm{VB} / \mathrm{CB}$ or $\mathrm{FD} / \mathrm{CD}$ were added to an $2,2^{\prime}-$ azinobis-(3-ethylbenzthiazoline-6-sulphonate) radical solution and the decrease in radical concentration was monitored spectrophotometrically.

\section{Blood lipids and antioxidant measurements}

Serum lipids and serum triglycerides were analysed by enzymatic hydrolysis with subsequent enzymatic determination of the liberated glycerol by colourimetry (Boehringer, Mannheim, Germany). Total cholesterol was analysed by enzymatic conversion to a stable chromogen, which can easily be detected with colourimetry (Boehringer). HDL cholesterol was analysed by precipitation with polyethylene glycol, centrifugation and enzymatic detection by colourimetry (Boehringer), and LDL-cholesterol was calculated using the Friedewald formula (Friedewald et al. 1972).

Total antioxidant capacity as measured by the TEAC was determined according to the method described by van den Berg et al. (1999). Briefly, plasma samples were deproteinized by adding an equal volume of $10 \%$ trichloroacetic acid. After centrifugation the supernatant was added to an 2,2'-azinobis-(3-ethylbenzthiazoline-6sulphonate) radical solution. The decrease in radical concentration was monitored spectrophotometrically and related to the decrease obtained with Trolox.

Serum vitamin $A, E$ and carotenoid concentrations were quantified by reversed phase HPLC using a modified version of a method described previously (van Vliet et al. 1991). Tocopherols were quantified by fluorometric detection and vitamin $\mathrm{A}$ and carotenoid profile were quantified with diode array detection.

Vitamin C in deproteinized blood was analysed by an HPLC method with fluorometric detection (Speek et al. 1984). 
Table 2. Characterization of test products (per $100 \mathrm{~g}$ for the burgers and per $330 \mathrm{~mL}$ for the drinks) ${ }^{1}$

\begin{tabular}{|c|c|c|c|c|}
\hline & $\begin{array}{c}\text { Vegetable } \\
\text { burger }\end{array}$ & $\begin{array}{l}\begin{array}{l}\text { Control } \\
\text { burger }\end{array} \\
\end{array}$ & $\begin{array}{l}\text { Fruit } \\
\text { drink }\end{array}$ & $\begin{array}{c}\text { Control } \\
\text { drink }\end{array}$ \\
\hline Protein $(g)$ & 16.1 & 18.0 & 1.2 & 0.02 \\
\hline Carbohydrate (g) & 15.9 & 5.5 & 33.3 & 30.9 \\
\hline Fat $(\mathrm{g})$ & 6.7 & 11.8 & $<0.2$ & $<0.2$ \\
\hline Energy $(\mathrm{kJ})^{2}$ & 790 & 840 & 580 & 520 \\
\hline Vitamin C (mg) & 118 & 0.8 & 52.5 & 0.03 \\
\hline \multicolumn{5}{|l|}{ Carotenoids } \\
\hline Lutein (mg) & 0.85 & 0.1 & $<0.03$ & $<0.03$ \\
\hline Zeaxanthin (mg) & 2.1 & $<0.01$ & $<0.03$ & $<0.03$ \\
\hline$\beta$-Cryptoxanthin (mg) & 0.89 & $<0.01$ & 0.07 & $<0.03$ \\
\hline Lycopene (mg) & 1.3 & $<0.01$ & $<0.03$ & $<0.03$ \\
\hline$\alpha$-Carotene (mg) & 4.0 & $<0.01$ & $<0.03$ & $<0.03$ \\
\hline$\beta$-Carotene (mg) & 9.0 & 0.02 & $<0.03$ & $<0.03$ \\
\hline \multicolumn{5}{|l|}{ Vitamin E } \\
\hline$\alpha$-Tocopherol (mg) & 7.6 & 2.2 & n.a & n.a. \\
\hline$\beta$-Tocopherol (mg) & 0.21 & $<0.1$ & n.a. & n.a. \\
\hline$\gamma$-Tocopherol (mg) & 4.6 & 8.2 & n.a. & n.a. \\
\hline$\delta$-Tocopherol (mg) & 0.35 & 0.49 & n.a. & n.a. \\
\hline \multicolumn{5}{|l|}{ Flavonoids } \\
\hline Myricitin (mg) & n.d. & n.d. & 4.62 & n.d. \\
\hline Quercetin (mg) & 24.43 & 2.48 & 34.68 & n.d. \\
\hline Naringenin (mg) & 0.19 & n.d. & 3.83 & n.d. \\
\hline Luteolin (mg) & 0.66 & n.d. & 0.13 & n.d. \\
\hline Hesperitin (mg) & n.d. & 0.25 & 10.20 & n.d. \\
\hline Kaempherol (mg) & 2.28 & n.d. & 1.12 & n.d. \\
\hline Apigenin (mg) & 0.28 & n.d. & 0.59 & n.d. \\
\hline Isorhamnetin (mg) & 0.63 & n.d. & 1.85 & n.d. \\
\hline Total flavonoids $(\mathrm{mg})^{3}$ & 28.5 & 2.7 & 57.0 & 0 \\
\hline TEAC (mmol TE) & 3.3 & 0.5 & 5.6 & $<0.03$ \\
\hline
\end{tabular}

'Mean of duplicate analysis. ${ }^{2}$ Calculated based on the macronutrient composition as analysed.

${ }^{3}$ Sum of all flavonoids measured; n.a. $=$ Not analysed; n.d. $=$ Not detected. 
Vitamin $\mathrm{C}$ was oxidized to dehydroascorbic acid and subsequently condensated with 1,2-diaminobenzene to quinoxaline, which was detected.

\section{Lipid, protein and DNA oxidative damage}

MDA was determined in plasma by derivatization of MDA with thiobarbituric acid and quantified by HPLC separation with a fluorometric detector according to a method described by Fukunaga et al. (1998). Plasma 8-epi-prostaglandin $F_{2 \alpha}$ was measured according to a method described by Nourooz-Zadeh et al. (1995) with some modifications. This method involves solid-phase extraction and conversion to pentafluorobenzyl ester and trimethylsilyl ether derivatives. 8-Epi-prostaglandin $F_{2 \alpha}$ was quantified using negative-ion chemical ionization high resolution mass spectrometry. Plasma protein carbonyl content was quantified by the reaction with 2,4dinitrophenylhydrazine, as previously described by Buss et al. (1997), using an enzyme-linked immunosorbent assay.

DNA oxidative damage, measured as the Comet assay, was conducted as described by Collins et al. (1993). The DNA strand breaks were analysed in untreated, $\mathrm{H}_{2} \mathrm{O}_{2}$-treated (to monitor resistance of the cells to oxidative stress) and endonuclease III-treated (to detect levels of oxidized pyrimidine bases) isolated human PBMCs. Comets were analysed quantitatively (100 cells per samples) using image analysis software (Comet Assay II; Perceptive Instruments, Suffolk, U.K.). The tail moments were converted to visual scoring system (Collins score) from class 0 (no damage) to class 4 (almost all DNA in tail).

\section{Markers of oxidative stress}

The GSH/GSSG ratio was determined in erythrocytes according to the method described by Baker et al. (1990) using the enzymatic DTNB-reductase recycling method. Reduced glutathione (GSH) is oxidized by DTNB leading to the formation of oxidized glutathione (GSSG) and TNB (5-thio-2-nitrobenzoic acid). The formation of TNB was measured at $405 \mathrm{~nm}$. GSSG was determined after derivatization of GSH with 2-vinylpyridine.

GST $\alpha$ enzyme activity in plasma was analysed using the Biotrin HEPKIT-Alpha kit (Biotrin International, Dublin, Ireland) for quantitative determination of GST $\alpha$ and GST $\pi$ in PBMCs was analysed using the Biotrin HEPKIT-Pi kit (Biotrin International) for quantitative determination of GST $\pi$. 
NF- $\mathrm{kB}$ activity in PBMCs was analysed according to method described by van den Berg et al. (2001a) as a 'functional' marker of oxidative stress. The electromobility shift assay (EMSA) with phosphor imaging was used to detect NF-кB. For the quantification of NF- $\mathrm{kB}$ activity, a commercially obtained HeLa nuclear (protein) extract (Promega Benelux, Leiden, The Netherlands) was used as a standard on each gel. NF- $\mathrm{kB}$ activity was expressed as HeLa equivalents / $10 \mu \mathrm{g}$ protein.

\section{Statistical analysis}

Data were analysed using the SAS statistical software package (SAS/STAT Version 6; SAS Institute, Cary, NC). All data are expressed as means \pm SD. Effects of consumption of vegetable and fruit concentrates on variables measured were tested by analysis of variance using the General Linear Model procedure. Only the 22 subjects with results for both treatments were included in the analysis. Results are based on those 22, unless indicted otherwise in the tables. Diffenrences were considered significant at 0.05 .

\section{Results \\ Volunteers}

The 22 men which entered the study were $33 \pm 11$ y old (range, 19-49 y); had a BMI of $23.6 \pm 3.0 \mathrm{~kg} / \mathrm{m}^{2}$ (range, $19.1-28.5 \mathrm{~kg} / \mathrm{m}^{2}$ ), and smoked $18 \pm 7$ cigarettes $/ \mathrm{d}$ (range, 10-40 cigarettes/d). The vegetable and fruit intake of the men, as assessed by a food frequency questionnaire, was estimated to be $167 \mathrm{~g} / \mathrm{d}$, which is around the $50^{\text {th }}$ percentile of the Dutch male population (174 g/d) (Hulshof et al. 1998). The test products were well tolerated by the subjects and compliance to the study protocol was good ( $>98 \%$ of all study products were used), as judged from the reported product consumption and the return of the remaining products. Subjects smoking habits were the same for both treatment periods, as judged by the returned question forms. None of the subjects had to be excluded due to illness.

Body weight, blood pressure, heart rate and serum lipid concentrations were not affected by the treatments (Table 3 ). 
Table 3. Baseline levels and effect after 3 weeks treatment with a vegetable burger and fruit drink (VB/FD) or a control burger and control drink (CB/CD) on body weight, blood pressure and lipid profile in 22 male smokers ${ }^{1}$

\begin{tabular}{|c|c|c|c|c|c|c|c|}
\hline \multirow{2}{*}{$\begin{array}{l}\text { Variable } \\
\text { Body weight, kg }\end{array}$} & \multicolumn{2}{|c|}{$\begin{array}{c}\text { Baseline } \\
(n=21)\end{array}$} & \multicolumn{2}{|c|}{$\begin{array}{c}\text { VB/FD treatment } \\
(n=22)\end{array}$} & \multicolumn{2}{|c|}{$\begin{array}{c}\text { CB/CD treatment } \\
(n=22)\end{array}$} & \multirow{2}{*}{$\frac{\text { p-value }}{\mathrm{ks}}$} \\
\hline & $78.7 \pm 11.3$ & $(59.4-99.9)$ & $78.6 \pm 11.5$ & $(58.5-101.5)$ & $78.5 \pm 11.6$ & $(59.7-102.2)$ & \\
\hline Systolic blood pressure, $\mathrm{mm} \mathrm{Hg}$ & $129 \pm 14$ & $(109-171)$ & $123 \pm 18$ & $(97-176)$ & $122 \pm 17$ & $(101-180)$ & ns \\
\hline Diastolic blood pressure, $\mathrm{mm} \mathrm{Hg}$ & $78 \pm 9$ & $(61-104)$ & $77 \pm 12$ & $(61-112)$ & $74 \pm 11$ & $(58-108)$ & Ns \\
\hline Heart rate, beats/min & $70 \pm 10$ & $(52-91)$ & $75 \pm 12$ & $(54-99)$ & $74 \pm 11$ & $(56-96)$ & ss \\
\hline Total cholesterol, $\mathrm{mmol} / \mathrm{L}$ & $5.52 \pm 0.96$ & $(3.31-7.22)$ & $5.39 \pm 1.08$ & $(3.43-7.61)$ & $5.27 \pm 0.99$ & $(3.46-7.51)$ & Ns \\
\hline LDL-cholesterol, mmol/L & $3.49 \pm 0.82$ & $(1.73-5.28)$ & $3.38 \pm 0.98$ & $(1.77-5.17)$ & $3.27 \pm 0.85$ & $(1.92-5.10)$ & NS \\
\hline HDL-cholesterol, $\mathrm{mmol} / \mathrm{L}$ & $1.38 \pm 0.22$ & $(1.09-1.84)$ & $1.37 \pm 0.28$ & $(0.89-1.91)$ & $1.42 \pm 0.27$ & $(0.99-2.06)$ & ns \\
\hline Triglycerides, $\mathrm{mmol} / \mathrm{L}$ & $1.55 \pm 0.82$ & $(0.64-4.59)$ & $1.52 \pm 0.81$ & $(0.52-3.53)$ & $1.36 \pm 0.81$ & $(0.67-4.29)$ & ns \\
\hline
\end{tabular}

'Values are means \pm SD (range); NS, not significant $(p>0.05)$.

\section{Study parameters}

\section{Antioxidant status}

Serum vitamin $C$ level was significantly increased $(p<0.0001)$ after the VB/FD treatment compared with the CB/CD treatment (Table 4). Serum levels of $\alpha$-carotene, $\beta$-carotene, $\beta$-cryptoxanthin and zeaxanthin were also significantly higher $(p<0.0001)$ after the VB/FD treatment, whereas serum lycopene and lutein levels did not differ between treatment periods (Table 4). Plasma TEAC was significantly increased after consumption of the VB and FD compared with the control products (Table 4). Serum retinol and tocopherol concentrations were not affected by the VB/FD treatment (Table 4).

\section{Lipid, protein and DNA oxidative damage}

Plasma MDA, protein carbonyls and 8-epi-PGF 2 levels were not affected by the type of treatment (Table 5). DNA breakage (in PBMC), expressed as Collins scores (blank and respectively $\mathrm{H}_{2} \mathrm{O}_{2}$ and endonuclease-III treated) also did not differ due to the treatments (Table 5).

\section{Markers of oxidative stress}

Baseline levels and the effect of treatment on GST $\alpha$ and GST $\pi$, GSH, GSSG, the GSH/GSSG ratio and NF-kB activity (in PBMC) are summarized in Table 6. GST $\alpha$ activity did not differ between treatments, but GST $\pi$ activity was slightly, but significantly, lower at the end of the vegetable treatment period compared with the end 
of the control treatment $(p=0.048)$. Erythrocyte levels of GSH and oxidized GSSG, respectively the GSH/GSSG ratio were not affected by the type of treatment. The NF$\kappa \mathrm{B}$ activity, expressed as HeLa equivalents/10 $\mu \mathrm{g}$ protein also was not affected by the type of treatment.

Table 4. Baseline levels and effect after 3 weeks treatment with a vegetable burger and fruit drink (VB/FD) or a control burger and control drink (CB/CD) on antioxidant status parameters in 22 male smokers ${ }^{\prime}$

\begin{tabular}{|c|c|c|c|c|c|c|c|}
\hline \multirow{2}{*}{$\begin{array}{l}\text { Variable } \\
\text { TEAC }(p), \mu \mathrm{mol} T E / L\end{array}$} & \multicolumn{2}{|c|}{$\begin{array}{l}\text { Baseline } \\
(n=21)\end{array}$} & \multicolumn{2}{|c|}{$\begin{array}{c}\text { VB/FD treatment } \\
(\mathrm{n}=22)\end{array}$} & \multicolumn{2}{|c|}{$\begin{array}{c}\text { CB/CD treatment } \\
(\mathrm{n}=22)\end{array}$} & \multirow{2}{*}{$\begin{array}{l}\begin{array}{l}\text { p-value } \\
\text { VB/FD vs } \\
\text { CB/CD }\end{array} \\
0.0014\end{array}$} \\
\hline & $524 \pm 48$ & $(418-598)$ & $562 \pm 47$ & $(478-642)$ & $538 \pm 49$ & $(436-604)$ & \\
\hline Vita & 6.2 & 8 & 7.4 & 12 & $37.6 \pm 15.0$ & $(15.0-70.6)$ & $<0.0001$ \\
\hline Retinol ( & $2 \pm 0.4$ & $(1.7-3.1)$ & $2.2 \pm 0.4$ & $(1.7-3.2)$ & $2.2 \pm 0.4$ & $(1.5-3.1)$ & NS \\
\hline$\alpha$-Carotene & \pm 0.06 & 8 & $0.31 \pm 0.20$ & $.71)$ & $0.08 \pm 0.08$ & $0.02-0.37)$ & $<0.0001$ \\
\hline$\beta$-Car & $0.30 \pm 0.25$ & $(0.10-1.05)$ & $0.67 \pm 0.43$ & $(0.16-1.58)$ & $0.29 \pm 0.23$ & 20) & $<0.0001$ \\
\hline Lycopene (s & $0.41 \pm 0.19$ & $(0.06-0.76)$ & $0.37 \pm 0.16$ & $(0.08-0.72)$ & $0.40 \pm 0.22$ & $(0.13-0.88)$ & NS \\
\hline Lute & $0.15 \pm 0.07$ & $(0.08$ & 0 & (0. & 0.1 & (as & NS \\
\hline Cryptoxanthin (s), $\mu \mathrm{mol} / \mathrm{L}$ & $0.16 \pm 0.08$ & $(0.05-0.35)$ & $0.26 \pm 0.12$ & $(0.10-0.51)$ & $0.15 \pm 0.08$ & $(0.05-0.39)$ & $<0.0001$ \\
\hline Zeaxa & $0.05 \pm 0.02$ & $(0.02-0.11)$ & $0.08 \pm 0.03$ & $(0.05$ & $0.04 \pm 0.01$ & $(0.02-0.08)$ & $<0.0001$ \\
\hline$\alpha$-Tocopherol (s), $\mu \mathrm{mol} / \mathrm{L}$ & $26.2 \pm 5.6$ & $(16.6-40.1)$ & $26.3 \pm 5.5$ & $(17.0-34.4)$ & $25.7 \pm 6.5$ & $(16.4-38.7)$ & N \\
\hline$\beta$-Tocopherol (s), $\mu \mathrm{mol} / \mathrm{L}$ & $0.58 \pm 0.20$ & $(0.28-1.21)$ & $0.56 \pm 0.18$ & $(0.27-0.95)$ & $0.54 \pm 0.18$ & $(0.32-1.13)$ & NS \\
\hline$\gamma$-Tocopherol (s), $\mu \mathrm{mol} / \mathrm{L}$ & $=0.08$ & $(0.04$ & 0.09 & $(0.0$ & 0.1 & $(0$. & Ns \\
\hline$\delta$-Tocopherol (s), $\mu \mathrm{mol} / \mathrm{L}$ & $2.67 \pm 1.54$ & $(1,00-6.43)$ & $3.13 \pm 1.29$ & $(1.38-6.56)$ & $3.29 \pm 1.05$ & $(1.71-6.30)$ & NS \\
\hline
\end{tabular}

${ }^{1}$ Values are means of duplicate analysis \pm SD (range); $s$, serum; $p$, plasma; NS, not significant $(p>0.05)$.

Table 5. Baseline levels and effect after 3 weeks treatment with a vegetable burger and fruit drink (VB/FD) or a control burger and control drink $(\mathrm{CB} / \mathrm{CD})$ on oxidative lipid, protein and DNA damage in 22 male smokers '

\begin{tabular}{|c|c|c|c|c|c|c|c|c|}
\hline \multicolumn{2}{|l|}{ Variable } & \multicolumn{2}{|c|}{$\begin{array}{c}\text { Baseline } \\
(n=21)\end{array}$} & \multicolumn{2}{|c|}{$\begin{array}{c}\text { VB/FD treatment } \\
(n=22)\end{array}$} & \multicolumn{2}{|c|}{$\begin{array}{c}\text { CB/CD treatment } \\
(\mathrm{n}=22)\end{array}$} & \multirow{2}{*}{\begin{tabular}{|l} 
p-value \\
VB/FD vs \\
CB/CD \\
NS
\end{tabular}} \\
\hline \multicolumn{2}{|c|}{$\mathrm{MDA}(\mathrm{p}), \mu \mathrm{mol} / \mathrm{L}$} & $0.47 \pm 0.15$ & $(0.23-1.00)$ & $0.43 \pm 0.14$ & $(0.28-0.77)$ & $0.43 \pm 0.14$ & $(0.28-0.92)$ & \\
\hline \multicolumn{2}{|c|}{ 8-Epi-PGF $2 a$ (p), ng/L } & $22.5 \pm 7.5$ & (11.5-39.1) & $21.7 \pm 6.9$ & $(13.1-36.9)$ & $22.1 \pm 6.9$ & $(12.1-36.0)$ & ns \\
\hline \multicolumn{2}{|c|}{ Carbonyls (p), nmol/mg protein } & $0.29 \pm 0.03$ & $(0.26-0.37)$ & $0.30 \pm 0.03$ & $(0.24-0.40)$ & $0.30 \pm 0.03$ & $(0.24-0.34)$ & NS \\
\hline Comet & Blanc, Collins ${ }^{2}$ & $89 \pm 30$ & $(36-145)$ & $68 \pm 14$ & $(47-92)$ & $71 \pm 18$ & $(32-102)$ & NS \\
\hline \multirow[t]{2}{*}{ (PBMCs) } & $\mathrm{H}_{2} \mathrm{O}_{2}$, Collins ${ }^{2}$ & $125 \pm 35$ & $(76-206)$ & $136 \pm 30$ & $(74-176)$ & $133 \pm 27$ & $(92-170)$ & NS \\
\hline & ENDO, Collins ${ }^{2}$ & $298 \pm 32$ & $(250-381)$ & $281 \pm 37$ & $(199-339)$ & $283 \pm 22$ & $(241-310)$ & Ns \\
\hline
\end{tabular}

\footnotetext{
'Values are means \pm SD (range).

${ }^{2}$ Collins score (Collins et al.1993); p, plasma; PBMCs, peripheral blood mononuclear cells; NS, not significant $(p>0.05)$.
} 
Table 6. Baseline levels and effect after 3 weeks treatment with a vegetable burger and fruit drink (VB/FD) or a control burger and control drink (CB/CD) on (functional) markers of oxidative stress in 22 male smokers ' .

\begin{tabular}{|c|c|c|c|c|c|c|c|}
\hline \multirow{2}{*}{$\begin{array}{l}\text { Variable } \\
\text { NF-kB (PBMCs), HeLa } \\
\text { equivalents / } 10 \text { \%g protein }\end{array}$} & \multicolumn{2}{|c|}{$\begin{array}{c}\text { Baseline } \\
(n=21)\end{array}$} & \multicolumn{2}{|c|}{$\begin{array}{c}\text { VB/FD treatment } \\
(n=22)\end{array}$} & \multicolumn{2}{|c|}{$\begin{array}{c}\mathrm{CB} / \mathrm{CD} \text { treatment } \\
(\mathrm{n}=22)\end{array}$} & \multirow{2}{*}{$\frac{\text { p-value }}{\text { NS }}$} \\
\hline & $8.8 \pm 3.3$ & $(5.6-18.4)$ & $10.5 \pm 4.3$ & $(2.6-18.6)$ & $11.0 \pm 4.6$ & $(4.6-23.3)$ & \\
\hline GSH/GSSG ratio & $2.9 \pm 0.6$ & $(1.9-4.1)$ & $2.8 \pm 0.8$ & $(1.6-5.0)$ & $2.7 \pm 0.7$ & $(1.5-4.3)$ & NS \\
\hline $\mathrm{GSH}(\mathrm{e}), \mu \mathrm{mol} / \mathrm{L}$ & $805 \pm 207$ & $(478-1230)$ & $733 \pm 197$ & $(489-1248)$ & $727 \pm 189$ & $(328-1055)$ & Ns \\
\hline GSSG (e), $\mu \mathrm{mol} / \mathrm{L}$ & $282 \pm 78$ & $(142-453)$ & $272 \pm 55$ & $(168-409)$ & $270 \pm 56$ & $(185-378)$ & Ns \\
\hline GST- $\alpha(p), n g / m L$ & $4.6 \pm 2.9$ & $(1.0-10.2)$ & $4.5 \pm 3.2$ & $(1.2-11.0)$ & $4.8 \pm 3.2$ & $(1.0-12.3)$ & NS \\
\hline GST $-\pi, n g / 10^{6}$ PBMCs $^{2}$ & $3.9 \pm 1.0$ & $(1.9-5.6)$ & $4.5 \pm 1.4^{3}$ & $(1.8-6.7)$ & $5.2 \pm 1.8$ & $(2.0-9.1)$ & 0.0480 \\
\hline
\end{tabular}

${ }^{1}$ Values are means \pm SD (range)

${ }^{2}$ Values given have to be multiplied by $10^{2}$

${ }^{3} \mathrm{n}=21$; $\mathrm{p}$, plasma; $\mathrm{c}$, erythrocytes; PBMCs, peripheral blood mononuclear cells; NS, not significant $(p>0.05)$.

\section{Discussion}

Observational epidemiological studies have consistently shown that a diet rich in fruit and vegetables is associated with a lower risk of specific cancers and of cardiovascular disease (Block 1992, Rimm et al. 1996). Oxidative stress and oxidative damage are considered to play a role in the early stages of the pathophysiological processes of both diseases. Many studies have already explored the potential of selected nutrients and bioactive compounds, present in fruit and vegetables on a range of biomarkers of (in vitro) oxidative stress and/or oxidative damage. Significant and possibly relevant effects have been reported, especially for the antioxidant vitamins C (Carr \& Frei 1999 review), and $E$ (Bramley et al. 2000 review), and $\beta$-carotene (van den Berg et al. 2000 review). However, there is a discrepancy between the outcome of the observational and experimental studies and the few controlled intervention studies investigating the effect of high dose supplementation on cancer or cardiovascular disease mortality and morbidity, reported so far. This discrepancy may partly be explained by the fact that in the intervention studies synthetic (pure) compounds were given in relatively high dosages compared with the level present in natural food. Moreover, other compounds in the food matrix may have a health beneficial effect, not necessarily associated with an antioxidant action. One complicating factor in interpretation of the (experimental) studies is our lack of knowledge with respect to the critical pathophysiological processes and the consequent questions with respect to validity and relevance of the various biomarkers used. 
The aim of this study was to evaluate the sensitivity of a number of biomarkers of oxidative damage and (functional) biomarkers of oxidative stress and to demonstrate beneficial effects with these biomarkers, in a potential risk group of smoking males with a relatively low habitual fruit and vegetable consumption, by increasing their intake of natural antioxidants and of other bioactive compounds from fruit and vegetables.

From the results as summarized in Table 5 and 6 it is, however, clear that no effect on markers of oxidative lipid, protein, DNA damage and functional markers of oxidative stress could be demonstrated after a treatment period of 3 weeks with these test products.

To account for these findings and apparent discrepancies with reported studies, the following items are discussed: i) the additional antioxidant dose achieved by the test products in relation to the anticipated response and ii) the study design, i.e. "suitability" of the study population and "power" of the study.

Antioxidant dose achieved by the test products in relation to the anticipated response (antioxidant status)

Analysis of the VB/FD, summarized in Table 2, showed that these products indeed contained substantial amounts of antioxidants and had a high potential antioxidant activity (TEAC). The high TEAC of the VB and the FD is largely explained by the high vitamin $\mathrm{C}$ content (118 $\mathrm{mg}$ in the $\mathrm{VB}$ and $53 \mathrm{mg}$ in the FD) and the contribution from other natural antioxidants, such as flavonoids. Consumption of these products did indeed result in an increase in the serum levels of vitamin $C, \alpha$-carotene, $\beta$-carotene, $\beta$-cryptoxanthin, and zeaxanthin, respectively, as well as in an increased total plasma antioxidant capacity, measured as the TEAC (Table 4). The main contribution to the product TEAC comes from vitamin $\mathrm{C}$ and the flavonoids, wheraes carotenoids do not, or only minimally contribute (van den Berg et al. 1999). The total flavonoid content measured in the product was $\sim 28 \mathrm{mg}$ for the $\mathrm{VB}$ and $\sim 57 \mathrm{mg}$ in the FD, and $\sim 20-30 \%$ of the TEAC might be explained by the flavonoids and other bioactive compounds with antioxidant capacity present. An uncertain factor is the bioavailability and postprandial metabolism of flavonoids contained in the products. As far as data are available, it seems that bioavailability of flavonoids is generally low (Hollman 1997). Plasma flavonoid levels were not determined, but the increase in plasma TEAC might in part explained by these compounds (or metabolites). 
The additional amount of vitamin $\mathrm{E}$ provided by the VB was $\sim 8.2 \mathrm{mg} \alpha$-tocopherol equivalents ( $\alpha$-TE) and $\sim 3.0 \mathrm{mg} \alpha$-TE for the CB. According to Traber and Sies (1996) a daily dietary intake of $\sim 15-30 \mathrm{mg} \alpha$-tocopherol would be needed to reach an "optimal" plasma $\alpha$-tocopherol level above $30 \mu \mathrm{mol} / \mathrm{L}$, associated with lower cardiovascular and cancer risk. We have no data on the actual total dietary vitamin $\mathrm{E}$ intake in our subjects, but serum $\alpha$-tocopherol levels were slightly below $30 \mu \mathrm{mol} / \mathrm{L}$. Observational epidemiological and intervention studies indicate that the major effect (if any) of vitamin $\mathrm{E}$ supply are found only with a daily intake higher than $74 \mathrm{mg} \alpha$-TE (see Bramley et al. 2000 for review). Therefore, the amount used in the present study apparently was not sufficient to increase the serum tocopherol level, and/or to affect parameters of oxidative damage and stress.

The carotenoid content of the VB was at least $50-70 \%$ lower as expected from the contents in the equivalent "fresh" vegetables. Lycopene content was $1.3 \mathrm{mg}$, whereas $\sim 3 \mathrm{mg}$ was expected on the basis of $\sim 47 \mathrm{~g}$ "fresh" tomatoes. For lutein, the expected content was $\sim 3 \mathrm{mg}$, but only $0.85 \mathrm{mg}$ was detected. Apparently, losses have occurred in production of the VB, which included blanching and freeze-drying (van den Berg et al. 2000).

The lowest lycopene intake reported to increase plasma lycopene levels is $3.3 \mathrm{mg}$ in heat processed vegetable juice given for 15 days (Yeum et al. 1996). In other studies, using tomato products, higher amounts were achieved, such as $40 \mathrm{mg} / \mathrm{d}$ (Pool-Zobel et al. 1997b), $16.5 \mathrm{mg} / \mathrm{d}$ (Riso et al. 1999) or $10 \mathrm{mg} / \mathrm{d}$ (Hininger et al. 1997) to increase plasma lycopene levels. The bioavailability of lycopene, which depends on the matrix, is also an important factor. Bohm and Bitsch (1999) reported that lycopene from capsules and tomato juice (processed tomatoes) was better absorbed from the intestine than lycopene from raw tomatoes. They also showed that administration of $5 \mathrm{mg}$ lycopene/day did not affect plasma antioxidant capacity. If the protective effect of tomatoes on prostate cancer risk is indeed due to lycopene then the protective lycopene intake should be $\geq 6.5 \mathrm{mg} /$ day (Giovanucci et al. 1999). In the present study the additional intake of lutein and lycopene from the burger was apparently too low to achieve an increase of serum levels.

The VB/FD provided per day an additional $4.0 \mathrm{mg} \alpha$-carotene and $9.0 \mathrm{mg} \beta$-carotene. This resulted in an increase in plasma $\alpha$ - and $\beta$-carotene. $\beta$-Cryptoxanthin and zeaxanthin levels were also increased, but the obtained higher levels were not associated with changes in oxidative stress and damage-related markers. Using data 
reported in the various epidemiological trials on cardiovascular risk and mainly observational studies, a threshold level for serum $\beta$-carotene of $0.4 \mu \mathrm{mol} / \mathrm{L}$ has been derived (Gey 1995). This level is reached at an intake of $\geq 1.5-2 \mathrm{mg} /$ day $\beta$-carotene. We have no data on the 'actual' total $\beta$-carotene dietary intake in our subjects, but $\beta$ carotene levels were $\sim 0.3 \mu \mathrm{mol} / \mathrm{L}$ after $\mathrm{CB} / \mathrm{CD}$ and $0.67 \mu \mathrm{mol} / \mathrm{L}$ after $\mathrm{VB} / \mathrm{FD}$ treatment. "High dose" supplementation with synthetic $\beta$-carotene in smokers has been associated with an increased risk for lung cancer (ATBC Study Group 1994, Omenn et al. 1996).

Previously, reduced genetic damage by natural products has been reported in humans, using the Comet assay (Pool-Zobel et al. 1997b). After a 2-wk carotenoid depletion period, followed by a daily intake for 2 weeks of $330 \mathrm{~mL}$ tomato juice (containing 40 $\mathrm{mg}$ lycopene) or $330 \mathrm{~mL}$ carrot juice (containing $22.3 \mathrm{mg} \alpha$-carotene and $15.7 \mathrm{mg} \beta$ carotene) or $10 \mathrm{~g}$ dried spinach powder (containing $11.3 \mathrm{mg}$ lutein) a significant decrease in endogenous levels of strand breaks in lymphocyte DNA has been found.

Vitamin $\mathrm{C}$ is an important contributor to the oxidant defence system and has been shown to protect against in vivo oxidation of lipids and DNA in humans, particularly in persons exposed to enhanced oxidative stress, such as smokers (Henning et al. 1991, Carr and Frei 1999). Numerous epidemiological studies strongly suggest that 90-100 $\mathrm{mg}$ vitamin $\mathrm{C} / \mathrm{d}$ (for review see Carr and Frei 1999) and plasma concentrations $>50$ $\mu \mathrm{mol} / \mathrm{L}$ (Gey 1998) have been associated with a lower incidence, and mortality from cardiovascular disease and cancer.

The VB/FD provided an additional vitamin C intake of $170.5 \mathrm{mg} / \mathrm{d}$. This resulted in an increase in plasma vitamin $C$ level of $\sim 20 \mu \mathrm{mol} / \mathrm{L}$. This increase likely explains the increase in plasma TEAC $(+38 \mu \mathrm{mol} / \mathrm{L})$. Calculated using the TEAC of 1 for vitamin $\mathrm{C}$ (van den Berg et al. 1999) the contribution of vitamin $\mathrm{C}$ to the increase in TEAC is $\sim 83 \%$. However, for analysis of plasma TEAC no precautions could be taken to prevent loss of vitamin $\mathrm{C}$, as done for analysis of vitamin $\mathrm{C}$ and therefore the contribution of vitamin $C$ to the increase in TEAC might be overestimated.

In our subjects vitamin $C$ levels were $\sim 40 \mu \mathrm{mol} / \mathrm{L}$ before and $58 \mu \mathrm{mol} / \mathrm{L}$ after VB/FD treatment. This is in line with kinetic data showing an increase in fasting plasma levels of vitamin $C$ to $\sim 60 \mu \mathrm{mol} / \mathrm{L}$, after a 200-mg dose (Levine et al. 1997).

High dose supplementation with vitamin C (500 mg/day) has been shown to elevate red blood cell glutathione in healthy adults (Johnston et al. 1993). Erythrocyte 
glutathione oxidation is considered to be a consistent marker of oxidative stress (Exner et al. 2000).

In our study the GSH/GSSG ratio was not altered, but GSH levels appeared to be lower then baseline after both treatments. Hininger et al. (1997) reported increased GSH levels in smokers, which also decreased to the "normal" non-smoking levels after a fruit and vegetable-rich diet. This increase was unrelated to an increase in GSSG. The observed higher GSH in erythrocytes of smokers might reflect an adaptation to enhanced production of reactive oxygen species from cigarettes.

Duthie et al. (1996) reported that supplementation of the diet for 20 weeks with vitamin C (100 mg/day), in combination with vitamin E ( $280 \mathrm{mg} /$ day) and $\beta$-carotene (25 mg/day), resulted in a highly significant decrease in endogenous oxidative base damage in lymphocyte DNA of both smokers and non-smokers. In addition, lymphocytes of antioxidant supplemented subjects showed an increased resistance to oxidative damage when challenged in vitro with $\mathrm{H}_{2} \mathrm{O}_{2}$.

\section{Effect on (functional) markers of oxidative stress}

Antioxidant status and markers of oxidative damage (DNA adducts, lipid- and protein oxidation products) are frequently used to assess antioxidant and pro-oxidant effects. However, gene expression, being an important modulator of cell functions, has been shown, in some cases, to be under redox control. Changes in gene expression can provide a sensitive marker of oxidative stress (or changes in oxidative status). A welldefined transcription factor, NF- $\mathrm{KB}$, has been identified to be regulated by the intracellular redox state. Activation of the transcription factor NF- $\mathrm{KB}$ was measured in this study to assess the potential of these markers as a 'functional' marker of oxidative stress. This redox-controlled mechanism is quite distinct from the response to antioxidant that involves up-regulation of certain specific genes (e.g. glutathione-Stransferase) as a consequence, for example of the antioxidant responsive element present in the promotor. Such genes respond to a diverse selection of antioxidants and might reflect changes in oxidative status. Induction of both glutathione-S-transferases (GST $\alpha$ and GST $\pi$ ), a family of phase II enzymes, was measured in this study to assess the potential of these markers as markers of oxidative stress.

Induction of phase II enzymes has been postulated as a key mechanism for the anticarcinogenic effects of fruits, vegetables and antioxidants (Bogaards et al. 1994, Hayes \& Pulford 1995, Nijhoff et al. 1995). GSTs are able to conjugate electrophiles with 
glutathione, or by a glutathione-dependent peroxidase activity. They may also participate in the repair of cellular macromolecules damaged by oxidative stress. In addition, GST $\pi$ can react directly with reactive oxygen species via a sensitive SHgroup, or be inactivated by disulfide formation that can be reversed by glutathione. Therefore, it has a specific response to oxidative stress (Xia et al. 1996). Several genetic elements in the promoter regions of the genes encoding phase II enzymes have been identified. GST $\pi$ is regulated by the redox status of the cell (Xia et al. 1996). In the regulatory element of the GST $\pi$ gene, an antioxidant responsive element, as well as a NF- $\mathrm{kB}$-binding site, has been identified.

In our study GST $\pi$ was lower after treatment with the VB/FD compared with the $\mathrm{CB} / \mathrm{CD}$. This is in contrast with a previous study with non-smokers, where an induction of GST $\pi$ was observed in 6 of the 23 subjects after treatment with tomato and carrot juices (Pool-Zobel et al. 1997b). Smokers may have higher levels of GST $\pi$ compared with non-smokers to protect them against oxidative stress caused by smoking. A higher intake of antioxidants prevents formation of reactive oxygen species, and therefore GST $\pi$ is down-regulated.

$\mathrm{NF}-\mathrm{\kappa B}$ is activated by oxidative stress and this enhanced activity can be modulated by antioxidants (Blackwell et al. 1996). To assess in vivo NF-kB activity, the activation. was measured in freshly isolated PBMCs. In a previous study we found a higher NF$\kappa B$ activity in male "heavy" smokers compared with non-smokers (van den Berg et al. $2001 \mathrm{~b}$ ). Because of the high TEAC of the VB/FD, the relatively high concentrations of vitamin $C$ and quercetin, a decrease in NF- $\mathrm{KB}$ activation was anticipated. In vitro reduction of NF- $\mathrm{KB}$ activation by antioxidants has been reported, such as by vitamin C, vitamin E and resveratrol (Sen \& Packer 1996, Manna et al. 2000). However, we did not find a counteraction in the present study.

Study design: "suitability" of the study population and test products, "power" of the study

The study was designed as a randomized, free living, open, placebo-controlled, crossover study to simulate the normal home situation and intervention with processed vegetables, rather than with food supplements. Compliance was checked, and considered adequate. Subjects supplemented the product to their usual diet. However, no further data on the actual fruit and vegetable intake during the study were collected. Replacement of other food products and changes in dietary pattern as a result of the 
intervention per se therefore cannot be excluded but, if any, should be balanced by the cross-over design with iso-energetic placebo products. Also, the selection of male smokers with a relatively low fruit and vegetable intake on the basis of food questionnaires might have been insufficiently discriminative to select subjects with increased oxidative stress. In some studies, e.g. Bub et al. (2000), a depletion stage was included in which subjects are fed a "low carotenoid diet" before the actual intervention, which might increase the sensitivity and power of the design to demonstrate effects.

Smokers are considered to be exposed to an increased oxidative stress, because of their apparent lower antioxidant intake (Marangon et al. 1998) in combination with a relatively high free radical exposure. Several studies have been reported showing lower antioxidant vitamin and/or carotenoid plasma levels in smokers (Stryker et al. 1988, Weber et al. 1996, Hininger et al. 1997). This also is true with respect to markers of oxidative damage, such as increased plasma conjugated dienes (Duthie et al. 1991), increased oxidative DNA damage (Duthie et al. 1996) or increased plasma levels of $\mathrm{F}_{2}$-isoprostanes (Morrow et al. 1995).

We recently reported that (baseline) NF- $\mathrm{KB}$ activity is higher in male smokers compared with non-smokers (van den Berg et al. 2001b). However, we did not compare the present baseline data with those for a comparable group of non-smokers. Comparison with values reported by other groups is complicated because of methodological differences and, for some markers, relatively large inter-assay variabilities.

\section{Test products}

To maximize the intake of natural antioxidants we used a VB and FD, prepared from commercially obtained ingredients (freeze-dried vegetables and fruit extracts), selected because of their potential antioxidant contents and reported health effects. These VB/FD had indeed relatively "high" TEACs, but for some compounds, such as the carotenoids, the actual additional intake achieved was lower than anticipated, most probably because of losses during processing of the extracts/lyophilized products. As discussed above, carotenoid and vitamin E levels were apparently too low to achieve an effect, if any, on the markers evaluated in this study. 


\section{Power of the study}

The relatively low antioxidant content of the test products, and/or the low level of oxidative stress in the study population, may explain the lack of effects of fruits and vegetables supplementation on the selected biomarkers in our study. To assess the sensitivity of these markers, we used our data set to calculate the number of subjects needed to demonstrate a $10 \%$ difference between treatments $(\alpha=0.05$, two-sided and a power of $80 \%$ ). Based on the observed within-subject variability during treatment with the control products, we calculated that for some of the biomarkers, the number of subjects was indeed insufficient. Table 7 shows that in our study, using 22 subjects, only an effect ( $10 \%$ difference) on protein carbonyls and plasma TEAC could have been demonstrated.

Whether an effect of $10 \%$ is also functionally relevant is another issue, which remains unanswered. Answering this question requires a better understanding of the underlying pathophysiology, and further standardization and validation of biomarkers, by relating responses in biomarkers to hard endpoints of the disease.

Table 7. Percentage difference which could have been demonstrated in the study as executed and subjects needed in the study for the detection of a $10 \%$ significant difference between treatments.

\begin{tabular}{|c|c|c|c|}
\hline Markers & $\begin{array}{c}\begin{array}{c}\text { Control treatment } \\
\text { (mean) }\end{array} \\
\mu \\
\end{array}$ & $\begin{array}{c}\text { Difference to } \\
\text { be detected } \\
\text { with } n=22^{1} \\
\% \\
\end{array}$ & $\begin{array}{c}\text { Subjects } \\
\text { needed for } \\
10 \% \%^{2} \\
n\end{array}$ \\
\hline MDA & 0.43 & 22 & 103 \\
\hline 8-Epi-PGF $2 \alpha$ & 22.1 & 10 & 23 \\
\hline Protein carbonyls & 0.295 & 4 & 6 \\
\hline Comet - blanc & 71 & 18 & 67 \\
\hline Comet $-\mathrm{H}_{2} \mathrm{O}_{2}$ & 133 & 15 & 50 \\
\hline Comet - Endo-III & 283 & 11 & 27 \\
\hline TEAC & 538 & 3 & 5 \\
\hline GSH/GSSG ratio & 2.7 & 22 & 95 \\
\hline GSH & 727 & 16 & 55 \\
\hline GSSG & 270 & 11 & 29 \\
\hline GST $\alpha$ & 4.8 & 12737 & 54508 \\
\hline $\mathrm{GST} \pi$ & 520 & 19 & 75 \\
\hline NF- $k B-$ HeLa eq. & 11 & 19 & 75 \\
\hline
\end{tabular}

${ }^{\mathrm{I}}$ Test significant level $\alpha=0.05,2$-sided $\mathrm{n}=22$ and a power of $80 \%$

${ }^{2}$ Test significant level $\alpha=0.05$, 2-sided, $10 \%$ difference and a power of $80 \%$ 
This will require further (intervention) studies, using subjects with an established oxidative stress, or in patients with a disease associated with increased oxidative stress such as in diabetes or with inflammation related diseases. This seems an ambitious but essential task to make further progress.

\section{References}

ATBC Study Group (the Alpha-Tocopherol, $\beta$-Carotene Cancer Prevention Study Group) (1994) The effects of vitamin $E$ and $\beta$-Carotene on the incidence of lung cancer and other cancers in male smokers. New Engl. J. Med. 334: 1019-1035.

Baker, M.A., Cernigilia, G.J., Aman, A. (1990) Microtiterplate assay for the measurement of glutathione and glutathione disulphide in large number of biological samples. Anal. Biochem. 190: 360-365.

Baynes, J.W., Thorpe, S.R. (1999) Role of oxidative stress in diabetic complications: a new perspective on an old paradigm. Diabetes 48: 1-9.

Benzie, I.F. (1996) Lipid peroxidation: a review of causes, consequences, measurement and dietary influences. Int. J. Food Sci. Nutr. 47: 233-261.

Blackwell, T.S., Blackwell, T.R., Holden, E.P., Christman, B.W., Christman J.W. (1996) In vivo antioxidant treatment suppresses nuclear factor- $\mathrm{KB}$ activation and neutrophillic lung inflammation. J. immunol. 157: 1630-1637.

Block, G., Patterson, B., Subar, A. (1992) Fruit, vegetables and cancer prevention: A review of the epidemiological evidence. Nutr. Cancer 18: 1-29.

Bogaards, J.J., Verhagen, H., Willems, M.I., Van Poppel, G., van Bladeren, P.J. (1994) Consumption of Brussels sprouts results in $\alpha$-class glutathione S-transferase levels in human blood plasma. Carcinogenesis 15: 1073-1075.

Bohm, V., Bitsch, R. (1999) Intestinal absorption of lycopene from different matrices and interactions to other carotenoids, the lipid status, and the antioxidant capacity of human plasma Eur. J. Nutr. 38: 118-125.

Bramley, P.M., Elmadfa, I., Kafatos, A., Kelly, F.J., Manios, Y., Roxborough, H.E., Schuch, W., Sheehy, P.J.A., Wagner, K-H. (2000) Vitamin E. J. Sci. Food Agric. 80: 913-938.

Bresnick E, Birt DF, Wolterman K, Wheeler M, Markin RS. (1990) Reduction in mammary tumorigenesis in the rat by cabbage and cabbage residue. Carcinogenesis 11:1159-1163.

Broekmans, W.M.R., Klopping-Ketelaars, I.A.A., Schuurman, C.R.W.C., Verhagen, H., van den Berg, H., Kok, F.J., van Poppel, G. (2000) Fruits and vegetables increase plasma carotenoids and vitamins and decrease homocysteine in humans. J. Nutr. 130: 1578-1583.

Bub, A., Watzl, B., Abrahamse, L., Delincee, H., Adam, S., Wever, J. Muller, H., Rechkemmer, G. (2000) Moderate intervention with carotenoid-rich vegetable products reduces lipid peroxidation in men J. Nutr. 130: 2200-2206.

Buss, H., Chan, T.P., Sluis, K.B., Domigan, N.M., Winterbourn, C.C. (1997) Protein carbonyl measurement by a sensitive ELISA method. Free Radic. Biol. Med. 23: 361-366.

Carr, A.C., Frei, B. (1999) Towards a new recommended dietary allowance for vitamin C based on antioxidant and health effect in humans. Am. J. Clin. Nutr. 69: 1086-1 107.

Collins, A.R., Duthie, S.J., Dobson, V.L. (1993) Direct enzymic detection of endogenous oxidative base damage in human lymphocyte DNA. Carcinogenesis 14, 1733-1735.

Duthie, G.G., Arthur, J.R., James, W.P. (1991) Effects of smoking and vitamin E on blood antioxidant status. Am. J. Clin. Nutr. 53: 1061 S-1063S.

Duthie, S.J., Ma, A., Ross, M.A., Collins, A.R. (1996) Antioxidant supplementation decreases oxidative DNA damage in human lymphocytes. Cancer Res. 56: 1291-1295. 
Exner, R., Wessner, B., Manhart, N., Roth, E. (2000) Therapeutic potential of glutathione. Wien. Klin. Wochenschr. 112:610-616.

Friedewald, W.T., Levy, R.I., Fredrickson, D.S. (1972) Estimation of the concentration of low-density lipoprotein cholesterol in plasma, without use of the preparative ultracentrifuge. Clin. Chem. 18: 499-502.

Fukunaga, K., Yoshida, M., Nakazono, N. (1998) A simple, rapid, highly sensitive and reproducible quantification method for plasma malondialdehyde by high-performance liquid chromatography. Biomed. Chromatogr.12: 300-303.

Gey, K.F. (1995) Ten-year retrospective on the antioxidant hypothesis of arteriosclerosis: threshold plasma levels of antioxidant micronutrients related to minimum cardiovascular disease. Nutr. Biochem. 6: 206-236.

Gey, K.F. (1998) Vitamins E plus C and interacting conutrients required for optimal health. A critical and constructive review of epidemiology and supplementation data regarding cardiovascular disease and cancer. Biofactors. 7: 113-174.

Gillman, M.W., Cupples, L.A., Gagnon, D., Posner, B.M., Ellison, R.C., Castelli, W.P., Wolf, P.A. (1995) Protective effect of fruits and vegetables on development of stroke in men. JAMA 273: $1113-1117$.

Giovanucci, E. (1999) Tomatoes, tomato-based products, lycopene and cancer: review of the epidemiological literature. J. Natl. Cancer Inst. 91: 317-331.

Halliwell, B. (1996) Oxidative stress, nutrition and health. Experimental strategies for optimization of nutritional antioxidant intake in humans. Free Rad. Res. 25: 57- 74.

Hayes, J.D., Pulford, D.J. (1995) The glutathione S-transferase supergene family: regulation of GST and the contribution of the isoenzymes to cancer chemoprotection and drug resistance. Crit. Rev. Biochem. Mol. Biol. 30: 445-600.

Henning, S.M., Zhang, J.Z., McKee, R.W., Swendseid, M.E., Jacob, R.A. (1991) Glutathione blood levels and other oxidant defence indices in men fed diets low in vitamin C. J. Nutr. 121: $1969-1975$.

Hertog, M.G., Hollman, P.C. Venema, D.P. (1992) Optimization of a quantitative HPLC determination of potentially anticarcinogenic flavonoids in vegetable and fruits. J. Agric. Food. Chem. 40: 1591-1598.

Hertog, M.G., Bueno de Mesquita, H.B., Fehily, A.M., Sweetnam, P.M., Elwood, P.C., Kromhout, D. (1996) Fruit and vegetable consumption and cancer mortality in the Caerphilly Study. Cancer Epidemiol. Biomarkers Prev. 5: 673-677.

Hininger, I., Chopra, M., Thurnham, D.I., Laporte, F., Richard, M.J., Favier, A., Roussel, A.M. (1997) Effect of increased fruit and vegetable intake on the susceptibility of lipoprotein to oxidation in smokers. Eur. J. CJin. Nutr. 51: 601-606.

Hollman, P.C. (1997) Bioavailability of flavonoids. Eur. J. Clin. Nutr. 51: S66-S69.

Hulshof, K.F.A.M., Kistenmaker, C., Bouwmans, M., Löwik, M.R.H. (1998) Energy and nutrient intake of the Dutch population - Dutch Nutrition Surveillance System 1997-1998. TNO report V98.805 (in Dutch), pg. 1-13.

Johnston, C.S., Meyer, C.G., Srilakshmi, J.C. (1993) Vitamin C elevates red blood cell glutathione in healthy adults. Am. J. Clin. Nutr. 58: 103-105.

Levine, M., Rumsey, S.C., Wang, Y., Park, J., Kwon, O., Amano, N. (1997) In situ kinetics: an approach to recommended intake of vitamin C. Methods Enzymol. 281: 425-437.

Loft, S., Poulsen, H.E. (1996) Cancer risk and oxidative DNA damage in man. J. Mol. Med. 74: $297-312$.

Mahmoud, N.N., Carothers, A.M., Grunberger, D., Bilinski, R.T., Churchill, M.R., Martucci, C., Newmark, H.L., Bertagnolli, M.M. (2000) Plant phenolics decrease intestinal tumors in an animal model of familial adenomatous polyposis. Carcinogenesis 21: 921-927. 
Manna, S.K., Mukhopadhyay, A., Aggarwal, B.B. (2000) Resveratrol suppresses TNFinduced activation of nuclear transcription factors NF-kappa B, activator protein-1, and apoptosis: potential role of reactive oxygen intermediates and lipid peroxidation. J. Immunol. 164: 6509-6519.

Marangon, K., Herbeth, B., Lecomte, E., Paul-Dauphin, A., Grolier, P., Chancerelle, Y., Artur, Y., Siest, G. (1998) Diet, antioxidant status, and smoking habits in French men. Am. J. Clin. Nutr. 67: 231-239.

Morrow J.D., Frei, B., Longmire, A.W., Gaziano, J.M., Lynch, S.M., Shyr, Y., Strauss, W.E., Oates, J.A., Roberts, L.J. II (1995) Increase in circulating products of lipid peroxidation (F2-isoprostanes) in smokers. Smoking as a cause of oxidative damage. N. Engl. J. Med. 332: 1198-1203.

Nijhoff, W.A., Mulder, T.P., Verhagen, H., van Poppel, G., Peters, W.H. (1995) Effects of consumption of brussels sprouts on plasma and urinary glutathione S-transferase classalpha and -pi in humans. Carcinogenesis 16: 955-957.

Nourooz-Zadeh, J., Gopaul, N.K., Barrow, S., Mallet, A.I., Anggard, E.E. (1995) Analysis of F2-isoprostanes as indicators of non-enzymatic lipid peroxidation in vivo by gas chromatography-mass spectrometry: development of a solid-phase extraction procedure. $\mathrm{J}$. Chromatogr. B: Biomed. Appl. 667: 199-208.

Omenn, G.S., Goodman, G.E., Thornquist, M.D., Balmes, J., Cullen, M.R., Glass, A., Keogh, J.P., Meyskens, F.L. Jr., Valanis, B., Williams, J.H. Jr., Barnhart, S., Cherniack, M.G., Brodkin, C.A., Hammar, S. (1996) Risk factors for lung cancer and for intervention effects in CARET, the Beta-Carotene and Retinol Efficacy Trial. J. Natl. Cancer Inst. 88: 15501559.

Pool-Zobel, B.L., Bub, A., Liegibel, U.M., Treptow-van Lishaut, S., Rechkemmer, G. (1997a) Mechanisms by which vegetable consumption reduces genetic damage in humans. Cancer Epidemiol. Biomarkers Prev. 7: 891-899.

Pool-Zobel, B.L., Bub, A., Müller, H., Wollowski, I., Rechkemmer, G. (1997b) Consumption of vegetables reduces genetic damage in humans: first results of an intervention trial with carotenoid-rich foods. Carcinogenesis 18: 1847-1850.

Porrini, M., Riso, P. (2000) Lymphocyte lycopene concentration and DNA protection from oxidative damage is increased in women after a short period of tomato consumption. $J$. Nutr. 130: 189-192.

Rimm, E.B., Katan, M.B., Ascherio, A., Stampfer, M.J., Willett, W.C. (1996) Relation between intake of flavonoids and risk for coronary heart disease in male health professionals. Ann. Intern. Med. 125: 384-389.

Riso, P., Pinder, A., Santangelo, A., Porrini, M. (1999) Does tomato consumption effectively increase the resistance of lymphocyte DNA to oxidative damage? Am. J. Clin. Nutr. 69: 712-718.

Sen, C.K., Packer, L. (1996) Antioxidant and redox regulation of gene transcription. FASEB J. 10: 709-720.

Speek, A.J., Schrijver, J., Schreurs, W.H.P. (1984) Fluorimetric determination of total vitamin $\mathrm{C}$ and total vitamin iso-C in foodstuff and beverages by high performance liquid chromatography with pre-column derivatization. J. Agr. Food Chem. 32: 352-355.

Speek, A.J., Schrijver, J., Schreurs, W.H.P. (1985) The vitamin E composition of some seed oils as determined by high performance liquid chromatography with fluorometric detection. J. Food Sci. 50: 121-124.

Stryker, W.S., Kaplan, L.A., Stein, E.A., Stampfer, M.J., Sober, A., Willett, W.C. (1988) The relation of diet, cigarette smoking, and alcohol consumption to plasma beta-carotene and a)pha-tocopherol levels. Am. J. Epidemiol. 127: 283-296. 
Traber, M.G., Sies, H. (1996) Vitamin E in humans: demand and delivery, in Annual Reviews in Nutrition, ed. McCormick, D.B. Vol 16, Annual Reviews, Palo Alto, pp 321-347.

Van den Berg, H., Faulks, R., Fernando-Granado, H., Hirschberg, J., Olmedilla, B., Sandman, G., Southon, S., Stahl, W. (2000) The potential for the improvement of carotenoid levels in food and the likely systemic effects. J. Sci. Food Agric. 80: 880-912.

Van den Berg, R., Haenen, G.R.M.M., van den Berg, H., Bast, A. (1999) Applicability of an improved Trolox equivalent antioxidant capacity (TEAC) assay for evaluation of antioxidant capacity measurements of mixtures. Food Chemistry 66, 511-517.

Van den Berg, R., Haenen, G.R.M.M., van den Berg, H., Bast, A. (2001 a) Nuclear factor-кB as a potential biomarker of oxidative stress. Br. J. Nutr. (in press).

Van den Berg, R., Haenen, G.R.M.M., Van den Berg, H., Bast, A. (2001b) Nuclear factor-KB activation is higher in peripheral blood mononuclear cells of male smokers. Environ. Tox. Phar. 9: 147-151.

Van Poppel, G., van den Berg, H. (1997) Vitamins and cancer. Cancer Lett. 114: 195-202.

Van Vliet, T., van Schaik, F., van Schoonhoven, J., Schrijver, J. (1991) Determination of several retinoids, carotenoids and $\mathrm{E}$ vitamers by high-performance liquid chromatography. Application to plasma and tissues of rats fed a diet rich in either beta-carotene or canthaxanthin. J. Chromatogr. 553: 179-186.

Verhagen, H., Poulsen, H.E., Loft, S., van Poppel, G., Willems, M.I., van Bladeren, P.J. (1995) Reduction of oxidative DNA-damage in humans by brussels sprouts. Carcinogenesis 16: 969-970.

Wattenberg, L.W., Coccia, J.B. (1991) Inhibition of 4-(methylnitrosamino)-1-(3-pyridyl)-1butanone carcinogenesis in mice by $\mathrm{D}$-limonene and citrus fruit oils. Carcinogenesis 12: 115-117.

Weber, P., Bendich, A., Schalch, W. (1996) Vitamin C and human health--a review of recent data relevant to human requirements. Int. J. Vitam. Nutr. Res. 66: 19-30.

Xia, C., Hu, J., Ketterer, B., Taylor, J.B. (1996) The organization of the human GSTP1-1 gene promoter and its response to retinoic acid and cellular redox status. Biochem. J. 313: 155-161.

Yeum, K.J., Booth, S.L., Sadowski, J.A., Liu, C., Tang, G., Krinsky, N.I., Russell, R.M. (1996) Human plasma carotenoid response to the ingestion of controlled diets high in fruits and vegetables. Am. J. Clin. Nutr. 64: 594-602.

Young J.F., Nielsen, S.E., Haraldsdottir, J., Daneshvar, B., Lauridsen, S.T., Knuthsen, P., Crozier, A., Sandstrom, B., Dragsted, L.O. (1999) Effect of fruit juice intake on urinary quercetin excretion and biomarkers of antioxidative status. Am. J. Clin. Nutr. 69: 87-94. 
Chapter 9

General Discussion and Conclusions 
In order to defend against oxidative damage from ROS/RNS, humans and other living organisms developed powerful and complex antioxidant systems. Components of these systems are antioxidants, a diverse group of molecules that protect key biological sites from oxidative damage. It is important to note that individual antioxidants do not function in isolation, but as part of systems with significant interdependence and additive or synergistic effects.

Oxidative stress may result from a serious imbalance due to excessive production of ROS/RNS and/or weakening of the antioxidant system due to lower intake or endogenous production of antioxidants, or from increased antioxidant utilization. Oxidative stress can cause cell damage and has been implicated in the etiology of a wide variety of degenerative processes, including carcinogenesis, cardiovascular and inflammatory diseases, emphysema and cataract (Halliwell et al. 1992). This has raised a strong interest in ways to prevent oxidative stress and to maintain an optimal antioxidant status supporting health during lifetime. As research continues, paradoxical effects accumulate (Halliwell 2000). For example, subjects consuming diets rich in fruit and vegetable apparently have a lower risk of getting cancer and an increase in the concentration of $\beta$-carotene in the blood. Supplements of $\beta$-carotene, however, do not have an anti-cancer effect, but rather the opposite occurs in smokers (Rowe 1996). Two factors, which should be kept in mind, could explain many of the contradictions. First, a protective effect of the diet is not equivalent to a protective effect of antioxidants in the diet. Second, several gene transcription factors require transient oxidation for their function (Sen 1998), so that low quantities of ROS often stimulate cell proliferation (Burden 1995). Apoptosis is accompanied by increased oxidation, but too much oxidation will stop apoptosis by oxidizing and inactivating enzymes involved in apoptosis (Hampton \& Orrenius 1998). Thus antioxidants can both suppress and facilitate apoptosis (Clement \& Pervaiz 1999). A prerequisite for accurately establishing these effects is the ability to measure accurately the antioxidant capacity of food, antioxidant status and oxidative stress in humans.

How can we accurately assess antioxidant capacity of food, antioxidant status and oxidative stress in humans?

As the diet is an important source of antioxidants in humans, a non-specific technique seems useful for assessing the total antioxidant capacity of food products. Such a technique might be used to compare or screen and give an overall ranking of the 
antioxidant capacity of different food products. If the total antioxidant capacity of food could be used as a marker for intake, one could ask to what extent this is reflected in the human (plasma) antioxidant status.

To assess whether changes in antioxidant intake and/or status affect oxidative stress at the cellular level, human intervention trials using validated and accepted markers as intermediate endpoints seems a successful research strategy.

Therefore, to assess effects of food on antioxidant status and oxidative stress in humans the following questions were raised: ( $i$ ) Can the TEAC assay be used for assessment of the antioxidant capacity of food products, (ii) Can we establish a relationship between the TEAC of food (products), the antioxidant status and markers of oxidative stress in humans and (iii) can we use NF- $\mathrm{kB}$ activation as a biomarker of oxidative stress.

(i) Can we use the TEAC assay for assessment of the antioxidant capacity of food products?

In Chapter 2 we describe a modification of the TEAC assay originally described by Miller et al. (1993). With the original assay artefacts could easily be introduced. By using separately generated ABTS radicals, before the test compounds are introduced in the assay, we could prevent overestimation of 'true' antioxidant capacity due to interference with the radical-generating system rather then scavenging (Strube et al. 1997).

With the modified assay we could accurately assess antioxidant capacity of a number of compounds as well as mixtures of compounds using various solvents. Using food products, standardization of the assay (one extraction solvent and two time-points) is extremely important and concentration dependence and solvent dependence should be taken into account. Based on the data presented in Chapter 2 and 3, one should be very careful in interpretation of the results of the TEAC assay. We believe that quantitative evaluation of antioxidant capacity using the TEAC can be troublesome or even impossible, but can be used to provide a ranking order of antioxidants and food products.

Still a question remains: Why use the TEAC assay? Because all in vitro assays have there own limitations, the TEAC assay seems more favourable due to its simplicity and non-specificity. Although we did succeed in solubilizing lipophilic compounds, 
such as $\beta$-carotene, the aqueous TEAC assay medium remains a problem; a low TEAC might reflect either limited scavenging or limited solubility.

(ii) Can we establish a relationship between the TEAC of food (products) and the potential effect on antioxidant status and markers of oxidative stress in humans?

In Chapter 3 we compared the antioxidant activity of different compounds using various in vitro assays. We found that the TEAC correlated with microsomal lipid peroxidation and also doxorubicin-induced toxicity, but not with hydroxyl radical scavenging. However, it seems a simplification to assume that one type of assay can give answers to all questions related to antioxidant capacity. Therefore a range of methods for establishing antioxidant capacity of food with different types radicals or indirect scavenging systems should be used to assess the antioxidant potential of food for predicting its in vivo antioxidant effect.

With this knowledge we performed a human cross-over intervention study with 22 smoking males using a vegetable burger and a fruit drink (Chapter 8 ). These products had a high antioxidant capacity compared to the control products, measured with the TEAC assay, and the potential to affect the antioxidant status and subsequently the oxidative stress markers. In the study, there was indeed a significant effect on antioxidant status, however no effect on any marker of oxidative stress was found. The relatively low antioxidant content of the test products, and/or the low level of oxidative stress in the study population, may explain why no effect of fruits and vegetables supplementation on the selected biomarkers was observed. Nevertheless we could establish the relationship between the TEAC of food (products) and the effect of food on antioxidant status, but not on markers of oxidative stress in humans. Although we speculated that the increase in plasma TEAC is mainly due to the increase in vitamin C measured in blood, the in vivo contribution of flavonoids to the plasma TEAC is still unclear. There is still not much known about the absorption of flavonoids from flavonoids rich products when structural changes due to conjugation, ring cleavage and other metabolic pathways enter the equation. This might influence their antioxidant properties in the context of what the TEAC is measuring (Rice-Evans 2000). Additional (intervention) studies have to be performed, using subjects with an established oxidative stress, or in patients suffering from a disease associated with increased oxidative stress such as in diabetes, or with inflammation related diseases, to 
establish the relationship between the TEAC of food (products) and the potential effect on markers of oxidative stress in humans.

In conclusion, the TEAC is a useful screenings assay for assessing antioxidant capacity of food products, however its predictive value for an in vivo effect is limited.

(iii) Is $N F-\kappa B$ activation a potential biomarker of oxidative stress?

The redox-controlled transcription factor NF- $\mathrm{KB}$ has for some years been recognized as an important mediator in the regulation of the inflammatory genes and is likely to be involved in the pathophysiology of several diseases. Using the EMSA procedure as described in Chapter 4, measurement of NF-KB offers the possibility to evaluate both the 'baseline' activation of NF- $\mathrm{KB}$ in various pathologies, as well as the strategy used to reduce NF-KB activation.

Our observations with EMSA on a macrophage cell line, with healthy subjects, in hepatitis $C$ patients, sarcoidosis patients and even in smokers compared to nonsmokers, confirm that NF- $\mathrm{kB}$ can be used as a marker of oxidative stress. However, more experiments are needed to validate this marker and to fully unveil the role of this important nuclear factor in pathogenesis and the effect of antioxidants on human health.

Fundamental research in this rapidly developing area is focussed on elucidating the exact role of NF- $\mathrm{KB}$ in oxidative stress related processes and the molecular mechanism of action of antioxidants. This may lead to new pharmacotherapeutic strategies. Applied research is directed towards the development of new probes and methods for the evaluating the role of NF- $\mathrm{KB}$ and the efficacy of clinical treatment schedules. However it should also be taken into account that not only ROS can activate NF-кB, but also ultraviolet radiation, cytokines or bacterial and viral products (Baeurele \& Baltimore, 1996; Siebenlist et al. 1994), making this assay less specific for oxidative stress.

A study with diabetic patients performed by Hofmann et al. (1999) showed that compared to the control group, the patients with diabetes mellitus and albuminuria had an increased NF- $\mathrm{kB}$

activity. More interestingly was that when they treated the patients with diabetic nephropathy for three days with $600 \mathrm{mg}$ of the antioxidant $\alpha$-lipoic acid, this resulted in a $38 \%$ decrease of NF-KB activity. Our studies (Chapter 6 and 7) also showed that 
$\mathrm{NF}-\mathrm{kB}$ activity is increased in sarcoidosis and in smokers. However, no effect of glucocorticoids for sarcoidosis and of antioxidants with smokers was found.

Finally, our human cross-over intervention study with 22 smoking males using a vegetable burger and a fruit drink as antioxidant source (Chapter 8) did show increased NF- $\mathrm{kB}$ activity in smokers. This activity could, however, not be counteracted with our products. Therefore, we could not establish an effect of antioxidants on NF- $\mathrm{KB}$ activity, questioning its validity as a potential marker of oxidative stress. An additional intervention study has to be performed, using a food supplement with a high antioxidant contents and subjects with an established oxidative stress, or in patients suffering from a disease associated with increased oxidative stress to really assess the potential of NF- $\mathrm{kB}$ activity as a marker of oxidative stress in humans.

\section{References}

Baeuerle, P.A., Baltimore, D. (1996) NF-kappa B: ten years after. Cell. 87: 13-20.

Burden, R.H. (1995) Superoxide and hydrogen peroxide in relation to mammalian cell proliferation. Free Radic. Biol. Med. 18: 775-794.

Clement, M.V., Pervaiz, S. (1999) Reactive oxygen intermediates regulate cellular response to apoptotic stimuli: a hypothesis. Free Radic Res. 30: 247-252.

Halliwell B., Gutteridge J.M., Cross C.E. (1992) Free radicals, antioxidants, and human disease: where are we now? J. Lab. Clin. Med. 119: 598-620.

Halliwell, B. (2000) The antioxidant paradox. Lancet. 355: 1179-1180.

Hampton, M.B., Orrenius, S. (1998) Redox regulation of apoptotic cell death. Biofactors. 8: $1-5$.

Hofmann, M.A., Schiekofer, S., Isermann, B., Kanitz, M., Henkels, M., Joswig, M., Treusch, A., Morcos, M., Weiss, T., Borcea, V., Abdel Khalek, A.K., Amiral, J., Tritschler, H., Ritz, E., Wahl, P., Ziegler, R., Bierhaus, A., Nawroth, P.P. (1999) Peripheral blood mononuclear cells isolated from patients with diabetic nephropathy show increased activation of the oxidative-stress sensitive transcription factor NF-kappa B. Diabetologia. 42: 222-232.

Miller, N.J., Rice-Evans, C., Davies, M.J., Gopinathan, V., Milner, A. (1993) A novel method for measuring antioxidant capacity and its application to monitoring the antioxidant status in premature neonates. Clin. Sci. 84: 407-412.

Rowe, P.M. (1996) Beta-carotene takes a collective beating. Lancet. 347: 249.

Rice-Evans C.A. (2000) Measurement of total antioxidant activity as a marker of antioxidant status in vivo: procedures and limitations. Free Radic. Res. 33: S59-66.

Sen, C.K. (1998) Redox signaling and the emerging therapeutic potential of thiol antioxidants. Biochem. Pharmacol. 55: 1747-1758.

Siebenlist, U., Franzoso, G., Brown, K. (1994) Structure, regulation and function of NF-kappa B. Annu. Rev. Cell Biol. 10: 405-455.

Strube, M., Haenen, G.R., Van den Berg, H., Bast, A. (1997) Pitfalls in a method for assessment of total antioxidant capacity. Free Radic. Res. 26: 515-521. 


\section{Summary}

Free radicals, reactive oxygen-containing species (ROS) and reactive nitrogencontaining species (RNS) are an integral part of life and our metabolism. Actually, free radicals and ROS/RNS may be produced in our body deliberately to serve important biological functions, such as vasorelaxation or metabolism. However, they can also be damaging because they are extremely reactive and almost instantly attack molecules, e.g. lipids, proteins and DNA, which are in the immediate vicinity. In order to defend against damage from ROS/RNS, humans and other living organisms developed powerful and complex antioxidant systems. Components of these systems are antioxidants, a diverse group of molecules that protect key biological sites from oxidative damage by preventing the formation or scavenging of free radicals. A serious imbalance in radical production/scavenging is defined as oxidative stress. Oxidative stress has been implicated in the etiology of a wide variety of degenerative processes, including carcinogenesis, cardiovascular and inflammatory diseases, emphysema and cataract. For this reason, there has been strong interest in preventing oxidative stress and maintaining an antioxidant status that supports 'optimal' health. Although the interest in the use of antioxidants for treatment of human diseases, and in the role of dietary antioxidant in the prevention of disease is intensively investigated, paradoxal results accumulate. For example vitamin E supplements were protective against cardiovascular disease in the CHAOS study (Stephens et al. 1996), but not in the GISSI-Prevenzione trial (GISSI-Prevenzione Investigators 1999). Also, subjects consuming diets rich in fruits and vegetables apparently have a lower risk of getting cancer and an increased the concentration of $\beta$-carotene in the blood. Intervention with (high dose) $\beta$-carotene supplements, however, did not exert an anti-cancer effect, rather the opposite effect was found in smokers (Rowe 1996).

The rationale behind the work described in this thesis was to develop and evaluate methods to assess the total antioxidant capacity of food (products), including both the water- and lipid-soluble components. Next, to 'evaluate' these methods with respect to their prognostic value for 'in vivo' efficacy, i.e. to assess the relationship between the total antioxidant capacity of food products and the (plasma) antioxidant status, respectively, the effect on biomarkers of oxidative stress in subjects after consumption 
of these products. In this project we especially focussed on the total antioxidant capacity (TEAC) assay to assess the total antioxidant capacity of food, and on the in vivo activation of the redox controlled transcription factor NF- $\mathrm{KB}$ as a functional biomarker for oxidative stress. A prerequisite for achieving these objectives is the ability to measure accurately the antioxidant capacity of food, the antioxidant status and to assess oxidative stress in humans. Therefore, with regard to establishing effects of food on antioxidant status and oxidative stress in human we modified and evaluated the 'original' TEAC assay for assessment of the antioxidant capacity of food products (Chapter 2). In the original assay, ABTS radicals were generated in the presence of the test compounds, which might result in overestimation of 'true' antioxidant capacity due to interference with the radical-generating system rather then scavenging. In the modified assay ABTS radicals are generated separately before the test compound is introduced in the assay. However, for most antioxidants tested, a biphasic reaction pattern was seen, i.e. a fast and slow scavenging rate. We also found that the TEAC of phenolic compounds like quercetin depends on the concentration used in the assay, which complicates interpretations of the assay results. Several organic solvents, compatible with water, were tested with $\alpha$-tocopherol, quercetin and $\beta$-carotene. It was found that the TEACs of these compounds differed in various solvents. However, under standardized conditions additivity of TEACs obtained from individual antioxidants could be demonstrated, which enables application of the assay for the identification of 'unknown' antioxidants.

To evaluate the predictive value of the TEAC, the antioxidant activity of a series structurally related flavonoids was compared in various in vitro assays, measuring the effect on hydroxyl scavenging, lipid peroxidation and doxorubicin-induced toxicity as typical scavenging or damage assays, respectively (Chapter 3 ). The flavonoids tested were monoHER (aromatic hydroxyl group at the 5, 3' and 4'-position), diHER (hydroxyl group at the 5 and 3 '-position), triHER (hydroxyl group at the 5-position) tetraHER (no hydroxyl group) and triHEQ (hydroxyl group at the 5 and 3-position), differing in the number of aromatic hydroxyl groups. It was found that these compounds showed both a fast and slow scavenging effect in the TEAC assay. Therefore the 'fast' TEAC (at 10 seconds) and the 'total' TEAC (at 6 minutes) was determined. Both the 'total' and 'fast' TEAC were negatively correlated with hydroxyl radical scavenging. The 'total' TEAC showed a better correlation than the 'fast' TEAC with the inhibition of lipid peroxidation and the protection against doxorubicin- 
induced toxicity. This indicates that beside the fast reaction of scavengers with the ABTS radical, also the slow reaction should be taken into consideration. It is concluded that the antioxidant capacity, assessed with the modified TEAC assay, can be useful to predict the in vivo antioxidant effect in a series of structurally related compounds.

In Chapter 4 the potential of NF- $\mathrm{KB}$ activation as a biomarker of oxidative stress is discussed. The redox-controlled transcription factor NF- $\mathrm{kB}$ has for some years been recognized as an important mediator in the regulation of the inflammatory genes and is likely to be involved in the pathophysiology of several diseases. Using the electro mobility shift assay (EMSA) procedure as described in this chapter, measurement of $\mathrm{NF}-\mathrm{KB}$ offers the possibility to evaluate both the 'baseline' activation of NF- $\mathrm{BB}$ in various pathologies, as well as the effect of antioxidants on NF- $k B$ activation. The nuclear activity of NF- $\mathrm{KB}$ in clinical studies can be assessed in isolated human peripheral blood mononuclear cells (PBMCs). To compare results obtained from different studies, the assay has to be standardized. Using another transcription factor, such as the 'housekeeping' transcription factor spl, as a standard has the advantage that also a correction for the loss of nuclear proteins during the isolation procedure can be made. However the activity of sp1, which is suggested to be continuously activated, was found to vary among different conditions/pathologies, which limits the use of $\mathrm{spl}$ as a standard. Using a commercially available HeLa nuclear extract we did not encounter this problem. This nuclear extract can therefore serve as a control to check the EMSA, as well as a standard to relate the NF- $\mathrm{KB}$ signal on separate gels. Our observations with EMSA using a macrophage cell line and in PBMC samples from healthy subjects suggested that NF- $\mathrm{KB}$ activity, expressed as HeLa equivalents, could be used as a marker of oxidative stress.

In the study using patients with hepatitis $C$ (Chapter 5), we evaluated the antioxidant action of glycyrrhizin by investigating the effect of 6 times/week $200 \mathrm{mg}$ glycyrrhizin given as Stronger Neo-Minophagen C (SNMC). Fifteen patients with chronic hepatitis $C$ received intravenously 6 times/week $200 \mathrm{mg}$ glycyrrhizin for 4 weeks. The results of this study show that serum alanine amino transferase (ALT) and plasma malondialdehyde (MDA) levels significantly decreased after treatment with glycyrrhizin and increased, again, after the wash-out period. Plasma TEAC remained stable. NF- $\mathrm{kB}$ activity, assessed in peripheral blood mononuclear cells, decreased after glycyrrhizin treatment, but did not increase after the wash-out period. The results 
suggest that glycyrrhizin could act as a 'specific' antioxidant and that reduction of NF$\kappa \mathrm{B}$ activation is, at least, partly involved in the mechanism of action.

In Chapter 6 we hypothesized that NF- $\mathrm{KB}$ activation might also be involved in the pathological process of sarcoidosis. Therefore, twelve sarcoidosis patients, biopsy proven, and five healthy control subjects, all non-smokers, were studied. Mononuclear cell NF- $\mathrm{kB}$ activity expressed per $\mu \mathrm{g}$ protein was twice as high in both untreated $(n=5)$ and treated $(n=7)$ patients with sarcoidosis compared to the control subjects $(p<0.001)$. In contrast, the serum angiotensin converting enzyme ( $\mathrm{ACE}$ ) level appeared to be low in the treated patients compared to the untreated patients $(p<0.01)$. These results indicate that the inflammation in sarcoidosis is associated with NF- $\mathrm{kB}$ activation. However, the suppression of the activated NF- $\mathrm{KB}$ response by glucocorticoids seems less successful than the suppression of the SACE activity.

Chapter 7 describes a study in which the NF-kB activity in peripheral blood mononuclear cells of smokers is compared to non-smokers. In this study, with 6 smokers and 10 non-smokers, we showed that NF- $\mathrm{KB}$ activity in peripheral blood mononuclear cells of smokers compared to non-smokers is significantly higher in smokers. This suggested that NF- $\mathrm{KB}$ is involved in cigarette smoke induced inflammatory responses and that NF- $\mathrm{BB}$ activation might be used as a functional marker of oxidative stress.

To establish the relationship between the TEAC of food (products) and the potential effect on antioxidant status and markers of oxidative stress in humans, a volunteer study was performed (Chapter 8 ). The potential benefit of a high fruit and vegetable intake on the antioxidant status and on relevant biomarkers of oxidative damage to lipids, proteins and DNA and on (functional) markers of oxidative stress was evaluated. A randomized, free living, open, placebo-controlled cross-over trial of 3 weeks, with a two-week wash out period between both treatments, was performed in a group of male smokers with a relatively low usual vegetable/fruit intake. In the treatment period a vegetable burger containing the equivalent of approximately $500 \mathrm{~g}$ mixed 'fresh' vegetables (freeze-dried broccoli, tomato, carrot, red sweet pepper and onion) and a fruit drink containing a mixture of juice concentrates of orange, blueberry, apple, lemon and lime were used. Consumption of the vegetable burger and fruit drink did increase serum levels of vitamin $C, \alpha$-carotene, $\beta$-carotene, $\beta$ cryptoxanthin, zeaxanthin and also plasma total antioxidant capacity (TEAC). However, no effect on any marker of oxidative damage to lipids (MDA, $F_{2}$ - 
isoprostane), proteins (carbonyls) and DNA (Comet assay) and (functional) markers of oxidative stress (GSH/GSSG ratio, GST $\alpha$, GST $\pi$, NF- $\mathrm{kB}$ ) could be demonstrated. Apparently, these increased levels of antioxidants in serum were not sufficiently high to show beneficial changes with the selected biomarkers. Alternatively, oxidative stress in male smokers with a relatively low fruit and vegetable intake might have been still too low to demonstrate a beneficial effect of antioxidants.

In conclusion, the objectives from this project were to assess effects of food on antioxidant status and oxidative stress in humans and therefore the following questions were raised: (i) can the TEAC assay be used for assessment of the antioxidant capacity of food products (ii) can we establish a relationship between the TEAC of food (products), the antioxidant status and markers of oxidative stress in humans and (iii) can we use NF- $\mathrm{KB}$ activation as a biomarker of oxidative stress.

The results of Chapter 2, 3 and 8 show that the TEAC assay can be used to assess antioxidant capacity of foodproducts, but its predicting value of an in vivo antioxidant effect is limited. Food products with a high TEAC can improve plasma antioxidant status, but there is, however, no relationship with an increased antioxidant status and an effect of any marker of oxidative stress. Results described in Chapter 4, 5, 6, 7 en 8 show that NF-kB activation is increased in oxidative stress related processes and therefore might be used as functional biomarker of oxidative stress. However, no effect of antioxidant intervention was found with this marker, therefore more research is needed to 'validate' this marker and to fully unveil its role in oxidative stress related processes. 


\section{Samenvatting}

Vrije radicalen, reactieve zuurstof of stikstof species (ROS/RNS), hebben een belangrijke functie in het lichaam. Zo worden vrije radicalen in het lichaam gevormd bij belangrijke fysiologische processen, zoals de vaatwandfunctie (vasorelaxatie), bij immuunreacties en andere metabole omzettingen. Vrije radicalen kunnen ook echter schadelijk zijn wanneer ze in overmaat worden geproduceerd of onvoldoende snel geëlimineerd. Dit komt doordat de vrije radicalen zeer reactieve verbindingen zijn die schade kunnen aanrichten aan moleculen, zoals DNA, eiwitten en vetten, die in de directe nabijheid zijn. Om het lichaam tegen deze schade te beschermen beschikt de mens over een complex antioxidant beschermingsmechanisme. Antioxidanten vormen een belangrijk onderdeel van dit mechanisme en zijn een groep van verschillende moleculen die radicalen (ROS/RNS) wegvangen of de vorming van ROS/RNS kunnen voorkomen.

Oxidatieve stress is gedefinieerd als een verstoorde balans in productie van radicalen en bescherming door antioxidanten. Oxidatieve stress wordt in verband gebracht met het ontstaan van bepaalde degeneratieve ziektebeelden, zoals carcinogenese, hart- en vaatziekten, ontstekingsgerelateerde ziektebeelden, longemfyseem en staar. Voorkomen van oxidatieve stress, door in het lichaam een voldoende optimale antioxidant capaciteit beschikbaar te hebben, wordt wel gepropageerd als bescherming tegen het ontstaan van deze ziekten, maar de meningen zijn hierover verdeeld. Tegenstrijdige resultaten van verschillende studies met voeding of antioxidanten en het effect daarvan op bepaalde ziektebeelden zorgen ervoor dat het ultieme bewijs nog niet geleverd is. Bijvoorbeeld in een Britse studie (CHAOS studie), waarin vitamine E supplementen aan hartpatiënten gegeven werden kon een beschermende werking tegen hart- en vaat ziekten worden aangetoond, terwijl in een zelfde soort studie in Italië (GISSI studie) zo'n effect niet werd gevonden. Uit een ander onderzoek blijkt dat wanneer proefpersonen een groente en fruit rijk dieet volgen de $\beta$-caroteen concentratie in het bloed hoger is en geassocieerd met een kleinere kans om kanker te krijgen. Uit een interventie studie waarin rokers gedurende 5-8 jaar $\beta$-caroteen supplementen kregen toegediend, bleek dit beschermende effect er echter niet te zijn, in rokers werd zelfs een negatief effect aangetoond. 
Het doel van het project, beschreven in dit proefschrift, was om enerzijds een methode te ontwikkelen waarmee de 'totale' antioxidant capaciteit van voeding/ voedingsmiddelen (dus zowel wateroplosbare als vetoplosbare antioxidanten) bepaald kan worden. Daarnaast werd onderzocht of de 'in vitro' bepaalde totale antioxidant capaciteit (TEAC) van voedingsmiddelen een voorspellende waarde heeft ten aanzien van een 'in vivo' antioxidant effect, oftewel de relatie tussen de TEAC van voedingsmiddelen en de antioxidant status in plasma, tevens de relatie tussen de TEAC van voedingsmiddelen en het effect op markers van oxidatieve stress bij de mens.

In dit project hebben we ons vooral gericht op de 'Trolox equivalent antioxidant capaciteit' (TEAC) assay om de antioxidant capaciteit van voeding te meten en op de 'in vivo' activering van de reductie/oxidatie (redox) gereguleerde transcriptie factor 'nucleaire factor kappa B' (NF-kB) als mogelijke functionele marker voor oxidatieve stress.

Om de TEAC van voedingsmiddelen nauwkeurig te kunnen bepalen, is de 'originele' TEAC assay aangepast (Hoofdstuk 2). In de originele methode worden radicalen in de aanwezigheid van de testcomponenten gegenereerd. De testcomponenten kunnen dan echter niet alleen de radicalen 'wegvangen' maar ook de aanmaak van radicalen remmen, wat tot een overschatting van de antioxidant capaciteit kan leiden. In de verbeterde TEAC assay worden de radicalen eerst gegenereerd en pas daarna worden de testcomponenten toegevoegd.

Bij de bepaling vertoonden bijna alle antioxidanten, behalve Trolox en vitamine $\mathrm{E}$, een bifasisch effect, $\mathrm{nl}$. een snelle en een langzame reactie. Bij fenolische componenten, zoals bijvoorbeeld quercetine, bleek de TEAC concentratie-afhankelijk te zijn. Tevens bleek dat voor vet-oplosbare componenten, zoals $\beta$-caroteen, de TEAC afhankelijk was van het gebruikte oplosmiddel. Dit maakt interpretatie van de uitkomsten van de TEAC assay gecompliceerd. Om toch de antioxidant capaciteit van voedingsmiddelen te kunnen bepalen werd daarom ethanol gebruikt, waarin zowel wateroplosbare als vetoplosbare antioxidanten kunnen worden gesolubiliseerd. Onder gestandaardiseerde condities kon additiviteit van de TEAC van individuele antioxidanten aangetoond worden en kan de assay toepasbaar worden gemaakt voor het bepalen van de antioxidant capaciteit van voedingsmiddelen.

De voorspellende waarde van de TEAC assay werd vervolgens onderzocht door van vijf structuur-gerelateerde flavonoiden (steeds één aromatische hydroxylgroep 
verschil) de TEAC te bepalen en vervolgens deze verbindingen in andere 'in vitro' assays te testen (Hoofdstuk 3). De andere testen waren de 'hydroxyl radicaal scavenging' assay, een 'lipidperoxidatie' assay als typische scavenging assays en de bescherming tegen doxorubicine geïnduceerde hart schade als typische schadeassay. De verschillende flavonoiden, met oplopende TEAC, hadden een tegengesteld effect in de hydroxyl radicaal scavenging assay. Zowel met de lipidperoxidatie assay als ten aanzien van de bescherming tegen doxorubicine geïnduceerde hart schade assay waren de flavonoiden met de hoogste TEAC ook de verbindingen die de meeste bescherming gaven tegen radicaal schade.

Hieruit werd geconcludeerd dat de TEAC assay gebruikt kan worden om het effect, van structuur-gerelateerde flavonoiden, in meer 'in vivo-achtige' assays te voorspellen.

De voorspellende waarde van de TEAC van voedingsmiddelen werd vervolgens

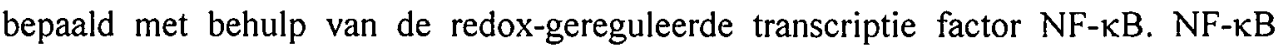
wordt beschouwd als een belangrijk factor in de regulatie van genen die betrokken zijn bij het ontstaan van ontstekingen en daarbij een rol hebben in het ontstaan van aan ontsteking gerelateerde ziektebeelden. De elektro mobiliteit shift assay (EMSA), beschreven in Hoofdstuk 4, is een methode waarmee de activering van NF-kB in humane mono nucleaire bloedcellen (o.a. lymfocyten) gemeten kan worden. Op deze manier kan nu zowel basale activering van NF- $\mathrm{kB}$ als het effect van antioxidant interventie op de NF- $\kappa B$ activering bepaald worden.

Voor vergelijking van resultaten van verschillende (patiënten)studies is standaardisatie van de EMSA methode noodzakelijk. De 'huishoud' transcriptie factor $s p 1$ is een transcriptie factor die geacht werd constant geactiveerd te zijn. Dit leek daarom een geschikte keuze voor standaardisatie. Echter, onder bepaalde condities bleek spl toch niet stabiel te zijn. Een commercieel verkrijgbaar celkernextract (van HeLa cellen) bleek wel als standaard gebruikt te kunnen worden, zodat de activering van NF-kB gerelateerd kan worden aan een constante hoeveelheid kernextract. Op deze manier werd basale activering van NF- $\mathrm{KB}$ in een macrofagencellijn bepaald alsmede de basale activering van NF- $\mathrm{kB}$ in humane mononucleaire cellen (HMNC, o.a. lymfocyten) van gezonde personen. Op deze wijze kan de meting van NF- $\kappa B$ activering in lymfocyten (HMNC), uitgedrukt in HeLa equivalenten, gebruikt worden als oxidatieve stress marker. 
In een studie met hepatitis C patiënten (Hoofdstuk 5) is vervolgens het eventuele antioxidant effect van glycyrrhizine onderzocht. Vijftien patiënten kregen hiertoe gedurende 4 weken, 6 keer in de week $200 \mathrm{mg}$ intraveneus glycyrrhizine toegediend. Als markers voor het ziektebeeld, plasma antioxidant status, lipidenschade en functionele oxidatieve stress marker werden serum alanine amino transferase (sALT), een leverenzym dat een verhoogde aktiviteit heeft bij hepatitis $C$ patiënten, plasma TEAC, plasma malondialdehyde (MDA) en activering van NF- $\kappa B$ respectievelijk gemeten. Na 4 weken behandeling waren serum ALT en plasma MDA significant gedaald echter na de 'wash-out' periode waren ze weer op het uitgangsniveau. De TEAC van het plasma bleef onveranderd. Helaas waren er onvoldoende cellen om van alle patiënten de NF- $\mathrm{KB}$ activering te bepalen. In drie hepatitis $C$ patiënten was na 4 weken behandeling met $200 \mathrm{mg}$ glycyrrhizine een daling in NF- $\mathrm{kB}$ activering te zien, echter na de 'wash-out' periode waren de waarden nog steeds verlaagd. De resultaten van deze studie tonen aan dat glycyrrhizine een specifiek antioxidant effect heeft, maar dat NF- $\mathrm{kB}$ activering een beperkte rol lijkt te spelen in dit ziekteproces.

Hoofdstuk 6 beschrijft een studie met sarcoidose patiënten (ontstekingen aan luchtwegen) waarbij verondersteld werd dat NF-kB activering mogelijk een rol speelt in dit ziekteproces. Bij 12 sarcoidose patiënten en 5 'gezonde', niet rokende, controle personen werd de basale activering van NF- $\mathrm{kB}$ door middel van de EMSA in lymfocyten (HMNC) bepaald. Van de 12 patiënten waren er 7 behandeld met glucocorticosterö̈den en 5 onbehandeld. De activiteit van NF- $\mathrm{KB}$, uitgedrukt als $\mathrm{HeLa}$ equivalenten, was twee keer zo hoog in de sarcoidose patiënten, zowel behandeld als onbehandeld, in vergelijking met de controle personen $(p<0.001)$. Dit in tegenstelling tot de 'serum angiotensine converting enzyme' (SACE) waarden, die als marker voor het ziektebeeld gebruikt wordt, waarvan de waarden wel lager waren na behandeling met corticosteroïden $(\mathrm{p}<0.01)$. Hieruit kan geconcludeerd worden dat NF- $\mathrm{kB}$ activering betrokken zou kunnen zijn in het onstekingsproces van sarcoidose. De behandeling van sarcoidose patiënten met glucocorticosteroïden heeft alleen effect op de SACE waarden, niet op de NF- $\kappa B$ activering.

In Hoofdstuk 7 wordt NF- $\mathrm{kB}$ activering in lymfocyten (HMNC) van rokers vergeleken met niet-rokers. In de studie, met 6 rokers en 10 niet-rokers, werd een hogere activering in rokers vergeleken met de niet-rokers gevonden $(p<0.05)$. Deze resultaten tonen aan dat activering van NF- $\mathrm{KB}$ in HMNC een rol zou kunnen spelen in 
sigarettenrook geïnduceerde onstekingsprocessen en dat NF-kB activering gemeten met de EMSA als functionele oxidatieve stress marker gebruikt zou kunnen worden. Hoofdstuk 8 beschrijft tenslotte een humane interventie studie waarin de relatie is onderzocht tussen voedingsmiddelen met een hoge TEAC en de antioxidant status van het plasma, respectivelijk de relatie met markers voor schade aan DNA, eiwitten en vetten en markers van oxidatieve stress. In deze studie kregen 22 rokers (die een relatief lage groente en fruit inname hadden) 3 weken lang, elke dag, een groenteburger en een fruitdrank of een controle burger en een controle drank. Na een 'wash-out' periode van 2 weken werd de behandeling omgedraaid, zodat alle proefpersonen zowel de groente/fruit producten als de controle producten kregen. De groenteburger bevatte broccoli, tomaten, wortelen, rode paprika en uien, de fruikdrank bevatte concentraten van sinaasappels, bosbessen, appels en citoen. Zowel de serum concentraties van vitamine $C, \alpha$-caroteen, $\beta$-caroteen, $\beta$-cryptoxanthine, zeaxanthine als de totale antioxidant capaciteit (TEAC) van plasma waren significant verhoogd na consumptie van de groenteburger en de fruitdrank. Helaas kon geen enkel effect worden aangetoond van behandeling op de schademarkers (respectievelijk, MDA, $F_{2}$ isoprostaan als lipidschade makers, carbonyls als eiwit schade marker en 'comets' als DNA schade marker), ook niet op de oxidatieve stress markers (gereduceerd/geoxideerd glutation ratio, glutation-S-transferase $\alpha$ en $\pi$ en NF-kB activering). Een verklaring waarom geen effect op deze markers werd gevonden is dat de verhoging van antioxidant concentraties niet hoog genoeg was om één van deze markers te kunnen beïnvloeden. Anderzijds is het ook mogelijk dat de mate van oxidatieve stress in rokers, met een relatief lage groente en fruit inname, niet hoog genoeg was om een positief effect van antioxidanten aan te kunnen tonen.

Conclusie: Doel van dit project was om het effect van voeding op de antioxidant status en op markers van oxidatieve stress bij de mens te bepalen. Hiertoe waren de volgende vraagstellingen geformuleerd: (i) kan de TEAC assay gebruikt worden om de totale antioxidant capaciteit van voeding te bepalen; (ii) kan een relatie worden vastgesteld tussen de TEAC van voedingsmiddelen, de antioxidant status en oxidatieve stress markers bij de mens; (iii) kan bepaling van de NF-kB activiteit in lymfocyten (HMNC) gebruikt worden als oxidatieve stress biomarker.

De resultaten uit Hoofdstuk 2, 3 en 8 tonen aan dat de TEAC assay kan worden gebruikt voor het bepalen van antioxidant capaciteit van voedingsmiddelen. De voorspellende waarde voor een in vivo antioxidant effect is echter minimaal. 
Producten met een hoge TEAC kunnen de antioxidant status verbeteren, maar er kon bij personen met een verondersteld verhoogde oxidatieve stress geen effect worden aangetoond op oxidatieve stress markers. Resultaten beschreven in de hoofstukken 4, $5,6,7$ en 8 tonen echter aan dat activering van NF- $\mathrm{KB}$ verhoogd is bij patienten met aan oxidatieve stress gerelateerde ziektebeelden. In hoeverre activering van NF- $\mathrm{kB}$ een voldoende valide marker is voor oxidatieve stress dient daarom nader te worden onderzocht. 


\section{Dankwoord}

Tenslotte is dit het meest gelezen deel van het boekje waar ik iedereen die op welke wijze dan ook betrokken is geweest bij het tot stand komen van dit proefschrift kan bedanken. Dit ga ik dan ook nu doen.

Allereerst mijn promotor Prof. dr. Aalt Bast, er zijn denk ik niet veel promotoren die zo enthousiast en betrokken zijn als hij. Ook heb ik erg veel geluk gehad met m'n beide co-promotoren dr. Guido Haenen en dr. Henk van den Berg. De besprekingen die we eerst regelmatig hielden maar later wat minder vaak waren altijd erg gezellig. We dwaalden nogal eens af naar wat minder relevante onderwerpen die ons ook bezighielden. Henk wist altijd wel weer een link te vinden naar de fysiologie en aanverwant antioxidant of voedingseffect die hij dan ook altijd met literatuur uit een van de stapeltjes op z'n netjes geordende kamer wist te ondersteunen. Jou kritische kijk op het onderzoek gaf het boekje een duidelijke vorm. Guido wist een vastgelopen deel van het onderzoek altijd zo'n wending te geven zodat er weer nieuwe ideeën ontstonden. Lange discussies over de telefoon, vele e-mails en faxen hebben ervoor gezorgd dat het boekje er uitziet zoals het nu is.

Ook wil ik m'n begeleidingscommissie bij TNO Voeding bedanken voor de stimulerende discussies. Eén keer per jaar werd door deze commissie met daarin naast m'n promotor en co-promotoren, dr. Geert (ben je nou nog niet klaar) van Poppel, dr. Hans Verhagen en in het laatste jaar ook dr. ir. Alwine Kardinaal, de voortgang gecontroleerd.

Bij de uitvoering van het eerste deel van het onderzoek waren een aantal studenten betrokken, die ik zeker niet zal vergeten. Met name Edwin met wie ik samen de NF$\kappa \mathrm{B}$ assay aan de $\mathrm{VU}$ heb opgezet en Martina die aan het begin van haar stage opstartproblemen tegenkwam maar zich daar goed door heen wist te slaan.

Dr. Marjolein Drent van de afdeling longziekten van het Academisch Ziekenhuis Maastricht wil ik bedanken voor de samenwerking in de studie met de sarcoidose 
patiënten en dr. Tekla van Rossum van de afdeling hepatogastroenterologie van het Academisch Ziekenhuis Rotterdam voor de samenwerking in de glycyrrhizine studie met de hepatitis $C$ patiënten.

Vier jaar lang heb ik met veel plezier gewerkt bij de afdeling voedingsfysiologie. Op m'n eerste werkdag bleek dat ik gelijk met een andere AIO op de afdeling was begonnen. We moesten samen met de secretaresse Ada het bekende TNO handtekeningen rondje doen. Vanaf dat moment zijn Martijn en ik niet alleen collega's maar ook goede vrienden geworden. We deelden al het AIO 'leed' en maakten er, beiden als fanatieke sporters, een soort wedstrijd van. Dat je er van de ene op de andere dag niet meer was heeft me erg diep geraakt, daarom Martijn is dit boekje ook voor jou.

M'n collega's bij TNO Voeding wil ik in willekeurige volgorde bedanken; oa. Joost (gabbertje), Piet, Han, Arjan, Rob en Marja voor de gezelligheid in m'n eerste jaar op het lab. Daarnaast oa. Steven, Hillie, Nicole, Len, als toxicologen. Van de afdeling Pharma, Els, Linda, Barry, Angelique en anderen, ook Mieke voor het gebruik van het C-lab en Viev als gezellige kletsmiep van dat lab.

Van onze eigen afdeling voedingsfysiologie natuurlijk medevoorzitter van 'de Neus/Gele M' club Vanessa om lekker slap te ouwehoeren en mensen in de maling te nemen en ook SAS-Wendy die me niet alleen geholpen heeft met de statistische analyses maar die het als enige met mij op één kamer vol gehouden heeft (ik vindt het daarom ook erg leuk dat jullie toegezegd hebben om op deze dag mijn paranimfen te willen zijn). Wilrike als ex-kamergenoot die gelukkig wat van mijn 'sportgekte' begreep, Trinette die me de wereld van de GLP/GCP introduceerde (is studie 458 al gearchiveerd?), Henk "alcohol verklaart alles" $\mathrm{H}$, en alle anderen van de afdeling die ik hier wel allemaal kan gaan noemen maar dan heb ik nog 4 pagina's nodig. Als laatste wil ik Wouter nog bedanken, want die trip naar Japan was FAAAAAAAANTASTISCH!

Ook al ben ik niet zo vaak in Maastricht bij de vakgroep farmacologie en toxicologie geweest wil ik toch de twee AIO's Rachel en Chantal ook bedanken. Rachel vooral voor al het werk wat je met die 'rot'cellijn voor me verricht heb en Chantal voor de 
overnachting tijdens de cursus. Zeker moet ik Mia niet vergeten die me met alle secretariële zaken ontzettend goed geholpen heeft.

Tenslotte natuurlijk het thuisfront; m'n ouders voor de steun die jullie me altijd hebben gegeven en omdat jullie altijd voor me klaar staan en Deborah, omdat je er altijd voor me bent en al die keren dat je weer alleen aan je avondeten zat, je bent een van de weinigen die me bij kan houden en daarom hou ik je ook voor altijd bij me.

Iedereen BEDANKT,

\section{Pabin.}




\section{Curriculum vitae}

Robin van den Berg werd op 1 juli 1972 geboren te Amsterdam, waarna hij opgroeide in Amstelveen. Hier behaalde hij in 1990 aan de scholengemeenschap Snellius het HAVO diploma. In dat zelfde jaar begon hij aan de Hogere Laboratorium School bij de Hogeschool van Amsterdam die hij in 1994, met als hoofdrichting biochemie, met goed gevolg afsloot. Vervolgens begon hij in datzelfde jaar met de studie scheikunde aan de Vrije Universiteit in Amsterdam. Hier heeft hij zich gespecialiseerd in de richting farmacochemie. De studie werd in 1996 afgesloten met een project bij de werkgroep moleculaire farmacologie onder begeleiding van Prof. dr. A. Bast en dr. G.R.M.M. Haenen. Deze samenwerking kreeg een vervolg toen hij een AIO positie accepteerde bij de Vrije Universiteit, gedetacheerd bij TNO Voeding te Zeist met als extra begeleider vanuit TNO dr. H. van den Berg. Zijn promotor en begeleider verhuisden in 1999 van de Vrije Universiteit naar de Universiteit Maastricht, faculteit geneeskunde, vakgroep farmacologie en toxicologie waar ook de AIO positie werd voortgezet. De resultaten van 4 jaar goede samenwerking staan beschreven in dit proefschrift. Op 23 juni 2000 is hij getrouwd met Deborah den Boer. Sinds januari 2001 is hij werkzaam bij TNO Voeding op de afdeling voedingsfysiologie en de afdeling voedingsmiddelen en voedingssupplementen analyse te Zeist. 


\section{List of publications}

Aalt Bast, Guido R.M.M. Haenen, Robin van den Berg, Henk van den Berg (1998) Antioxidant effects of carotenoids. Int. J. Vit. Nutr. Res. 68: 399-403.

Robin van den Berg, Guido R.M.M. Haenen, Henk van den Berg, Aalt Bast. Voordelen en beperkingen van screeningsmethodes die antioxidant capaciteit bepalen Foliola - jaargang 1998, no. 2

Robin van den Berg, Guido R.M.M. Haenen, Henk van den Berg, Aalt Bast (1999) Applicability of an improved Trolox equivalent antioxidant capacity (TEAC) assay for evaluation of antioxidant capacity measurements of mixtures. Food Chemistry 66 (4): 511-517.

Robin van den Berg, Guido R.M.M. Haenen, Henk van den Berg, Wim J.F. van der Vijgh, Aalt Bast (2000) The predictive value of the antioxidant capacity of structurally related flavonoids using the Trolox Equivalent Antioxidant Capacity (TEAC) assay. Food Chemistry 70 (3): 391-395.

Martijn S. van der Gaag, Robin van den Berg, Henk van den Berg, Gertjan Schaafsma, Henk F.J. Hendriks (2000) Moderate consumption of beer red wine and spirits has counteracting effects on plasma antioxidants in middle aged men. European Journal of Clinical Nutrition 54: 586-591.

Robin van den Berg, Guido R.M.M. Haenen, Henk van den Berg, Aalt Bast (2001) Transcription factor NF- $\mathrm{KB}$ as a potential biomarker for oxidative stress. British Journal of Nutrition 85: S1-S8 (in press)

Marjolein Drent, Robin van den Berg, Guido R.M.M. Haenen, Henk van den Berg, Emiel F.M. Wouters, Aalt Bast (2001) NF-kB activation in sarcoidosis. Sarcoidosis Vasculitis and Diffuse Lung disease. 18: 50-56.

Robin van den Berg, Guido R.M.M. Haenen, Henk van den Berg, Aalt Bast (2001) Nuclear factor- $\mathrm{kB}$ activation is higher in peripheral blood mononuclear cells of male Smokers. Environmental Toxicology and Pharmacology 9: 147-151.

Robin van den Berg, Trinette van Vliet, Wendy M.R. Broekmans, Nicole H.P. Cnubben, Wouter H.J. Vaes, Guido, R.R.M. Haenen, A. Bast, Len Roza, Henk van den Berg. (2001) A vegetable/fruit concentrate with a high antioxidant capacity has no effect of on biomarkers of antioxidant status in smokers. Journal of Nutrition 131 (in press). 